\title{
Structure-Activity Relationships of Triple-Action Platinum(IV) Prodrugs with Albumin-Binding Properties and Immunomodulating Ligands
}

Philipp Fronik, "Isabella Poetsch," Alexander Kastner, Theresa Mendrina, Sonja Hager, Katharina Hohenwallner, Hemma Schueffl, Dietmar Herndler-Brandstetter, Gunda Koellensperger, Evelyn Rampler, Joanna Kopecka, Chiara Riganti, Walter Berger, Bernhard K. Keppler, Petra Heffeter,* and Christian R. Kowol*

Cite This: J. Med. Chem. 2021, 64, 12132-12151

Read Online

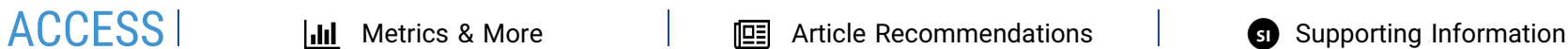

ABSTRACT: Chemotherapy with platinum complexes is essential for clinical anticancer therapy. However, due to side effects and drug resistance, further drug improvement is urgently needed. Herein, we report on triple-action platinum(IV) prodrugs, which, in addition to tumor targeting via maleimide-mediated albumin binding, release the immunomodulatory ligand 1-methyl-Dtryptophan (1-MDT). Unexpectedly, structure-activity relationship analysis showed that the mode of 1-MDT conjugation distinctly impacts the reducibility and thus activation of the prodrugs. This in turn affected ligand release, pharmacokinetic properties, efficiency of immunomodulation, and the anticancer

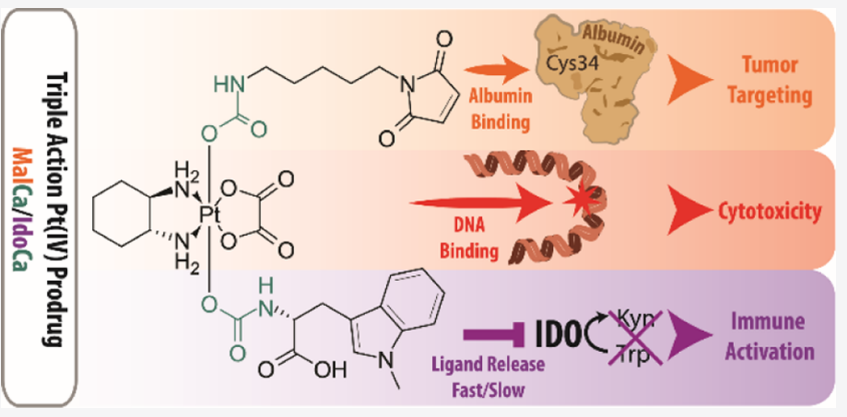
activity in vitro and in a mouse model in vivo. Moreover, we could demonstrate that the design of albumin-targeted multi-modal prodrugs using platinum(IV) is a promising strategy to enhance the cellular uptake of bioactive ligands with low cell permeability (1-MDT) and to improve their selective delivery into the malignant tissue. This will allow tumor-specific anticancer therapy supported by a favorably tuned immune microenvironment.

\section{INTRODUCTION}

The antitumor activity of cisplatin was already discovered in the 1960s, resulting in its approval in 1978 . $^{1,2}$ Subsequently, two additional platinum(II) complexes, carboplatin and oxaliplatin, have been approved worldwide. ${ }^{3}$ This compound class is still widely used as a first-line treatment in many therapeutic schemes and has more recently caused another surge of interest, due to its synergism with immune checkpoint inhibitors like pembrolizumab. ${ }^{3}$ Moreover, it is already widely accepted that oxaliplatin requires an intact immune system to fully unfold its anticancer activity. ${ }^{3}$ However, the low selectivity of platinum drugs for the malignant tissue is still a major limitation as treatment with these compounds frequently results in severe side effects. ${ }^{4}$ Additionally, intrinsic or acquired resistance, often based on reduced drug accumulation in the cancer tissue, represents another major drawback. ${ }^{5}$ Consequently, drug combination strategies, exploiting the specific cancer biology, are of high interest to improve the efficacy of therapy in tandem with reduced side effects.

Cancer cells are known to actively inhibit immune recognition through diverse mechanisms, including loss of the antigen-presenting machinery or expression of inhibitory molecules and enzymes that induce T-cell suppression. ${ }^{6}$ One specific enzyme is indoleamine 2,3-dioxygenase (IDO), which catabolizes the amino acid tryptophan (Trp) to kynurenine (Kyn). Binding of Kyn to the aryl hydrocarbon receptor inhibits T-cell activation and supports regulatory $\mathrm{T}$-cell proliferation. ${ }^{7}$ IDO expression has been described for several tumor types and identified as a major mechanism supporting immune evasion of cancer cells. The interest in this enzyme is also reflected by the clinical development of several IDO inhibitors, such as 1-methyltryptophan $(1-\mathrm{MT}){ }^{8}$ In numerous preclinical studies, 1-MT has been investigated, both as pure stereoisomers as well as racemic mixtures. ${ }^{9-11}$ Interestingly, even though the L-isomer [1-methyl-L-tryptophan (1-MLT)] inhibits IDO more efficiently in cell culture, the D-isomer [1methyl-D-tryptophan (1-MDT); indoximod] has emerged as preferential compound for clinical development, due to its higher immunogenic anticancer activity in vivo. ${ }^{10}$ With regard

Received: April 28, 2021

Published: August 17, 2021 
Scheme 1. (A) Synthetic Routes for 1-MDT and Maleimide Building Blocks; (a) $60 \% \mathrm{HClO}_{4}, t$-Butyl Acetate, $0{ }^{\circ} \mathrm{C}-\mathrm{Room}$ Temperature (RT); (b) 1,1'-Carbonyldiimidazole, $N, N$-Diisopropylethylamine (DIPEA), Dichloromethane (DCM), RT; (c) Dimethyl Sulfoxide (DMSO), $80^{\circ} \mathrm{C}$; (d) Di-t-butyl Dicarbonate, NaOH, Dioxane/Water 2:1, RT; (e) Diphenylphosphoryl Azide (DPPA), Triethylamine (TEA), Toluene; and (f) Toluene, $100{ }^{\circ} \mathrm{C}$; (B) Synthetic Routes for the Final MaleimidePlatinum(IV) 1-MDT Complexes; (g) $\mathrm{H}_{2} \mathrm{O}_{2}(50 \% \mathrm{w} / \mathrm{w}), \mathrm{H}_{2} \mathrm{O}, \mathrm{RT}$; (h) 6a, DMSO, RT; (i) 4, TBTU, TEA,

Dimethylformamide (DMF), RT; (j) 10\% TFA in DCM, RT; (k) 3, DMSO, RT; (1) 6a, DMF, RT; (m) 5, N-Ethyl Maleimide, TBTU, TEA, DMF, RT; and (n) 4, 6a, TBTU, TEA, DMF, RT
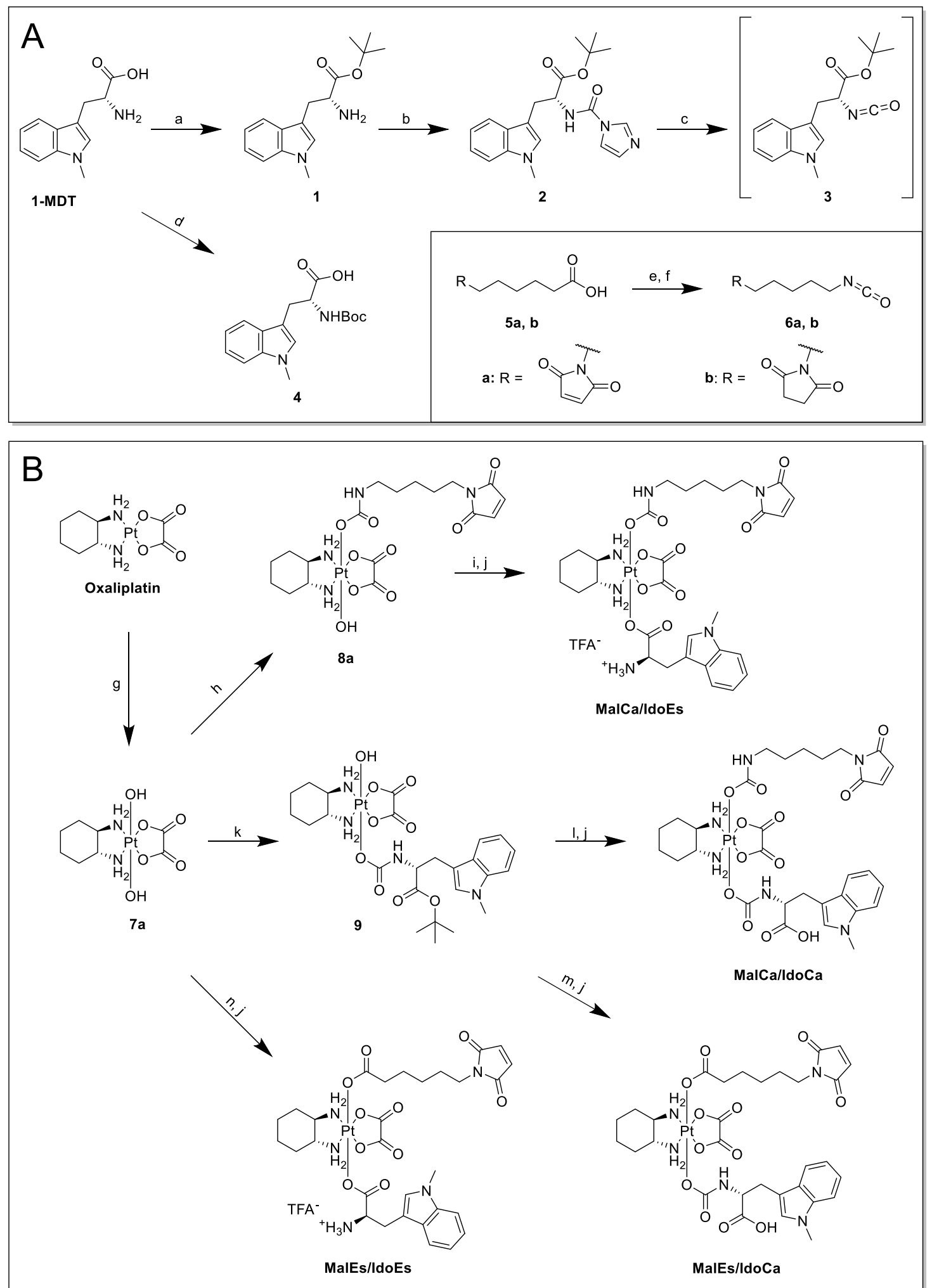
to platinum drugs, there is strong evidence that the combination with IDO inhibition (e.g., by 1-MDT) is highly synergistic. $^{12-15}$ There are already some promising reports on nano-formulations combining platinum-based chemotherapy with IDO inhibitors. ${ }^{13,14,16}$ However, such nano-formulations exhibit various major limitations for clinical use including challenging preparation procedures, difficulties in batch-tobatch reproducibility, stability/shelf-life, and varying loading efficiency. ${ }^{17}$ Therefore, other more stable and controllable approaches are of interest, such as platinum(IV) prodrugs. Platinum(IV) complexes are promising tools to design multimodulatory drugs as they are not only kinetically more inert than their platinum(II) counterparts but also offer the ability to attach additional ligands. ${ }^{18,19}$ Thus, upon reduction, platinum(IV) complexes release both, the cytotoxic platinum(II) species and the bioactive compound(s). In this way, simultaneous, tumor-specific release of two or more drugs is possible, which can target the cancer cells by different and ideally synergistic modes of actions. ${ }^{20}$ Moreover, this strategy is especially interesting for ligands which are characterized by a low cell penetration. The clinically investigated IDO inhibitor 1-MDT is a zwitterionic amino acid under physiological $\mathrm{pH}$ conditions, which hampers its cellular uptake. Consequently, usually very high levels of 1-MDT have to be applied for sufficient activity. Formation of a platinum(IV) prodrug with intracellular release of $1-\mathrm{MDT}$ is an elegant way to modulate the characteristics of this IDO inhibitor. Recently, the first prodrug approach using cisplatin-releasing complexes and an albumin-targeting prodrug strategy has been reported by Awuah et al. ${ }^{16}$

Binding to serum albumin represents one of the most efficient strategies to target the tumor tissue. ${ }^{21,22}$ Due to the fact that albumin serves as a transporter for several nutrients in the blood stream, fast-growing tumor cells are characterized by an increased uptake of this plasma protein and additionally use albumin as an amino acid source. ${ }^{23}$ Furthermore, the enhanced permeability and retention effect, that is based on the combination of leaky blood vessels together with impaired lymph drainage, contributes to albumin accumulation in the malignant tissue. ${ }^{24,25}$ The potential of targeting cancer cells by their enhanced need for albumin has been demonstrated by nab (nanoparticle albumin-bound) paclitaxel (ABRAXANE), which is already approved for treatment of various cancer types. $^{26,27}$ In addition, aldoxorubicin, a compound which successfully finished a phase III clinical trial (study number NCT02049905) in soft tissue sarcoma, is of note. This compound utilizes a maleimide moiety, which specifically targets the single free cysteine residue of albumin at position $34 .^{28} \mathrm{We}$ have recently reported on the first maleimide-bearing platinum(IV) complexes. ${ }^{29,30}$ Here, especially, the oxaliplatin derivatives not only showed excellent reduction properties and tumor accumulation but also promising antitumor activity in vivo. ${ }^{29}$ Noteworthy, our studies revealed that for the success of an albumin-targeted prodrug strategy, very stable platinum(IV) complexes are necessary. Platinum(IV) complexes with a cisplatin core faced much faster reduction kinetics (compared to oxaliplatin or carboplatin derivatives $)^{31,32}$ and are therefore less ideal for long-circulating drug delivery systems like albumin-conjugated prodrugs. ${ }^{29}$ Indeed, in the study by Awuah et al., the IDO-releasing cisplatin drug faced several problems. The authors used a very lipophilic $\mathrm{C}_{16}$-alkyl chain for non-covalent albumin binding and, consequently, the compound was hardly soluble and had to be encapsulated into polylactide-co-glycolide-polyethylene glycol polymers to achieve sufficient solubility. Despite their efforts, the in vivo plasma half-life of the drug was only $1 \mathrm{~h}$, indicating that the effect of the albumin nano-carrier did not apply. In order to successfully develop tumor-specific 1-MDT-releasing prodrugs, new complexes with enhanced stability and albumin-binding properties are required to achieve high tumor accumulation and anticancer activity. Based on their high reduction stability, oxaliplatin-releasing compounds are ideal candidates for this approach. Moreover, oxaliplatin is known for its strong immunogenic activity and promising synergistic activity with IDO inhibitors. ${ }^{13,33,34}$

In the present study, we designed the first oxaliplatin-based albumin-targeted platinum(IV) complexes with an 1-MDT ligand. For endogenous albumin targeting, ideally maleimides are used because of their exceptionally fast binding rates in serum and sufficient solubility for in vivo studies. Other moieties usually suffer either from very low solubility (long aliphatic alkyl chains ${ }^{16}$ ) or too slow binding kinetics (e.g., carbonylacrylic reagents ${ }^{35}$ ). In order to generate a lead candidate for further preclinical investigations, several 1MDT-bearing derivatives with different maleimide linkage types were synthesized to investigate chemical and pharmacological drug properties. As maleimide compounds are difficult to test in cell culture due to their proneness to hydrolysis and their reactivity with cell medium components, succinimide derivatives were additionally synthesized for in vitro analysis.

\section{RESULTS AND DISCUSSION}

Synthesis. It is known that the exact ligand coordination and inner sphere of a platinum(IV) core are substantial for its reduction behavior. ${ }^{36,37}$ Therefore, we decided to elucidate the detailed structure-activity relationships for the platinum(IV) prodrugs by synthesizing four distinctly different complexes based on the axial ligand-binding motifs of the maleimide and IDO inhibitor. 1-MDT is an amino acid that possesses two functional groups, which are potentially suitable for coupling to the platinum core: the carboxylic acid to form a carboxylate (in this manuscript denoted as "ester") and the primary amine with formation of a carbamate. Notably, so far only the "straightforward" coupling via the carboxylic acid has been reported. ${ }^{16}$ We successfully established the ester coupling to the oxaliplatin core using 2 -( $1 H$-benzotriazole-1-yl)-1,1,3,3tetramethylaminium tetrafluoroborate (TBTU) and the carbamate formation via isocyanates (Scheme 1). To obtain the building blocks for further synthesis, on the one hand, the carboxylic acid moiety of $1-\mathrm{MDT}$ was protected via $t$-butyl ester (1) before converting the amine to isocyanate (3) using $1,1^{\prime}$-carbonyldiimidazole (Scheme 1A). On the other hand, Boc-protection of the primary amine resulted in the esterbuilding block 4. Maleimide moieties were similarly coupled either as a commercially available carboxylic acid (5a) or as an isocyanate (6a) (Scheme 1A). The oxaliplatin precursors were obtained by oxidation with $\mathrm{H}_{2} \mathrm{O}_{2}$ in water yielding the dihydroxido complex (7a) or in acetic acid with formation of the mono-acetato complex $(7 \mathbf{b}){ }^{38,39}$ Subsequent reactions of $7 \mathrm{a}$ with either isocyanate building block yielded intermediates 8a or 9 (Scheme 1B). To generate the final complex MalCa/ IdoCa [maleimide via carbamate, 1-MDT as an IDO inhibitor (Ido) via carbamate], complex 9 reacted further with maleimido-isocyanate 6a. For MalEs/IdoCa [maleimide via ester, 1-MDT as an IDO inhibitor (Ido) via carbamate] and MalCa/IdoEs [maleimide via carbamate, 1-MDT as an IDO 


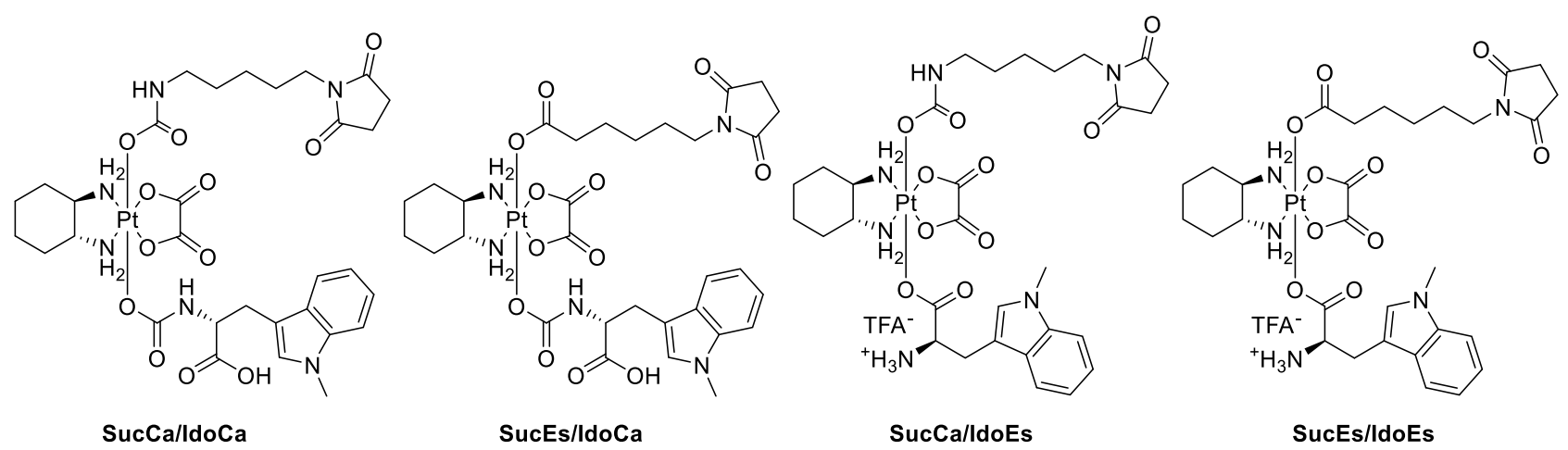<smiles>CC(=O)OOP1(N)(N[C@@H]2CCCC[C@H]2N[P+]2(N)OC(=O)C(=O)O2)OC(=O)CN1CCCCCNC(=O)O</smiles>

SucCa/OAc<smiles></smiles>

OAC/OAC<smiles>CC(=O)OOP(N)(N[C@@H]1CCCC[C@H]1N)(OC(=O)CCc1cn(C)c2ccccc12)OC(=O)C(=O)O</smiles>

OAC/IPAES

Figure 1. Structures of platinum(IV) reference compounds for cell culture investigations.
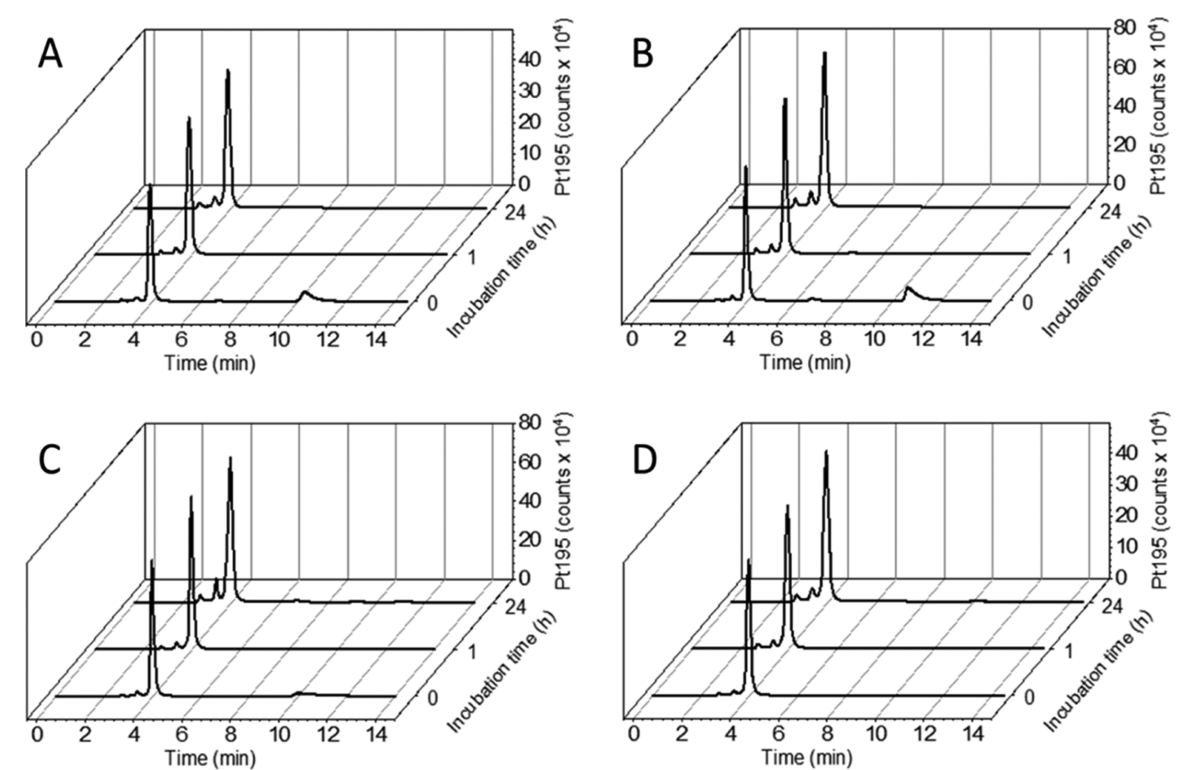

Figure 2. Platinum-SEC-ICP-MS traces of the complexes (A) MalEs/IdoCa, (B) MalCa/IdoCa, (C) MalCa/IdoEs, and (D) MalEs/IdoEs after incubation in FCS at $37{ }^{\circ} \mathrm{C}$ after 0,1 , and $24 \mathrm{~h}$. The small peaks at $\sim 11$ min retention time indicate the initial low-molecular-weight complexes; the peaks at $\sim 4$ min indicate the albumin-bound platinum.

inhibitor (Ido) via ester], the respective carbamato-intermediate $8 \mathbf{a}$ or 9 reacted with the other respective carboxylic acids via TBTU-mediated coupling (in case of $\mathbf{8 a}, N$-ethyl maleimide was added to the reaction mixture in order to prevent adduct formation of the TBTU side product with the maleimide of 8a). With regard to MalEs/IdoEs [maleimide via ester, 1-MDT as an IDO inhibitor (Ido) via ester], the coupling of both ligands was performed using a one-pot procedure. In all cases, subsequent deprotection with trifluoroacetic acid (TFA) yielded the final products after preparative high-performance liquid chromatography (HPLC) purification.
In parallel, the respective succinimides of all four complexes (SucCa/IdoCa, SucCa/IdoEs, SucEs/IdoCa, and SucEs/ IdoEs, Figure 1) were synthesized in an identical manner using the succinimide precursors ( $5 \mathbf{b}$ and $\mathbf{6 b}$ ). In addition, the acetato-derivative SucCa/OAc was prepared from the hydroxido/acetato platinum(IV) precursor $7 \mathbf{b}$ using isocyanate 6b (see the experimental section part).

Albumin Binding and Serum Stability. As a first step, we investigated the albumin-binding kinetics and serum stability of the novel maleimide-bearing drugs by size exclusion chromatography followed by inductively coupled plasma mass 
spectrometry (SEC-ICP-MS) after incubation in fetal calf serum (FCS, buffered with $150 \mathrm{mM}$ phosphate buffer to ensure a stable $\mathrm{pH}$ over $24 \mathrm{~h}$ and 1\% DMF for sufficient solubility) at $37{ }^{\circ} \mathrm{C}$ (Figure 2). Already at $t=0$, most of the platinum was bound to the albumin fraction with a retention time of $\sim 4 \mathrm{~min}$, and only small amounts were present in the low-molecular-weight region at around 10-12 min (a chromatogram of the sulfur trace of pure serum can be found in Figure S1). After $1 \mathrm{~h}$, no low-molecular-weight platinum species could be detected in either of the samples (Figure 2). This confirms very fast albumin-binding properties of all four derivatives. Interestingly, derivatives with 1-MDT coupled via an ester to the platinum(IV) core conjugated slightly faster to albumin than the derivatives with an 1-MDT carbamate bond to the metal. Moreover, the results also suggest that Michael addition to the thiol proceeds substantially quicker than hydrolysis of the maleimide, which would generate a species in the low-molecular-weight region unable to bind to albumin. The data also clearly indicate high stability of all complexes in serum without significant degradation of the platinum(IV) albumin adduct within 24 h. As reference measurements, also the succinimide analogues were investigated by SEC-ICP-MS in serum (Figure S2). No significant binding to albumin or other proteins could be observed, proving that the maleimide is indeed the crucial moiety for coupling.

Reduction Properties. As already mentioned, one of the most crucial parameters in the biological activity of platinum(IV) drugs is their ability to be reduced in tumor tissue. Recently, we have demonstrated that in case of maleimidebearing complexes, ${ }^{29}$ slow-reducing platinum(IV) derivatives are characterized by a longer plasma half-life time, improved tumor accumulation, and superior anticancer activity in vivo. However, the compounds should not be too stable as the platinum(IV) prodrugs need to be activated via reduction in the specific microenvironment of the tumor in order to exert their antitumor potential. ${ }^{36}$ Due to the hydrolysis of the maleimide moiety, we analyzed the reduction properties of the respective succinimide complexes by ultra-HPLC (UHPLC) after incubation in phosphate buffer at $\mathrm{pH} 7.4$ (including 1\% DMF) with a 10-fold excess of L-ascorbic acid (AA) as a reducing agent. Notably, huge differences between the platinum complexes could be observed. Unexpectedly, both complexes with ester-like 1-MDT conjugations (SucEs/IdoEs and SucCa/IdoEs) were completely reduced within $2 \mathrm{~h}$ (Figure 3). In comparison, the carbamate analogues SucEs/ IdoCa and SucCa/IdoCa displayed the expected very high

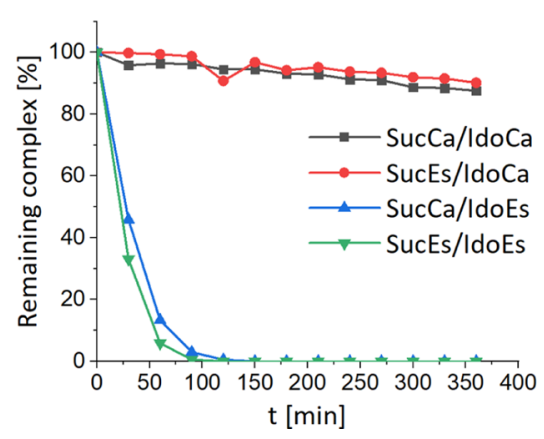

Figure 3. Reduction kinetics measured by UHPLC of succinimide complexes $(1 \mathrm{mM})$ at $20^{\circ} \mathrm{C}$ with a 10 -fold excess of AA in phosphate buffer ( $500 \mathrm{mM}, \mathrm{pH} 7.4)$ containing $1 \%$ DMF. stability in the reductive environment with $90 \%$ of the complex being intact after $6 \mathrm{~h}$ (Figure 3). This slow reduction behavior is in line with several literature reports on other oxaliplatin(IV) complexes. $^{29,40-42}$ In contrast, the binding mode of the maleimide moiety did not substantially influence the reduction properties of these complexes. However, the question remained how this dramatic divergence in the reduction kinetics, just by changing the coordination mode of 1-MDT from an ester to a carbamate, can be explained. The main difference is that in case of SucEs/IdoEs and SucCa/IdoEs the amino group of 1-MDT is free, whereas in case of SucEs/ IdoCa and SucCa/IdoCa, a free carboxylic acid is present. Therefore, it can be concluded that the very fast reduction is associated with the free amino group of the ester-bound complexes. To investigate this hypothesis, an analogue using 1methyl-indole-3-propanoic acid lacking the amino group was synthesized (OAc/IPAEs; Figure 1). Subsequently, incubation studies with AA indeed revealed comparable reduction kinetics to the carbamate-linked complexes (Figure S3A). Therefore, it can be assumed that the electron transfer is facilitated by an interaction/stabilization of the reducing agent with the amine. This phenomenon is not specific for AA but was also visible when using DL-dithiothreitol as a reductant. Again, distinctly slower reduction kinetics were observed for OAc/IPAEs in comparison to SucCa/IdoEs (Figure S4).

Impact of the Different Reduction Kinetics on the Anticancer Activity of the Succinimide Prodrugs. To evaluate whether the observed differences in the reduction kinetics also influence the biological activities of the compounds, the cytotoxicity of the new drugs was determined in cell culture after 48 and $72 \mathrm{~h}$. Since oxaliplatin is clinically used against gastrointestinal cancers, two colon carcinoma cell lines, one of human (HCT116) and one of murine origin (CT26), were analyzed for this purpose (Table 1 and Table S1). In general, we observed a similar structure activity pattern in both models. In more detail, all platinum(IV) drugs exhibited higher $\mathrm{IC}_{50}$ values than free oxaliplatin. This was not unexpected as based on the prodrug nature of these

Table 1. Cytotoxicity Determined by MTT Assay in Murine CT26 and Human HCT116 Colon Cancer Cells after 48 h Incubation with and without 5 equiv $\mathrm{AA}^{a}$

\begin{tabular}{lccc} 
& \multicolumn{2}{c}{$+\mathrm{AA}$} \\
& mean $\pm \mathrm{SD}$ & mean $\pm \mathrm{SD}$ & ratio \\
oxaliplatin & $\mathrm{CT} 26-\mathrm{IC}_{50}$ Values $(\mu \mathrm{M})-48 \mathrm{~h}$ & \\
OAc/OAc & $25.66 \pm 1.40$ & $22.60 \pm 0.16$ & 1.14 \\
SucCa/OAc & $75.21 \pm 0.11$ & $28.17 \pm 1.81$ & 2.67 \\
SucEs/IdoCa & $>100$ & $26.65 \pm 0.75$ & $\geq 3$ \\
SucCa/IdoCa & $>100$ & $38.84 \pm 3.84$ & $\geq 2.6$ \\
SucEs/IdoEs & $91.51 \pm 3.84$ & $11.15 \pm 0.37$ & 8.21 \\
SucCa/IdoEs & $60.09 \pm 6.49$ & $10.81 \pm 1.04$ & 5.56 \\
& $\mathrm{HCT} 116-\mathrm{IC}$ & $\mathrm{Values}$ \\
oxaliplatin & $0.72 \pm 0.01$ & $0.67 \pm 0.01$ & 1.07 \\
OAc/OAc & $26.56 \pm 2.41$ & $20.10 \pm 1.57$ & 1.32 \\
SucCa/OAc & $>100$ & $33.96 \pm 1.58$ & $\geq 2.9$ \\
SucEs/IdoCa & $>100$ & $35.39 \pm 6.54$ & $\geq 2.8$ \\
SucCa/IdoCa & $>100$ & $43.27 \pm 2.10$ & $\geq 2.3$ \\
SucEs/IdoEs & $22.80 \pm 1.15$ & $6.94 \pm 0.33$ & 3.28 \\
SucCa/IdoEs & $26.00 \pm 3.21$ & $7.36 \pm 1.14$ & 3.53 \\
\end{tabular}

${ }^{a}$ Values are given as mean \pm standard deviation (SD). 
compounds, they need additional time to be activated and to release their active platinum(II) species. Accordingly, the derivatives with ester-like 1-MDT conjugations (SucEs/IdoEs and SucCa/IdoEs), which were characterized by faster reduction, were more active than the 1-MDT carbamatelinked analogues (SucEs/IdoCa and SucCa/IdoCa) with higher reduction stability. In detail, after $48 \mathrm{~h}$, the 1-MDT carbamate-linked complexes did not show any anticancer activity up to the highest concentration of $100 \mu \mathrm{M}$ in both cell lines. In contrast, the 1-MDT ester-linked complexes had $\mathrm{IC}_{50}$ values of $\sim 60-90 \mu \mathrm{M}$ in CT26 cells and $\sim 25 \mu \mathrm{M}$ in HCT-116 cells after $48 \mathrm{~h}$. The same trends were also visible after $72 \mathrm{~h}$, although all compounds were more active than after $48 \mathrm{~h}$ (Table S1). The coordination of the succinimide moiety via ester or a carbamate only minimally influenced the antiproliferative activity. There was also a distinct difference between the two platinum(IV) reference drugs, with OAc/ OAc being at least 3-fold more active than SucCa/OAc. Noteworthy, the ratio between the activity of oxaliplatin and the platinum(IV) complexes became distinctly smaller upon longer incubation times (e.g., in case of SucEs/IdoEs in CT26 cells from a factor of 61 to a factor of 24). This again indicates that prolonged incubation provides sufficient time for more complete reduction and, thus, oxaliplatin release. To further investigate this hypothesis, the activity of the compounds was tested in the presence of 5-fold excess AA as an reducing agent (Figure S5). While the addition of AA did not have any effect on the cytotoxic properties of oxaliplatin, the anticancer activity of our new compounds was considerably enhanced after $48 \mathrm{~h}$. This effect was reduced, when we increased the incubation time of the cytotoxicity assays from 48 to $72 \mathrm{~h}$. Here, especially in case of HCT 116 cells (Table S1), addition of AA had basically no additional effect on the two fast reducing compounds, indicating that in this time frame, full reduction of the platinum(IV) was already achieved without additional AA. With regard to the reference drugs, SucCa/ OAc, lacking the free amino group, behaved as anticipated, similar to the carbamate-linked complexes. In contrast, OAc/ OAc could not be further activated by addition of AA. This is unexpected as the reduction kinetics of these two compounds were comparable (Figure S3B). To evaluate whether reduction leads to the release of a functional platinum(II) species from our prodrugs, we investigated the induction of two main hallmarks of oxaliplatin activity upon addition of AA: DNA damage indicated by phosphorylation of histone H2A.X at position Ser139 and cell cycle arrest in G2/M due to activation of the DNA damage sensor P53. ${ }^{43}$ As shown in Figures S6 and $\mathrm{S} 7$, reduction by AA resulted in both, increased $\mathrm{pH} 2 \mathrm{~A} . \mathrm{X}$ signals and an increased fraction of cells in the G2/M phase of the cell cycle similar to oxaliplatin, especially in case of the fast reducing agents SucEs/IdoEs and SucCa/IdoEs.

Finally, the effects of our prodrugs on healthy tissue were tested in non-malignant cell lines (Table S2). As kidney and liver tissue are typically strongly affected by therapy with platinum compounds, we chose human embryonic kidney cells (HEK293) and human hepatic (WRL68) cells for these experiments. The experiments revealed that while both cell lines were very sensitive to oxaliplatin treatment in the low $\mu \mathrm{M}$ range, the prodrugs were up to 40 -fold less toxic, suggesting a low side-effect profile of our compounds.

In order to rule out that the observed effects in the viability assays were based on differences in the uptake between fastand slow-reducing prodrugs, we investigated the intracellular platinum levels after $3 \mathrm{~h}$ incubation in HCT116 cells. Several interesting observations were made (Figure 4): (1) The

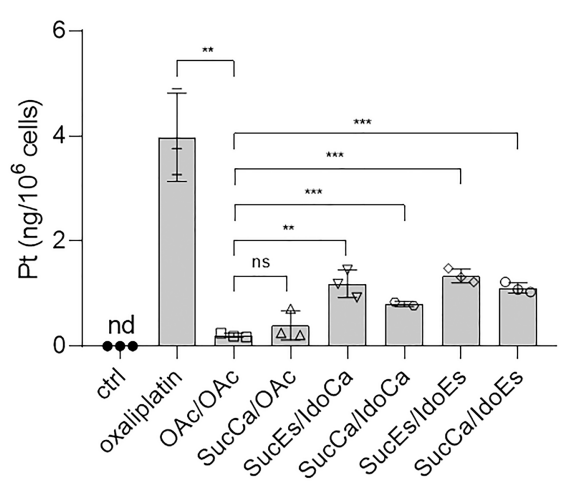

Figure 4. Cellular platinum levels in HCT116 cells after $3 \mathrm{~h}$ incubation with $20 \mu \mathrm{M}$ of the compounds measured by ICP-MS. Blanks (treated wells without cells) were subtracted from each value. Bars indicate mean \pm SD of triplicates. Significance was calculated compared to the $\mathbf{O A c} / \mathrm{OAc}$ mean value using an unpaired $t$-test (twotailed).

platinum(II) complex, oxaliplatin, was taken up by the cells much more efficiently than any of the platinum(IV) prodrugs. (2) Compounds that carry a 1-MDT ligand are taken up at higher levels than the platinum(IV) reference compounds OAc/OAc and SucCa/OAc. (3) There was no significant difference in the platinum levels of cells treated with different 1-MDT-bearing complexes. Lipophilicity is a parameter known to impact on the cellular drug accumulation and, thus, cytotoxicity. Hence, compounds with higher lipophilicity usually have higher cellular uptake and cytotoxicity. In order to assess this criterion, we determined the $\log D_{7.4}$ value for oxaliplatin, OAc/OAc, and the four 1-MDT-bearing prodrugs using the shake flask method, and platinum concentrations were measured by ICP-MS analysis (Table 2). Log $D_{7.4}$ was chosen due to the fact that our platinum(IV) prodrugs possess charged moieties $\left(\mathrm{NH}_{3}{ }^{+}\right.$or $\left.\mathrm{COO}^{-}\right)$at physiological $\mathrm{pH}$, and consequently, a direct comparison is only meaningful in buffered solution. The $\log D_{7.4}$ obtained for oxaliplatin $(-1.30)$ is in good agreement with the $\log P$-value reported in literature $(-1.39) .{ }^{44}$ The data for the 1 -MDT-bearing prodrugs reveal that the free carboxylic acid $\left(\log D_{7.4}\right.$ : SucEs/IdoCa at -2.02 ; SucCa/IdoCa at -1.49 ) results in distinctly higher hydrophilicity compared to the two analogues with a free amino group $\left(\log D_{7.4}:\right.$ SucEs/IdoEs at $-0.30 ;$ SucCa/IdoEs at $-0.16)$. However, as the cellular uptake of the four 1-MDTbearing complexes is quite similar (Figure 4), lipophilicity as an important parameter for the drug uptake can be widely excluded.

In general, the mode of uptake of the diverse platinum drugs is heavily discussed in the literature. In case of oxaliplatin, it is currently assumed that the drug enters the cancer cells mainly via active organic cation/carnitine transporter OCT1 and OCT $2 .{ }^{45}$ Therefore, one explanation for the differences in the uptake of oxaliplatin and the novel platinum(IV) complexes could be a different recognition of the drugs by these uptake mechanisms. However, as all 1-MDT-bearing compounds enter the cells at similar efficiency, this indicates, on the one hand, that the difference in cytotoxicity between the 1-MDTbearing drugs is not based on different drug uptake mechanisms. On the other hand, as oxaliplatin is accumulating 
Table 2. $\log D_{7.4}$-Values for Selected Complexes

\begin{tabular}{ccc} 
oxaliplatin & OAc/OAc & SucEs/IdoCa \\
-1.30 & -1.86 & -2.02 \\
\hline
\end{tabular}

with much higher potency, this suggests that the reduction (and thus oxaliplatin release) is an intracellular process.

Selection of an IDO-Expressing Cancer Cell Model for IDO Inhibition Studies. In order to select an appropriate cell model for the analysis of the IDO-inhibitory potency of our new platinum(IV) prodrugs, as a first step we tested a panel of 13 cell lines from human and murine origin for their IDO messenger RNA (mRNA) levels by the real-time polymerase chain reaction (Figure S8). In agreement with the literature, SKOV3 ovarian carcinoma cells possessed very high IDO expression. $^{16,46}$ Also, one patient-derived melanoma model VM7, which was established at our institute, ${ }^{47}$ was moderately positive for IDO expression. Unfortunately, of the tested murine colon cancer models, only CT-26 displayed some IDO mRNA levels, while all others were negative. Subsequently, we tested SKOV3 and VM7 for their sensitivity to our compound panel. Noteworthy, both cell models are characterized by a very low proliferation doubling time (Figure S9). Consequently, it is not surprising that both cell models were rather unresponsive to platinum treatment after $72 \mathrm{~h}$ (Table S3) as such anticancer drugs generally require a longer incubation time to show effects in slowly growing cancer cells. ${ }^{48}$ Thus, we extended the incubation time of our experiments with SKOV3 cells to $168 \mathrm{~h}$ and assessed the cell number using crystal violet stain. As expected, this effectively increased anticancer activity, especially for the platinum(IV) prodrugs (Figure 5). In line with the results in the colon cancer

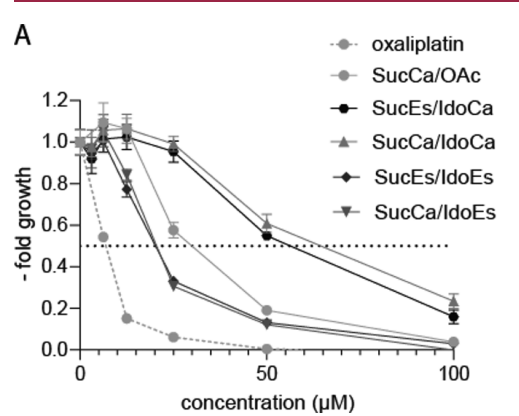

B

\begin{tabular}{l|l|l}
\multicolumn{2}{c}{$\mathrm{IC}_{50}$ value $(\mu \mathrm{M})$} \\
\hline oxaliplatin & $6.2 \pm 1.1$ \\
SucCa/OAc & $29.7 \pm 0.3$ \\
SucEs/IdoCa & $53.1 \pm 4.5$ \\
SucCa/IdoCa & $54.6 \pm 14.1$ \\
SucEs/IdoEs & $19.4 \pm 1.2$ \\
SucCa/IdoEs & $18.4 \pm 3.0$
\end{tabular}

Figure 5. Long-term cytotoxicity assay in SKOV3 cancer cells. (A) Cells were treated with increasing concentrations of the indicated drugs for $168 \mathrm{~h}$, fixed using ice-cold methanol, stained with crystal violet, and fluorescence intensity was measured. Fluorescence intensity was blotted as a full dose-response curve to calculate $\mathrm{IC}_{50}$ values. (B) Mean $\mathrm{IC}_{50}$ values given as mean $\pm \mathrm{SD}$.

cell models, the less stable SucCa/IdoEs and SucEs/IdoEs derivatives showed higher (and more rapidly emerging) anticancer activity, resulting in lower $\mathrm{IC}_{50}$ values. All subsequent studies on the IDO inhibition of the new compounds were performed in SKOV3 cells.

Kinetics of 1-MDT Release in SKOV3 Lysates. In order to determine whether our compounds are efficiently reduced and thereby release 1-MDT inside cancer cells, the succinimide prodrugs were incubated in SKOV3 lysates at $37{ }^{\circ} \mathrm{C}$. Subsequently, at various time points up to $72 \mathrm{~h}$, proteins were precipitated by addition of cold methanol $(\mathrm{MeOH})$, and the supernatant was analyzed by liquid chromatography-mass
SucCa/IdoCa

$-1.49$

SucEs/IdoEs

$-0.30$

SucCa/IdoEs

$-0.16$

spectrometry (LC-MS). We could nicely observe the released 1-MDT ligand (main fragment $m / z=202$; $\left[\mathrm{M}-\mathrm{NH}_{2}\right]^{+}$; Figure $6 \mathrm{~A}$ ). However, we plotted the reduction of the peak intensities of the intact platinum(IV) complexes over time because of the limited solubility of $1-\mathrm{MDT}$ in $\mathrm{MeOH}$, leading to quantification problems. In line with the other results, the data revealed that the 1-MDT ester-linked complexes were reduced to a much higher extent than their 1-MDT-carbamatocounterparts. After $72 \mathrm{~h}$, nearly 100\% 1-MDT release was observed for SucEs/IdoEs and SucCa/IdoEs, whereas both, SucEs/IdoCa and SucCa/IdoCa, were still present as platinum(IV) species to $\sim 50 \%$ (Figure $6 \mathrm{~B}$ ). These results not only support the hypothesis that the reduction-mediated 1MDT release is an intracellular event but also indicate that it is not dependent on intact cells.

IDO Inhibition in Cell Culture. As already mentioned in the introduction section, the enzymatic activity of IDO leads to the catabolism of Trp to Kyn. ${ }^{7}$ To evaluate the activity of IDO after treatment with our platinum(IV) complexes, Kyn levels were analyzed in the supernatants of SKOV3 cells using a colorimetric method and liquid chromatography-high resolution mass spectrometry (LC-HRMS). ${ }^{49}$ As a first step, the assays were performed with the supernatants collected after 72 $\mathrm{h}$ treatment with both 1-MT enantiomers (1-MDT and 1MLT). Noteworthy, due to their very poor cell permeability, for both drugs, very high concentrations are usually applied (2 $\mathrm{mM}){ }^{50,51}$ Moreover, although 1-MDT has better immunomodulatory properties in vivo, 1-MLT is the stronger IDO inhibitor in vitro. ${ }^{10}$ In good agreement with the literature, strong reductions in Kyn levels were observed with 1-MLT, while 1-MDT had borderline activity (Figure S10). As the LC-HRMS data indicated that serum-containing medium has already rather high Trp levels per se (data not shown), we subsequently used a modified setting for the investigation of our platinum(IV) drugs. In more detail, the cells were incubated with the drugs for $72 \mathrm{~h}$ under normal cell culture conditions. Then, the medium containing the test drugs and $10 \%$ FCS was replaced by serum-free medium for additional 24 $\mathrm{h}$, which was then used for the measurements. Drug treatment had no impact on cell viability at the used concentrations of 50 $\mu \mathrm{M}$ (data not shown). Corresponding to the accelerated 1MDT release, both fast-reducing compounds (SucEs/IdoEs and SucCa/IdoEs) showed stronger inhibition of IDO and therefore lower Kyn levels than the platinum(IV) reference complexes or the slow 1-MDT-releasing derivatives (SucEs/ IdoCa and SucCa/IdoCa) (Figure 7A). The results were confirmed by LC-HRMS measurements of Kyn, Trp, and kynurenic acid, a downstream metabolite of the IDO pathway (Figure $7 \mathrm{~B}-\mathrm{D}) .^{52}$ In addition, these data nicely show the metabolic connection between Kyn, Trp, and kynurenic acid: the stronger the IDO inhibition, the lower the Kyn and kynurenic acid levels and the higher the accumulation of Trp.

Noteworthy, the IDO inhibition of the two fast-reducing compounds was superior even to 1-MLT, which is especially interesting considering that the free IDO inhibitors were applied at a dose of $2 \mathrm{mM}$, compared to the release of max. 50 $\mu \mathrm{M}$ inhibitor in case of the platinum(IV) prodrugs. Consequently, these experiments not only confirm the release 

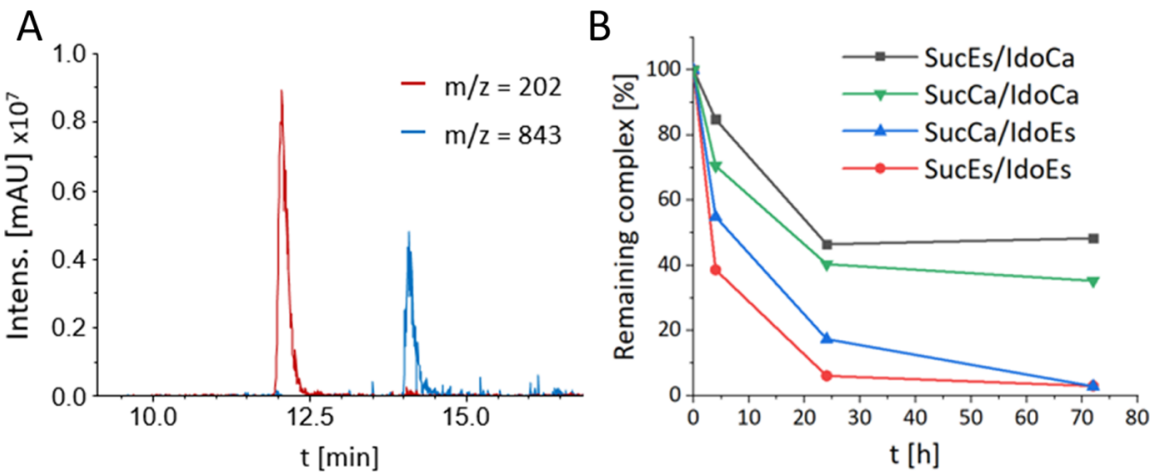

Figure 6. Reduction kinetics and release of 1-MDT in SKOV3 cell lysates. (A) Exemplary extracted ion chromatogram of 1-MDT release $(m / z=$ 202) from SucCa/IdoEs $(m / z=843)$ after $24 \mathrm{~h}$ incubation. (B) Reduction kinetics of all succinimide complexes in SKOV3 cell lysates at $37^{\circ} \mathrm{C}$. At $0,4,24$, and $72 \mathrm{~h}$, methanol extracts were measured by HPLC with UV detection at $230 \mathrm{~nm}$, as described in the experimental section. Data were normalized to the area under curve of the respective platinum(IV) complex at $t=0$.
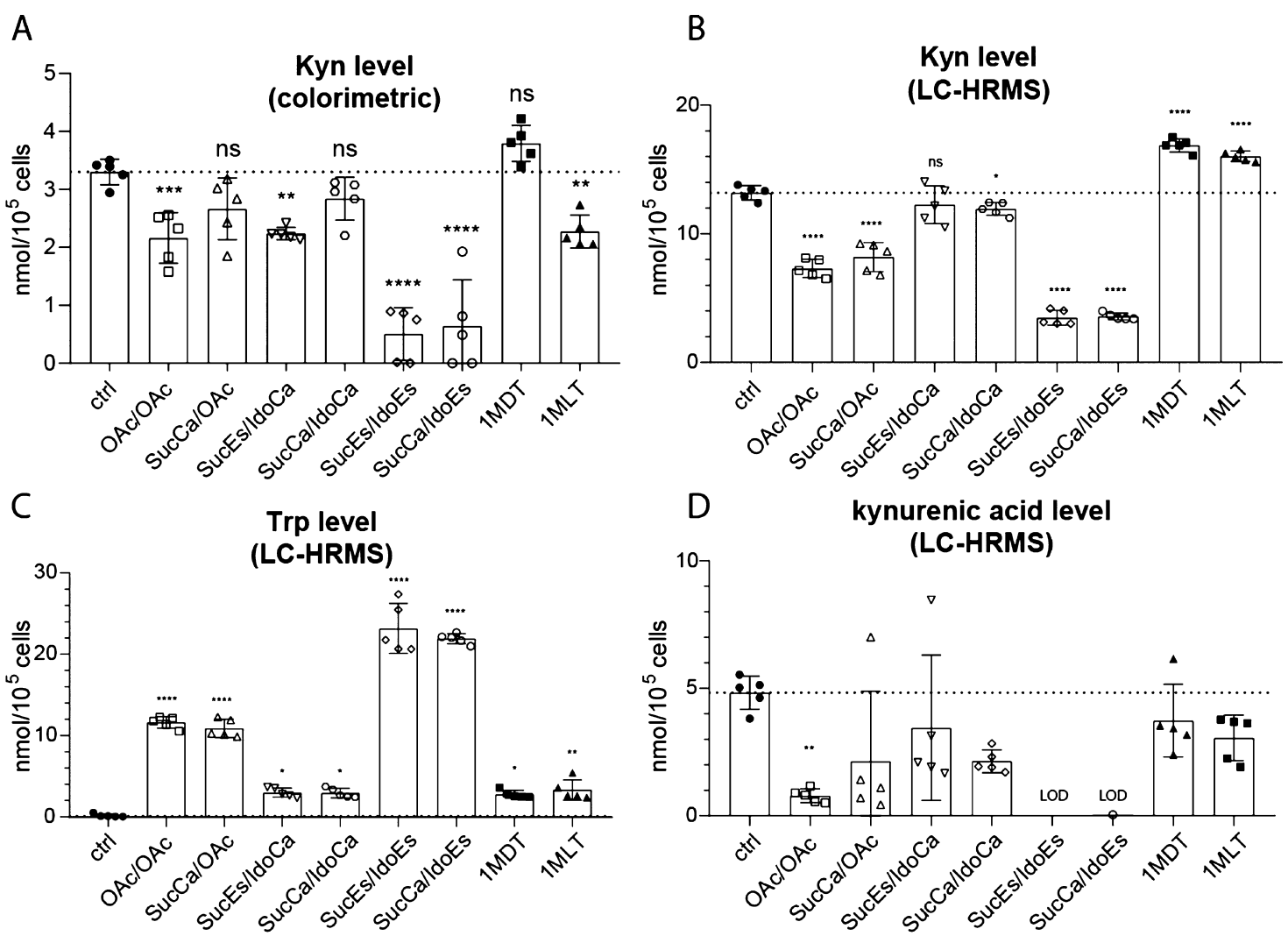

Figure 7. Inhibition of the enzymatic IDO activity of SKOV3 cells in vitro. (A) Colorimetric Kyn detection assay in serum-free supernatant of SKOV3 cells and LC-HRMS measurements of (B) Kyn, (C) Trp, and (D) kynurenic acid level normalized to cell number. Bars depict mean \pm SD of five replicates normalized to cell number. $\mathrm{LOD}=$ limit of detection. Significance was calculated in comparison to control conditions by multiple comparison analysis [one-way analysis of variance (ANOVA)] and Dunnett post-hoc-test $\left(*_{p}<0.05, * *_{p}<0.01, * * * p<0.001\right.$, and $* * * *<<$ $0.0001)$.

of functional 1-MDT from our new multi-modal complexes but also show that coupling to a platinum(IV) center is a very efficient way to enhance the transport of 1-MDT into cancer cells, where it is released after intracellular reduction.

Tissue and Organ Distribution of the MaleimideConjugated Drugs in Vivo. In order to investigate the impact of the reduction kinetics on the pharmacological behavior of the drugs in the living organism, as a next step, SKOV3-bearing SCID mice were treated with our test compound panel at concentrations equimolar to $9 \mathrm{mg} / \mathrm{kg}$ oxaliplatin. After $24 \mathrm{~h}$, the animals were sacrificed, and plasma, tumor, and organ samples were collected and snap-frozen in liquid nitrogen. Subsequently, platinum levels were analyzed by ICP-MS after microwave digestion. With regard to blood plasma, treatment with all maleimide derivatives led to distinctly higher platinum concentrations than oxaliplatin or OAc/OAc ( $\sim 12$-fold in case of MalEs/IdoCa and MalCa/ IdoCa). Noteworthy, there were also distinct differences between the fast- and the slow-reducing derivatives. Thus, the animals treated with the two fast-reducing derivatives had distinctly lower platinum levels ( 1.9 and $3.7 \mathrm{mg} / \mathrm{kg}$ for MalCa/ IdoEs and MalEs/IdoEs, respectively) than the two slow- 

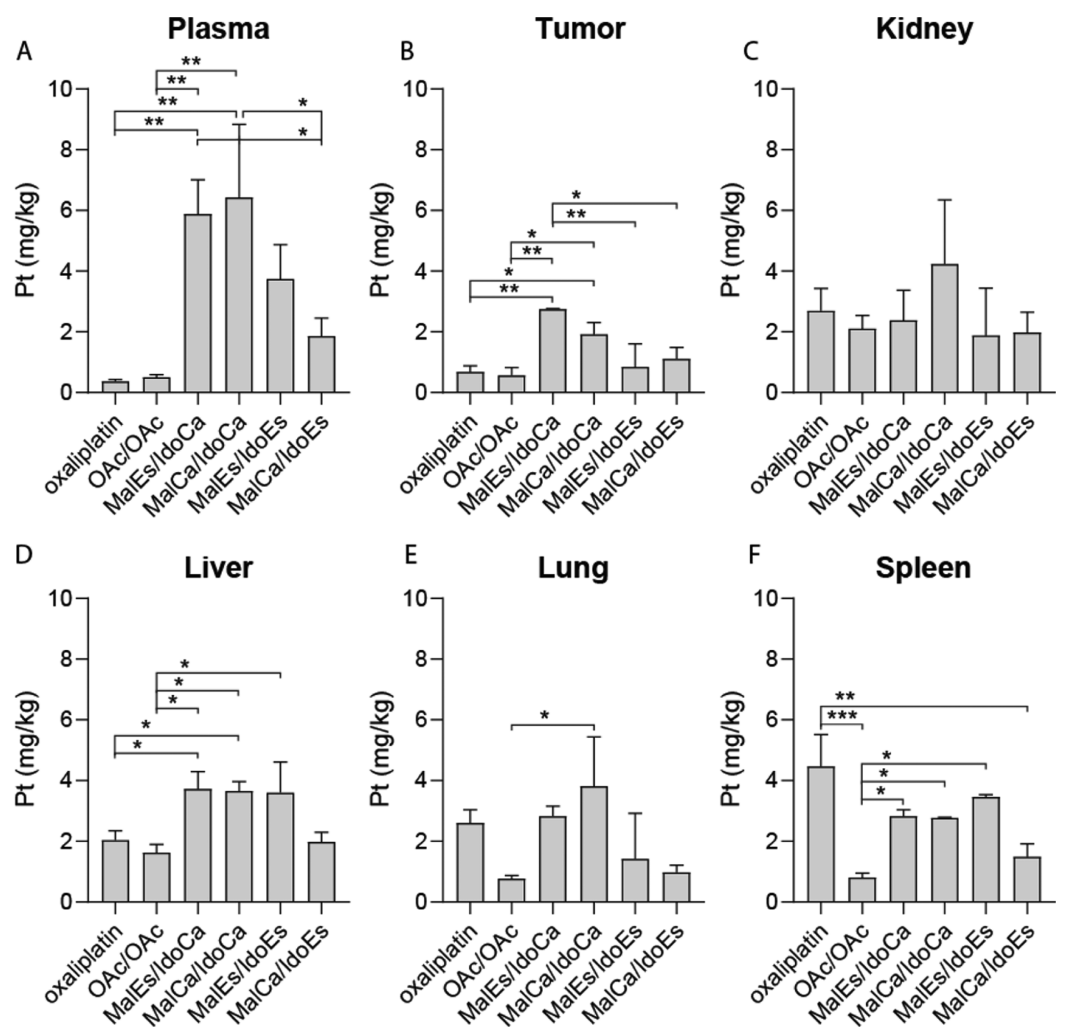

Figure 8. Plasma levels and drug distribution in vivo. SKOV3-bearing male SCID mice were treated once via the tail vein with the indicated drugs at doses equimolar to $9 \mathrm{mg} / \mathrm{kg}$ oxaliplatin. After $24 \mathrm{~h}$, animals were sacrificed, and plasma (A), tumor tissue (B), and diverse organs (C-F) were collected. Platinum levels in isolated tissues were detected by ICP-MS and normalized to tissue weight. Significance was calculated by ordinary one-way ANOVA and Tukey's multiple comparisons test $(* p<0.05, * * p<0.01$, and $* * * p<0.001)$.

reducing drugs (5.9 and $6.4 \mathrm{mg} / \mathrm{kg}$ for MalEs/IdoCa and MalCa/IdoCa, respectively) (Figure 8A). Subsequently, especially the slow-reducing drugs showed pronounced tumor accumulation in comparison to both of the reference platinum complexes (Figure $8 \mathrm{~B}-\mathrm{F}$ ). Noteworthy, as can be seen in the oxaliplatin- and OAc/OAc-treated animals, the malignant tissue is usually characterized by rather low drug levels resulting, for example, in tumor to organ ratios of $\sim 0.3$ in case of the liver and kidney, respectively (Table S4). This ratio was distinctly improved by the albumin-targeted prodrug concept. Thus, especially in case of the slow-reducing agents, tumor to organ ratios of 0.7 and 1.2 for the liver and kidney, respectively, were observed. Overall, the impact of the albumin targeting on drug distribution is congruent with previous observations, as it results in a distinctly prolonged plasma halflife together with preferential uptake by the tumor tissue. ${ }^{29,53}$ However, the plasma levels detected for our new drugs were lower, when compared to data on oxaliplatin-releasing platinum(IV) maleimide derivatives without the 1-MDT ligand. ${ }^{29}$ This suggests that the additional 1-MDT moiety might lead to enhanced clearance of the albumin conjugate or faster reduction/oxaliplatin release. Whether this is specific to IDO-containing compounds or a general phenomenon for multi-modal maleimide derivatives needs to be addressed in subsequent studies.

Anticancer and Immunomodulatory Activity against CT26 Colon Cancer Tumors in Vivo. As a first step, to gain more insights into the release of 1-MDT and subsequent IDO inhibition in vivo, the slow-reducing MalEs/IdoCa and the fast-reducing MalCa/IdoEs derivative were compared $24 \mathrm{~h}$ after treatment. To this end, the tumors were harvested and spiked with ${ }^{13} \mathrm{C}$-labeled metabolites. Tumor sample aliquots were 5-fold concentrated and the metabolites (Figure S11A) quantified by LC-HRMS. The relative quantification of 1MDT in the SKOV3 tumor tissue revealed a significant 1MDT release with both drugs. In good agreement with the ICP-MS data, the 1-MDT levels were $\sim 2$-fold higher in the tumors of MalEs/IdoCa-treated animals than upon MalCa/ IdoEs treatment (Figure S11B). Accordingly, the application of MalEs/IdoCa resulted in inhibition of IDO activity indicated by an improved Trp to Kyn ratio compared to solvent- or MalCa/IdoEs-treated animals (Figure S11C). Interestingly, when looking at the IDO downstream catabolite kynurenic acid (Figure S11D), enhanced signals were detected in the MalCa/IdoEs-treated tumors. This supports the hypothesis that slow-reducing maleimide derivatives are characterized by an enhanced plasma-half-life, which results in a prolonged IDO-inhibitory potential in vivo.

Next, we were interested in the in vivo anticancer activity of our maleimide-containing compound panel. However, as both IDO inhibition and oxaliplatin need an active immune system for their activity against tumor cells, for these experiments, a switch to an immune-competent model was necessary. Therefore, we chose CT26 colon cancer allografts which expressed the "highest" IDO levels among the tested murine cell models (Figure S8B). The applied drug doses were equimolar to the maximal tolerated dose of oxaliplatin $(9 \mathrm{mg} /$ $\mathrm{kg}$ ). In the first experiment, we compared the slow-reducing MalCa/IdoCa with the fast-reducing MalCa/IdoEs (Figure 9A). Both compounds had significant anticancer activity, which resulted in distinctly reduced tumor burden. However, MalCa/ IdoCa was superior in its activity against the CT26 tumors 


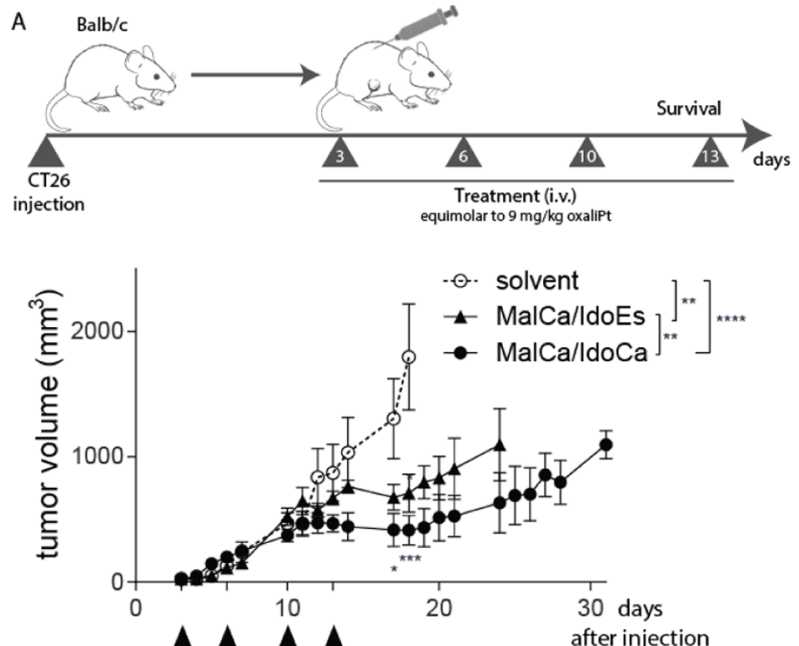

B

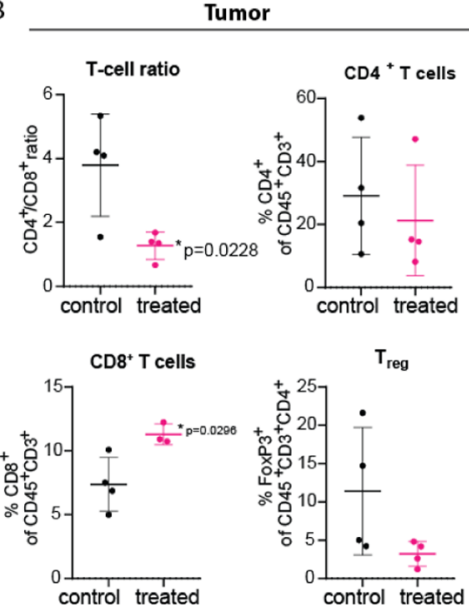

Tumor-draining lymph node

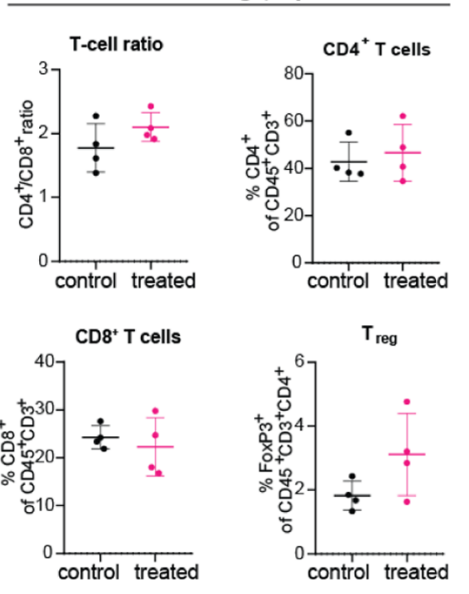

C

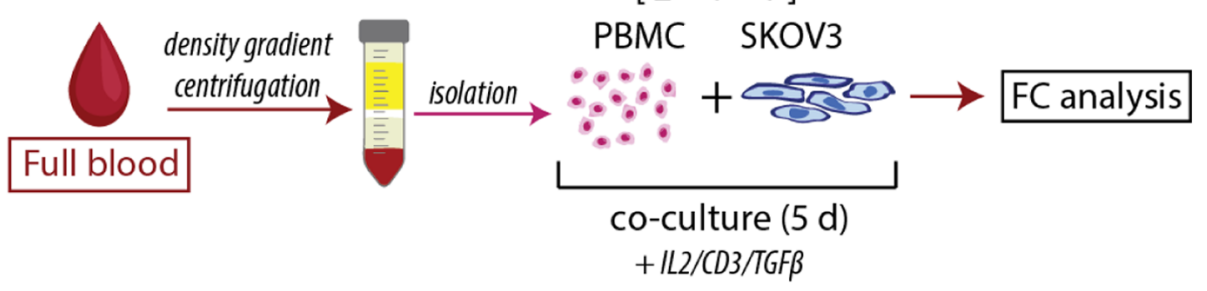

D

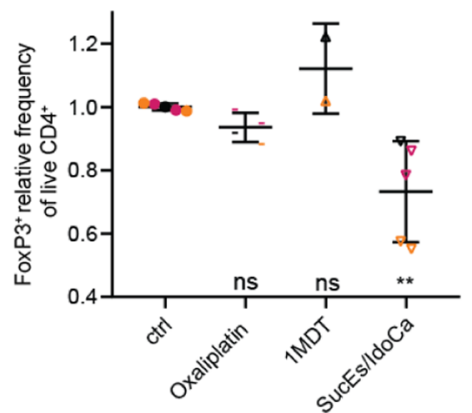

Figure 9. Anticancer activity and impact on tumor-infiltrating T-cell populations of our new 1-MDT-releasing drugs against CT26 allografts in immune-competent Balb/c mice. (A) Schematic timeline of the performed therapy experiment in CT26-bearing Balb/c mice. Tumor growth was measured daily by caliper after cell injection. Black arrows indicate treatments of solvent, MalCa/IdoEs or MalCa/IdoCa (iv) equimolar to 9 mg/ $\mathrm{kg}$ oxaliplatin. Significance was calculated in comparison to the solvent group by two-way ANOVA, multiple comparison analysis, and Bonferroni post-hoc-test. (B) CT26-bearing Balb/c mice were treated once with drug doses of MalEs/IdoCa equimolar to $9 \mathrm{mg} / \mathrm{kg}$ oxaliplatin via the tail vein. After $24 \mathrm{~h}$, animals were sacrificed, and tumors and tumor-draining lymph nodes were collected and analyzed for their T-cell populations by multicolor flow cytometry (FC). Significance was calculated in comparison to the solvent group and within each group by unpaired $t$-test (twotailed) $(* p<0.05, * * p<0.01, * * * p<0.001$, and $* * * * p<0.0001)$. (C) Schematic representation of the $\mathrm{T}_{\text {reg }}$ differentiation assay using a human PBMC/SKOV3 tumor cell co-culture model. (D) Relative frequency of $\mathrm{T}_{\text {reg }}$ in live $\mathrm{CD}^{+} \mathrm{T}$ cells $\left(\mathrm{CD} 45^{+} \mathrm{CD} 3^{+} \mathrm{CD}^{+}\right)$from a co-culture with PBMC and SKOV3 tumor cells for oxaliplatin $(10 \mu \mathrm{M}), 1-\mathrm{MDT}(50 \mu \mathrm{M})$, and SucEs/IdoCa $(50 \mu \mathrm{M})$. Each value is normalized to control, and values from the same donor are presented in the same color (black, orange, or pink). Significance was calculated using one-way ANOVA with Dunnett's multiple comparison tests.

compared to MalCa/IdoEs and led to a prolonged period of disease stabilization in all mice (tumor volumes of the individual animals and Kaplan-Meier curves for overall survival of the animals are shown in Figure S12). Subsequently, we also tested MalEs/IdoEs (Figure S13A), which was inactive, and MalEs/IdoCa (Figure S13B), which had activity comparable to MalCa/IdoCa. Finally, MalCa/IdoCa activity was directly compared to oxaliplatin (Figure S14). This experiment clearly indicates that $\mathrm{MalCa} / \mathrm{IdoCa}$ was superior to oxaliplatin with respect to both, impact on tumor growth and overall survival. Taken together, these initial experiments indicate that slow platinum(IV) reduction kinetics (which in cell culture experiments results in low activity) are very beneficial in the in vivo setting, resulting in prolonged plasma half-life, enhanced tumor accumulation, and superior anticancer activity.

Finally, we were interested whether treatment with an 1MDT-releasing platinum(IV) drug leads to a changed immune infiltration into CT26 tumors. To this end, flow cytometry of immune cells isolated from tumor tissue and from tumordraining lymph nodes was performed $24 \mathrm{~h}$ after single treatment with MalEs/IdoCa (Figure 9B). Indeed, therapy led to a significant shift in the ratio of $\mathrm{CD}^{+}$(immunosuppressive) to $\mathrm{CD}^{+}$(immunostimulatory) $\mathrm{T}$ cells in the malignant tissue. This was based on a significant increase in the population of cytotoxic $\mathrm{T}$ cells, while there was a trend toward a reduced number of $\mathrm{FoxP}^{+}$(immunosuppressive) regulatory $\mathrm{T}$ cells $\left(T_{\text {reg }}\right)$. In contrast, drug treatment had no effect on the immune cell population in the respective tumordraining lymph nodes. This indicates that the new drug indeed has the potential to reactivate the immune system inside the malignant tissue in a tumor-specific manner.

In order to investigate whether our prodrugs are also able to provoke a comparable immune response in human cells, we performed a series of co-culture experiments using isolated peripheral blood mononuclear cells (PBMCs) from three different healthy donors. $\mathrm{T}_{\text {reg }}$ differentiation and expansion were induced by co-culturing PBMCs and SKOV3 tumor cells for 5 days in the presence of $\mathrm{T}_{\text {reg }}$ differentiation medium [interleukin 2 (IL-2), CD3, and transforming growth factor $\beta$ (TGF $\beta)]$ and nontoxic concentrations of oxaliplatin $(10 \mu \mathrm{M})$, 1-MDT $(50 \mu \mathrm{M})$, or SucEs/IdoCa $(50 \mu \mathrm{M})$. Subsequently, the frequency of $\mathrm{T}_{\text {reg }}$ was assessed using multicolor flow cytometry (Figure 9C). Of note, in all three individuals, 
SucEs/IdoCa was superior to oxaliplatin or 1-MDT treatment and significantly reduced $\mathrm{T}_{\text {reg }}$ differentiation (Figure 9D). This suggests that through introduction of 1-MDT as a bioactive ligand, our prodrugs effectively reduced the amounts of tumorsuppressive $\mathrm{T}_{\text {reg }}$ also in a human co-culture setting.

\section{CONCLUSIONS}

During the last few decades, there is increased understanding that the malignant tissue differs from healthy organs in multiple aspects. ${ }^{54,55}$ Consequently, it is not only of interest to develop new drugs with better tumor-targeting properties but also to consider the changed tumor microenvironment for tumor-specific therapy (e.g., the tumor-promoting state of the immune cell population). This study reports on the first tripleaction prodrugs of oxaliplatin, which is the current state of the art therapy against colon cancer. ${ }^{2}$ To this end, we used wellestablished platinum(IV) prodrugs (which themselves have often insufficient targeting properties due to premature activation in e.g. red blood cells) and improved their tumor delivery by attaching an albumin-targeting maleimide moiety as one axial ligand. Albumin is efficiently taken up und degraded by cancer cells due to their enhanced needs for nutrients. ${ }^{25}$ In the second axial position, the clinically investigated IDO inhibitor 1-MDT was attached. ${ }^{8}$ This approach results in the tumor-specific release of the immunomodulator together with oxaliplatin after activation by reduction inside the cancer cell.

In order to allow the selection of the best lead candidate for further (pre)clinical development, we prepared several derivatives, where 1-MDT has been attached to the molecules via different strategies. Noteworthy, these derivatives distinctly differed in their reduction behavior (fast reducing SucEs/ IdoEs and SucCa/IdoEs; slow-reducing SucEs/IdoCa and SucCa/IdoCa). Overall, the low reductive stabilities observed for the SucEs/IdoEs and SucCa/IdoEs complexes were highly unexpected as similar oxaliplatin-based platinum(IV) complexes exhibit high reductive inertness. ${ }^{29,40-42}$ Subsequent analysis indeed confirmed that the complexes not only release (as expected) unmodified 1-MDT but also confirmed that this process has to be intracellular. This indicates that the coupling to a platinum(IV) center is also an efficient approach to deliver 1-MDT (which has rather low cell permeability) into cancer cells. Noteworthy, cell culture is rather limited when it comes to prediction of in vivo anticancer activity. This is especially true in case of maleimide-targeted drugs, as the moiety is not only prone to hydrolysis but also reacts with components of the cell culture medium (e.g. free cysteine). Moreover, cancer cells are usually "overfed" in the standard cell culture conditions, which can reduce their albumin uptake and catabolism. Consequently, in vivo experiments in tumorbearing mice were performed to gain preliminary information on pharmacokinetic, immunomodulatory potential, and anticancer activity. In general, there are two basic screening approaches: on the one hand, human cancer cells can be tested in immune-deficient mice. On the other hand, immunecompetent mice carrying murine allograft tumors can be used. For oxaliplatin prodrugs, immune-competent models are important, as it is well-known that the activity is dependent on the immune system. ${ }^{3}$ Consequently, anticancer activity and impact on tumor selectivity of the immune-inhibitory potential were tested in CT26 allografts. These investigations impressively confirm that there is no direct correlation between cell culture data and in vivo activity. The IdoEs complexes show higher activity in cell culture (due to faster reduction), however, lower activity in mice. In turn, the IdoCa compounds (with slower reduction) are widely inactive in common $48 \mathrm{~h}$ or $72 \mathrm{~h}$ viability assays but reveal higher tumor-inhibiting potential in vivo. The animal experiments also show that these complexes are able to inhibit IDO in the malignant tissue, which leads to tumor-specific changes in the T-cell population. However, our data also indicate that for the final selection of a lead candidate, further studies are required as our preliminary data reveal that the four 1-MDT-releasing derivatives differ in their pharmacological behavior (e.g., plasma half-life). The exact reasons for these effects need to be further dissected and more in-depth studies are necessary to establish the best therapeutic scheme (e.g., maximal tolerable dose and frequency of the treatment) for most favorable IDO inhibition.

In summary, in this study, we demonstrate that the design of albumin-targeted multi-modal prodrugs on platinum(IV) basis is a promising strategy to enhance the intracellular uptake of compounds with low cell permeability and additionally to improve their selective delivery into the malignant tissue. This should allow tumor-specific anticancer therapy supported by a favorable immune microenvironment.

\section{EXPERIMENTAL SECTION}

Synthesis. Materials and Methods. Potassium tetrachloridoplatinate was purchased from Johnson Matthey (Switzerland). Water for synthesis was taken from a reverse osmosis system and distilled twice before use. For HPLC measurements, Milli-Q water $(18.2 \mathrm{M} \Omega \cdot \mathrm{cm}$, Merck Milli-Q Advantage, Darmstadt, Germany) was used. Compound 5a, other chemicals, and solvents were purchased from commercial suppliers (Sigma-Aldrich, Merck, Acros, Fluka, and Fisher Scientific). Oxaliplatin, complexes $7 \mathbf{a}, 7 \mathbf{b}, \mathbf{O A c} / \mathbf{O A c}$, and 3-(1methyl-1H-indol-3-yl)propanoic acid (IPA) were synthesized similar to methods described in the literature. ${ }^{38,39,56,57}$ Electrospray ionization (ESI) mass spectra were recorded on a Bruker amaZon SL ion trap mass spectrometer in the positive and/or negative mode by direct infusion at the Mass Spectrometry Centre of the University of Vienna. One- and two-dimensional ${ }^{1} \mathrm{H}$ and ${ }^{13} \mathrm{C}$ spectra were recorded on a Bruker AV Neo 500 or AV III 600 spectrometer at 298 $\mathrm{K}$. For ${ }^{1} \mathrm{H}$ and ${ }^{13} \mathrm{C}$ NMR spectra, the solvent residual peak was taken as an internal reference. The ${ }^{1} \mathrm{H}$ and ${ }^{13} \mathrm{C}$ NMR spectra of the final compounds are depicted in Figures S17-S24. Purification by preparative reverse phase (RP) HPLC was performed on an Agilent 1200 series system using a Waters XBridge C18 column $(19 \times 250$ $\mathrm{mm}$ ). Elemental analysis measurements were carried out on a PerkinElmer $2400 \mathrm{CHN}$ elemental analyzer at the Microanalytical Laboratory of the University of Vienna and are within $\pm 0.4 \%$, confirming $>95 \%$ purity. Of course, the content of TFA and water can vary between different batches of the same compound. In addition, UHPLC chromatograms of the final compounds can be seen in Figures S25-S32. For NMR numbering of the final compounds, see Scheme S1.

General Procedure A for Isocyanate Formation from Carboxylic Acids. The carboxylic acid was dissolved in anhydrous toluene, and 1.2 equiv of TEA was added. DPPA (1 equiv) was slowly added, and the mixture was stirred under Ar at RT for $5.5 \mathrm{~h}$. A saturated $\mathrm{NaHCO}_{3}$ solution was added to the mixture, the phases were separated, and the organic layer was washed with brine, dried over $\mathrm{Na}_{2} \mathrm{SO}_{4}$, filtered, and subsequently refluxed under Ar for $17 \mathrm{~h}$. The solvents were removed in vacuo to obtain the crude isocyanate which was used without further purification.

tert-Butyl 1-Methyl-D-tryptophanate (1). 1-MDT (500 mg, 2.29 $\mathrm{mmol}$ ) was suspended in tert-butyl acetate $(10 \mathrm{~mL})$ and cooled to 0 ${ }^{\circ} \mathrm{C}$. Perchloric acid $(60 \%)(0.38 \mathrm{~mL}, 3.43 \mathrm{mmol}, 1.5$ equiv) was added slowly, and the reaction mixture was stirred at RT for $19 \mathrm{~h} .0 .5 \mathrm{M} \mathrm{HCl}$ $(4 \times 30 \mathrm{~mL})$ was added to the reaction mixture, and the phases were separated. The combined aqueous layers were basified to $\mathrm{pH} 9-10$ by 
addition of $10 \% \mathrm{~K}_{2} \mathrm{CO}_{3}$ solution, extracted with DCM $(4 \times 50 \mathrm{~mL})$, dried over $\mathrm{MgSO}_{4}$, and evaporated to dryness to obtain $1(244 \mathrm{mg}$, $38 \%)$ as a colorless oil. ${ }^{1} \mathrm{H}$ NMR $\left(500 \mathrm{MHz}\right.$, DMSO- $\left.d_{6}\right): \delta 7.53(\mathrm{~d}, J$ $=7.9 \mathrm{~Hz}, 1 \mathrm{H}), 7.36(\mathrm{~d}, J=8.2 \mathrm{~Hz}, 1 \mathrm{H}), 7.15-7.07(\mathrm{~m}, 2 \mathrm{H}), 7.02-$ $6.98(\mathrm{~m}, 1 \mathrm{H}), 3.72(\mathrm{~s}, 3 \mathrm{H}), 3.47(\mathrm{t}, J=6.4 \mathrm{~Hz}, 1 \mathrm{H}), 2.95(\mathrm{dd}, J=$ $14.2,6.3 \mathrm{~Hz}, 1 \mathrm{H}), 2.85(\mathrm{dd}, J=14.2,6.7 \mathrm{~Hz}, 1 \mathrm{H}), 1.74($ br s, $2 \mathrm{H})$, $1.29(\mathrm{~s}, 9 \mathrm{H})$. MS $(\mathrm{m} / z)$ : calcd for $\mathrm{C}_{16} \mathrm{H}_{23} \mathrm{~N}_{2} \mathrm{O}_{2}(\mathrm{M}+\mathrm{H})^{+}$, 275.18; found, 275.15 .

tert-Butyl $N^{\alpha}$-(1H-Imidazole-1-carbonyl)-1-methyl-o-tryptophanate (2). 1,1'-Carbonyldiimidazole ( $249 \mathrm{mg}, 1.54 \mathrm{mmol}, 2$ equiv) was dissolved in DCM $(10 \mathrm{~mL})$, and DIPEA $(0.34 \mathrm{~mL}, 1.92 \mathrm{mmol}$, 2.5 equiv) was added. 1 ( $211 \mathrm{mg}, 0.77 \mathrm{mmol}, 1$ equiv) was slowly added to the solution and stirred at RT for $4 \mathrm{~h}$. The reaction mixture was washed with half-saturated aqueous $\mathrm{NH}_{4} \mathrm{Cl}$ solution, and the organic phase was dried over $\mathrm{MgSO}_{4}$ and evaporated to dryness. The crude product was purified by flash column chromatography ( $40 \%$ hexane in EtOAc) to obtain title compound $2(150 \mathrm{mg}, 52 \%)$ as a white solid. ${ }^{1} \mathrm{H}$ NMR (500 MHz, DMSO- $\left.d_{6}\right): \delta 8.86(\mathrm{~d}, J=7.6 \mathrm{~Hz}$, $1 \mathrm{H}), 8.24(\mathrm{~m}, 1 \mathrm{H}), 7.69(\mathrm{t}, J=1.4 \mathrm{~Hz}, 1 \mathrm{H}), 7.58(\mathrm{~d}, J=7.9 \mathrm{~Hz}, 1 \mathrm{H})$, $7.38(\mathrm{~d}, J=8.2 \mathrm{~Hz}, 1 \mathrm{H}), 7.19(\mathrm{~s}, 1 \mathrm{H}), 7.15-7.11(\mathrm{~m}, 1 \mathrm{H}), 7.05-7.00$ $(\mathrm{m}, 2 \mathrm{H}), 4.47(\mathrm{ddd}, J=9.5,7.6,5.6 \mathrm{~Hz}, 1 \mathrm{H}), 3.72(\mathrm{~s}, 3 \mathrm{H}), 3.27(\mathrm{dd}, J$ $=14.6,5.5 \mathrm{~Hz}, 1 \mathrm{H}), 3.17(\mathrm{dd}, J=14.6,9.4 \mathrm{~Hz}, 1 \mathrm{H}), 1.34(\mathrm{~s}, 9 \mathrm{H})$. MS $(m / z)$ : calcd for $\mathrm{C}_{20} \mathrm{H}_{24} \mathrm{~N}_{4} \mathrm{O}_{3} \mathrm{Na}(\mathrm{M}+\mathrm{Na})^{+}$, 391.17; found, 391.19.

$N^{\alpha}$-(tert-Butoxycarbonyl)-1-methyl-D-tryptophan (4). 1-MDT (500 mg, $2.29 \mathrm{mmol}$ ) was suspended in $\mathrm{H}_{2} \mathrm{O}$ /dioxane 1:1 (12 mL). $\mathrm{NaOH}$ (229 mg, $5.73 \mathrm{mmol}, 2.5$ equiv) was added. Di-t-butyl dicarbonate was dissolved in $\mathrm{H}_{2} \mathrm{O}$ /dioxane 1:2 $(2 \mathrm{~mL})$ and added to the aforementioned solution. The reaction mixture was stirred at RT for $4 \mathrm{~h}$, poured into $\mathrm{H}_{2} \mathrm{O}(25 \mathrm{~mL})$, adjusted to $\mathrm{pH} 2$ with $1 \mathrm{M} \mathrm{HCl}$, and extracted with EtOAc $(3 \times 25 \mathrm{~mL})$. The organic layers were combined, washed with brine, dried over $\mathrm{NaSO}_{4}$, and evaporated to dryness to give $4(524 \mathrm{mg}, 71 \%)$ as a white powder. ${ }^{1} \mathrm{H}$ NMR (500 $\left.\mathrm{MHz}, \mathrm{CDCl}_{3}\right): \delta 7.59(\mathrm{~d}, J=7.9 \mathrm{~Hz}, 1 \mathrm{H}), 7.29(\mathrm{~d}, J=8.2 \mathrm{~Hz}, 1 \mathrm{H})$, $7.23(\mathrm{t}, J=7.6 \mathrm{~Hz}, 1 \mathrm{H}), 7.11(\mathrm{t}, J=7.5 \mathrm{~Hz}, 1 \mathrm{H}), 6.92(\mathrm{~s}, 1 \mathrm{H}), 5.08-$ $4.96(\mathrm{~m}, 1 \mathrm{H}), 4.70-4.44(\mathrm{~m}, 1 \mathrm{H}), 3.75(\mathrm{~s}, 3 \mathrm{H}), 3.37-3.26(\mathrm{~m}, 2 \mathrm{H})$, $1.43(\mathrm{~s}, 9 \mathrm{H})$. MS $(\mathrm{m} / z)$ : calcd for $\mathrm{C}_{17} \mathrm{H}_{21} \mathrm{~N}_{2} \mathrm{O}_{4}(\mathrm{M}-\mathrm{H})^{-}$, 317.15; found, 316.93 .

6-(2,5-Dioxopyrrolidine-1-yl)hexanoic Acid (5b). Succinic anhydride $(2.0 \mathrm{~g}, 20.0 \mathrm{mmol})$ was suspended in acetic acid $(30 \mathrm{~mL})$, and 6-aminohexanoic acid $(2.62 \mathrm{~g}, 20.0 \mathrm{mmol}, 1$ equiv) was added. The reaction mixture was refluxed for $3 \mathrm{~h}$, and the solvent was removed in vacuo. The crude product was purified by flash column chromatography (20\% hexane in EtOAc) to obtain $\mathbf{5 b}(2.46 \mathrm{~g}, 57 \%)$ as a white solid. ${ }^{1} \mathrm{H}$ NMR (500 MHz, $\left.\mathrm{CDCl}_{3}\right): \delta 3.54-3.47(\mathrm{~m}, 2 \mathrm{H}), 2.70(\mathrm{~s}$, $4 \mathrm{H}), 2.35(\mathrm{t}, J=7.4 \mathrm{~Hz}, 2 \mathrm{H}), 1.70-1.63(\mathrm{~m}, 2 \mathrm{H}), 1.63-1.55(\mathrm{~m}$, $2 \mathrm{H}), 1.40-1.31(\mathrm{~m}, 2 \mathrm{H})$. MS $(\mathrm{m} / z)$ : calcd for $\mathrm{C}_{10} \mathrm{H}_{15} \mathrm{NO}_{4} \mathrm{Na}(\mathrm{M}+$ $\mathrm{Na})^{+}, 236.09$; found, 236.07.

1-(5-Isocyanatopentyl)-1H-pyrrole-2,5-dione (6a). Compound 6a was synthesized according to general procedure A using 6maleimidohexanoic acid $(1.0 \mathrm{~g}, 4.73 \mathrm{mmol})$, toluene $(25 \mathrm{~mL})$, TEA $(0.79 \mathrm{~mL}, 5.68 \mathrm{mmol})$, and DPPA $(1.07 \mathrm{~mL}, 4.97 \mathrm{mmol})$. Yield: 1.10 g of crude colorless oil. ${ }^{1} \mathrm{H}$ NMR $\left(500 \mathrm{MHz}, \mathrm{CDCl}_{3}\right): \delta 6.69(\mathrm{~s}, 2 \mathrm{H})$, $3.53(\mathrm{t}, J=7.2 \mathrm{~Hz}, 2 \mathrm{H}), 3.30(\mathrm{t}, J=6.6 \mathrm{~Hz}, 2 \mathrm{H}), 1.67-1.59(\mathrm{~m}, 4 \mathrm{H})$, $1.42-1.33(\mathrm{~m}, 2 \mathrm{H})$.

1-(5-Isocyanatopentyl)pyrrolidine-2,5-dione (6b). Compound 6a was synthesized according to general procedure A using $\mathbf{5 b}(1.0 \mathrm{~g}$, $4.69 \mathrm{mmol})$, anh. toluene ( $40 \mathrm{~mL})$, TEA $(0.78 \mathrm{~mL}, 5.63 \mathrm{mmol}, 1.2$ equiv), and DPPA (1.01 mL, $4.69 \mathrm{mmol}, 1$ equiv). Yield: $0.92 \mathrm{~g}$ of crude colorless oil. ${ }^{1} \mathrm{H}$ NMR $\left(500 \mathrm{MHz}, \mathrm{DMSO}-d_{6}\right): \delta 3.36-3.31(\mathrm{~m}$, $4 \mathrm{H}), 2.61(\mathrm{~s}, 4 \mathrm{H}), 1.58-1.51(\mathrm{~m}, 2 \mathrm{H}), 1.51-1.43(\mathrm{~m}, 2 \mathrm{H}), 1.30-$ $1.22(\mathrm{~m}, 2 \mathrm{H})$.

(OC-6-34)-[(1R,2R)-1,2-Cyclohexanediamino][5-(2,5-dioxo-2,5dihydro-1 H-pyrrol-1-yl)pentylcarba mato]hydroxidooxalatoplatinum(IV) (8a). 7 (555 mg, $1.29 \mathrm{mmol}$ ) was suspended in anh. DMSO $(50 \mathrm{~mL})$. A solution of $6 \mathrm{a}(268 \mathrm{mg}, 1.29$ mmol, 1 equiv) in anh. DMSO $(1 \mathrm{~mL})$ was added to the mixture over a period of $16 \mathrm{~h}$ with the help of a syringe pump. The reaction mixture was stirred further at RT for $3 \mathrm{~h}$, and the solvent was removed in vacuo at $50{ }^{\circ} \mathrm{C} . \mathrm{MeOH}$ was added, and the crude product precipitated by addition of methyl tert-butyl ether. The resulting white powder $(680 \mathrm{mg})$ was used without further purification. For characterization purpose, a small fraction was purified via preparative RP-HPLC $\left[16 \%\right.$ acetonitrile $(\mathrm{MeCN})(+0.1 \% \mathrm{HCOOH})$ in $\mathrm{H}_{2} \mathrm{O}$ $(+0.1 \% \mathrm{HCOOH})$; isocratic]. ${ }^{1} \mathrm{H}$ NMR $\left(500 \mathrm{MHz}, \mathrm{DMSO}-d_{6}\right): \delta$ $10.00-9.57(\mathrm{~m}, 1 \mathrm{H}), 8.28$ (br s, $1 \mathrm{H}), 7.64($ br s, $1 \mathrm{H}), 7.07$ (br s, $1 \mathrm{H})$, $7.00(\mathrm{~s}, 2 \mathrm{H}), 6.41-6.01(\mathrm{~m}, 1 \mathrm{H}), 2.94-2.73(\mathrm{~m}, 2 \mathrm{H}), 2.59-2.51(\mathrm{~m}$, $2 \mathrm{H}), 2.26$ (br s, $1 \mathrm{H}), 2.13-2.00(\mathrm{~m}, 2 \mathrm{H}), 1.55-1.22(\mathrm{~m}, 8 \mathrm{H}), 1.20-$ $1.03(\mathrm{~m}, 4 \mathrm{H})$. MS $(\mathrm{m} / z)$ : calcd for $\mathrm{C}_{18} \mathrm{H}_{28} \mathrm{~N}_{4} \mathrm{O}_{9} \mathrm{NaPt}(\mathrm{M}+\mathrm{Na})^{+}$, 662.14; found, 662.04 .

(OC-6-34)-[(1R,2R)-1,2-Cyclohexanediamino][5-(2,5-dioxo-2,5dihydro-1 H-pyrrolidin-1-yl)pentylcarbamato]hydroxidooxalatoplatinum(IV) (8b). 7 (200 mg, $0.46 \mathrm{mmol})$ was suspended in anh. DMSO $(2.5 \mathrm{~mL})$. A solution of $6 \mathbf{b}(97 \mathrm{mg}, 0.46$ mmol, 1 equiv) in anh. DMSO (1 mL) was added to the mixture over a period of $17 \mathrm{~h}$ with the help of a syringe pump. The reaction mixture was stirred further at RT for $3 \mathrm{~h}$, the solvent was removed in vacuo at $50{ }^{\circ} \mathrm{C}$, and the crude product was purified by preparative RPHPLC [ $12 \% \mathrm{MeCN}\left(+0.1 \%\right.$ TFA) in $\mathrm{H}_{2} \mathrm{O}(+0.1 \%$ TFA); isocratic] to obtain title compound $\mathbf{8 b}(117 \mathrm{mg}, 36 \%)$ as a white powder. ${ }^{1} \mathrm{H}$ NMR $\left(500 \mathrm{MHz}\right.$, DMSO- $\left.d_{6}\right): \delta 10.04-9.40(\mathrm{~m}, 1 \mathrm{H}), 8.80-8.11(\mathrm{~m}$, $1 \mathrm{H}), 7.89-7.54(\mathrm{~m}, 1 \mathrm{H}), 7.17-6.93(\mathrm{~m}, 1 \mathrm{H}), 6.47-5.90(\mathrm{~m}, 1 \mathrm{H})$, $3.31(\mathrm{t}, J=7.1 \mathrm{~Hz}, 2 \mathrm{H}), 2.92-2.74(\mathrm{~m}, 2 \mathrm{H}), 2.61(\mathrm{~s}, 4 \mathrm{H}), 2.57-2.52$ $(\mathrm{m}, 2 \mathrm{H}), 2.17-1.99(\mathrm{~m}, 2 \mathrm{H}), 1.56-1.23(\mathrm{~m}, 8 \mathrm{H}), 1.21-1.06(\mathrm{~m}$ $4 \mathrm{H})$. MS $(m / z)$ : calcd $\mathrm{C}_{18} \mathrm{H}_{30} \mathrm{~N}_{4} \mathrm{O}_{9} \mathrm{NaPt}(\mathrm{M}+\mathrm{Na})^{+}, 664.16$; found, 664.15 .

(OC-6-34)-[(R)-(1-(tert-Butoxy)-3-(1-methyl-1H-indol-3-yl)-1-oxopropan-2-yl)carbamato][(1R,2R)-1,2-cyclohexanediamino]hydroxidooxalatoplatinum(IV) (9). In a dry flask, 2 (140 mg, 0.38 $\mathrm{mmol})$ was dissolved in anh. DMSO $(1.5 \mathrm{~mL})$ and stirred under Ar at $85{ }^{\circ} \mathrm{C}$ for $5 \mathrm{~h}$ in order to obtain isocyanate 3 . The reaction mixture was cooled to RT and added to a suspension of 7 (164 mg, 0.38 mmol, 1 equiv) in anh. DMSO $(1.5 \mathrm{~mL})$ over a period of $17 \mathrm{~h}$ with the help of a syringe pump. The solvent was removed in vacuo at 50 ${ }^{\circ} \mathrm{C}$, and the crude product was purified by preparative RP-HPLC $\left[38 \% \mathrm{MeCN}(+0.1 \% \mathrm{HCOOH})\right.$ in $\mathrm{H}_{2} \mathrm{O}(+0.1 \% \mathrm{HCOOH})$; isocratic] to obtain $9(70 \mathrm{mg}, 25 \%)$ as a yellow solid. ${ }^{1} \mathrm{H}$ NMR $\left(500 \mathrm{MHz}, \mathrm{DMSO}-d_{6}\right): \delta 9.79-9.40(\mathrm{~m}, 1 \mathrm{H}), 8.21(\mathrm{br} \mathrm{s}, 1 \mathrm{H}), 7.66$ (br s, $1 \mathrm{H}), 7.48$ (d, $J=7.9 \mathrm{~Hz}, 1 \mathrm{H}), 7.37(\mathrm{~d}, J=8.2 \mathrm{~Hz}, 1 \mathrm{H}), 7.16-$ $6.98(\mathrm{~m}, 4 \mathrm{H}), 6.36-6.01(\mathrm{~m}, 1 \mathrm{H}), 4.28-4.04(\mathrm{~m}, 1 \mathrm{H}), 3.73(\mathrm{~s}, 3 \mathrm{H})$, $2.99(\mathrm{~d}, J=6.8 \mathrm{~Hz}, 2 \mathrm{H}), 2.55-2.52(\mathrm{~m}, 2 \mathrm{H}), 2.36(\mathrm{~s}, 1 \mathrm{H}), 2.13-1.99$ $(\mathrm{m}, 2 \mathrm{H}), 1.54-1.39(\mathrm{~m}, 3 \mathrm{H}), 1.32-1.19(\mathrm{~m}, 10 \mathrm{H}), 1.17-0.99(\mathrm{~m}$, $2 \mathrm{H})$. MS $(m / z)$ : calcd $\mathrm{C}_{25} \mathrm{H}_{36} \mathrm{~N}_{4} \mathrm{O}_{9} \mathrm{NaPt}(\mathrm{M}+\mathrm{Na})^{+}, 754.20$; found, 754.21 .

General Procedure B for t-Butyl- and Boc-Deprotection. The protected complex was dissolved in DCM $(\sim 40 \mathrm{mM})$, and 10\% TFA (v/v) was added. The reaction mixture was stirred at RT for $1 \mathrm{~h}$, the solvents were evaporated, and the crude product was purified by preparative RP-HPLC.

(OC-6-34)-[(R)-2-Ammonio-3-(1-methyl-1H-indol-3-yl)propanoato $][(1 R, 2 R)-1,2$-cyclohexanediamino][5-(2,5-dioxo-2,5-dihydro-1H-pyrrol-1-yl) pentylcarbamato]oxalatoplatinum(IV) Trifluoroacetate (MalCa/IdoEs). 4 (169 mg, $0.53 \mathrm{mmol}$ ) was dissolved in DMF ( $6 \mathrm{~mL})$, and TEA ( $96 \mu \mathrm{L}, 0.69 \mathrm{mmol}, 1.3$ equiv) and TBTU (188 mg, $0.58 \mathrm{mmol}, 1.1$ equiv) were added. After $10 \mathrm{~min}$ at RT, crude $8 \mathrm{a}(340 \mathrm{mg})$ was added and stirred further at RT for $17 \mathrm{~h}$. The solvent was evaporated under reduced pressure, and the crude product was purified by preparative RP-HPLC $[42 \% \mathrm{MeCN}(+0.1 \%$ $\mathrm{HCOOH})$ in $\mathrm{H}_{2} \mathrm{O}(+0.1 \% \mathrm{HCOOH})$; isocratic] to obtain BocMalCa/IdoEs (52 mg, 8\% over two steps) as a yellow solid. Deprotection was performed according to general procedure $B$ starting from Boc-MalCa/IdoEs ( $51 \mathrm{mg}, 0.05 \mathrm{mmol}$ ). Preparative RPHPLC conditions: $28 \% \mathrm{MeCN}(+0.1 \%$ TFA $)$ in $\mathrm{H}_{2} \mathrm{O}(+0.1 \%$ TFA); isocratic. Yield: $32 \mathrm{mg}$ (58\%) of yellow solid. ${ }^{1} \mathrm{H}$ NMR $(600 \mathrm{MHz}$, DMSO- $d_{6}$; for NMR numbering, see Scheme S1): $\delta$ 9.93-9.43 (m, 1H, DACH-1), 8.83-8.59 (m, 1H, DACH-1), 8.13-8.05 (br s, $1 \mathrm{H}$, DACH-1), 8.05-7.96 (m, 3H, IDO-14), 7.64-7.54 (m, 2H, 1× DACH-1, IDO-5), 7.43 (d, $J=8.3 \mathrm{~Hz}, 1 \mathrm{H}, \mathrm{IDO}-8), 7.21-7.15$ (m, $1 \mathrm{H}$, IDO-7), 7.13 (s, 1H, IDO-2), $7.07(\mathrm{t}, J=7.4 \mathrm{~Hz}, 1 \mathrm{H}, \mathrm{IDO}-6)$, $7.00(\mathrm{~s}, 2 \mathrm{H}, \mathrm{MAL}-3), 6.87(\mathrm{t}, J=5.5 \mathrm{~Hz}, 1 \mathrm{H}, \mathrm{MAL}-9), 4.16-4.08$ (m, $1 \mathrm{H}, \mathrm{IDO}-12$ ), 3.75 (s, 3H, IDO-10), 3.35-3.28 (m, 3H, MAL-4, 1X 
IDO-11), 3.03 (dd, $J=15.2,8.2 \mathrm{~Hz}, 1 \mathrm{H}$, IDO-11), 2.89 (qd, $J=13.3$, $6.4 \mathrm{~Hz}, 2 \mathrm{H}, \mathrm{MAL}-8), 2.68-2.58$ (m, 2H, DACH-2), 2.18 (d, $J=11.2$ $\mathrm{Hz}, 1 \mathrm{H}, \mathrm{DACH}-3), 2.09$ (d, $J=9.7 \mathrm{~Hz}, 1 \mathrm{H}, \mathrm{DACH}-3), 1.53$ (d, $J=$ $11.6 \mathrm{~Hz}, 2 \mathrm{H}, 2 \times \mathrm{DACH}-4), 1.50-1.39$ (m, 4H, MAL-5, $2 \times \mathrm{DACH}-$ 3), $1.36(\mathrm{dt}, J=14.5,7.1 \mathrm{~Hz}, 2 \mathrm{H}$, MAL-7), $1.22-1.00(\mathrm{~m}, 4 \mathrm{H}, 2 \times$ DACH-4, MAL-6). ${ }^{13} \mathrm{C}$ NMR (151 MHz, DMSO- $\left.d_{6}\right): \delta 174.1$ (IDO13), 171.1 (2× MAL-2), 164.2 (MAL-10), 163.7, 163.7 ( $2 \times$ oxalate), 136.8 (IDO-9), 134.5 (2× MAL-3), 129.0 (IDO-2), 127.2 (IDO-4), 121.4 (IDO-7), 118.7 (IDO-6), 118.4 (IDO-5), 109.9 (IDO-8), 106.7 (IDO-3), 61.5, 60.3 (2× DACH-2), 53.1 (IDO-12), 40.7 (MAL-8), 37.0 (MAL-4), 32.4 (IDO-10), 31.00, 30.8 (2× DACH-3), 29.0 (MAL-7), 27.7 (MAL-5), 26.8 (IDO-11), 23.6, 23.6 (2× DACH-4), 23.4 (MAL-6). MS $(\mathrm{m} / z)$ : calcd $\mathrm{C}_{30} \mathrm{H}_{40} \mathrm{~N}_{6} \mathrm{O}_{10} \mathrm{NaPt}(\mathrm{M}+\mathrm{Na})^{+}$, 840.25; found, 840.24. EA calcd $\mathrm{C}_{30} \mathrm{H}_{40} \mathrm{~N}_{6} \mathrm{O}_{10} \mathrm{Pt} \cdot 1.5 \mathrm{TFA}$ : C, 39.21; H, 4.14; N, 8.31. Found: C, 39.28; H, 4.01; N, 8.50.

(OC-6-24)-[(R)-(1-Carboxy-2-(1-methyl-1H-indol-3-yl)ethyl)carbamato][(1R,2R)-1,2-cyclohexanediamino][5-(2,5-dioxo-2,5-dihydro-1 H-pyrrol-1-yl) pentylcarbamato]oxalatoplatinum(IV) (MalCa/ldoCa). In a dry flask, $9(35 \mathrm{mg}, 0.05 \mathrm{mmol})$ was dissolved in anh. DMF ( $1 \mathrm{~mL})$, and $6 \mathrm{a}(60 \mathrm{mg}, 0.29 \mathrm{mmol}, 6$ equiv) was added. The reaction mixture was stirred under Ar at RT for $18 \mathrm{~h}$. The solvent was evaporated in vacuo, and the crude product was purified by preparative RP-HPLC $\left[51 \% \mathrm{MeCN}(+0.1 \% \mathrm{HCOOH})\right.$ in $\mathrm{H}_{2} \mathrm{O}$ $(+0.1 \% \mathrm{HCOOH})$; isocratic] to obtain $\boldsymbol{t}$-butyl MalCa/IdoCa (33 $\mathrm{mg}, 73 \%$ ) as a yellow solid. Deprotection was performed according to general procedure B starting from $\boldsymbol{t}$-butyl $\mathrm{MalCa} / \mathrm{IdoCa}(35 \mathrm{mg}, 0.04$ mmol). Preparative RP-HPLC conditions: $30 \% \mathrm{MeCN}(+0.1 \%$ TFA) in $\mathrm{H}_{2} \mathrm{O}(+0.1 \% \mathrm{TFA})$; isocratic. Yield: $19 \mathrm{mg}(56 \%)$ of yellow solid. ${ }^{1} \mathrm{H}$ NMR (600 MHz, DMSO- $d_{6}$; for NMR numbering, see Scheme S1): $\delta 9.80-9.44$ (m, 1H, DACH-1), 9.25 (br s, $1 \mathrm{H}, \mathrm{DACH}-1), 8.55$ (br s, $1 \mathrm{H}, \mathrm{DACH}-1), 8.31(\mathrm{~s}, 1 \mathrm{H}, \mathrm{DACH}-1), 7.48(\mathrm{~d}, J=7.9 \mathrm{~Hz}, 1 \mathrm{H}$, IDO-5), $7.36(\mathrm{~d}, J=8.2 \mathrm{~Hz}, 1 \mathrm{H}$, IDO-8), $7.12(\mathrm{t}, J=7.6 \mathrm{~Hz}, 1 \mathrm{H}$, IDO-7), $7.06(\mathrm{~s}, 1 \mathrm{H}$, IDO-2), $7.00(\mathrm{t}, J=7.4 \mathrm{~Hz}, 1 \mathrm{H}, \mathrm{IDO}-6), 6.97(\mathrm{~s}$, $2 \mathrm{H}, 2 \times$ MAL-3), 6.80-6.59 (m, 1H, MAL-9), 6.58-6.05 (m, 1H, IDO-14), 4.31-4.12 (m, 1H, IDO-12), 3.73 (s, 3H, IDO-10), 3.363.34 (m, 2H, MAL-4), 3.08 (dd, $J=14.8,4.9 \mathrm{~Hz}, 1 \mathrm{H}, \mathrm{IDO}-11$ ), 3.02 (dd, $J=14.6,7.8 \mathrm{~Hz}, 1 \mathrm{H}$, IDO-11), 2.93-2.81 (m, 2H, MAL-8), 2.59-2.52 (m, $2 \mathrm{H}, 2 \times \mathrm{DACH}-2), 2.18-2.09(\mathrm{~m}, 2 \mathrm{H}, 2 \times \mathrm{DACH}-3)$, $1.54-1.47$ (m, 2H, 2× DACH-4), 1.47-1.41 (m, 2H, MAL-N-5), $1.41-1.26(\mathrm{~m}, 4 \mathrm{H}, 2 \times$ DACH-3, MAL-7), $1.20-1.03(\mathrm{~m}, 4 \mathrm{H}, 2 \times$ DACH-4, MAL-6). ${ }^{13} \mathrm{C}$ NMR (151 MHz, DMSO- $\left.d_{6}\right): \delta 174.0$ (IDO13), 171.2 (MAL-2), 164.5 (MAL-10), 163.9 (IDO-15), 163.4 (oxalate), 136.6 (IDO-9), 134.5 (2× MAL-3), 128.1 (IDO-2), 127.6 (IDO-4), 121.2 (IDO-7), 118.7 (IDO-6), 118.5 (IDO-5), 109.7 (IDO-8), 109.2 (IDO-3), 61.1, 61.0 (2× DACH-2), 55.3 (IDO-12), 40.7 (MAL-8), 37.1 (MAL-4), 32.4 (IDO-10), 31.1 (DACH-3), 29.1 (MAL-7), 27.8 (MAL-5), 26.7 (IDO-11), 23.7 (MAL-6), 23.5, 23.5 (2× DACH-4). MS $(m / z)$ : calcd $\mathrm{C}_{31} \mathrm{H}_{40} \mathrm{~N}_{6} \mathrm{O}_{12} \mathrm{NaPt}(\mathrm{M}+\mathrm{Na})^{+}$, 906.22; found, 906.22. EA calcd $\mathrm{C}_{31} \mathrm{H}_{40} \mathrm{~N}_{6} \mathrm{O}_{12} \mathrm{Pt} \cdot 1.5 \mathrm{H}_{2} \mathrm{O}: \mathrm{C}, 40.88$; $\mathrm{H}, 4.76$; N, 9.23. Found: C, 40.65; H, 4.54; N, 9.17.

(OC-6-34)-[(R)-(1-Carboxy-2-(1-methyl-1H-indol-3-yl)ethyl)carbamato][(1R,2R)-1,2-cyclohexanediamino][6-(2,5-dioxo-2,5-dihydro-1 H-pyrrol-1-yl)hexanoato]oxalatoplatinum(IV) (MalEs/ IdoCa). 5a (11 mg, $0.05 \mathrm{mmol}, 1.2$ equiv) was dissolved in DMF $(1 \mathrm{~mL})$. Subsequently, $N$-ethylmaleimide $(28 \mathrm{mg}, 0.23 \mathrm{mmol}, 5$ equiv), TEA ( $12.5 \mu \mathrm{L}, 0.09 \mathrm{mmol}, 2$ equiv), and TBTU ( $22 \mathrm{mg}, 0.07$ mmol, 1.5 equiv) were added. After $15 \mathrm{~min}$ at RT, 9 (33 mg, 0.05 mmol, 1 equiv) was added and stirred further at RT for $17 \mathrm{~h}$. The solvent was evaporated under reduced pressure, and the crude product was purified by preparative RP-HPLC $[50 \% \mathrm{MeCN}(+0.1 \%$ $\mathrm{HCOOH})$ in $\mathrm{H}_{2} \mathrm{O}(+0.1 \% \mathrm{HCOOH})$; isocratic] to yield $t$-butyl MalEs/IdoCa (25 mg, 60\%) as a yellow solid. Deprotection was performed according to general procedure B starting from $t$-butyl MalEs/IdoCa (25 mg, $0.03 \mathrm{mmol}$ ). Preparative RP-HPLC conditions: $35 \% \mathrm{MeCN}\left(+0.1 \%\right.$ TFA) in $\mathrm{H}_{2} \mathrm{O}(+0.1 \%$ TFA); isocratic. Yield: $19 \mathrm{mg}(74 \%)$ of yellow solid. ${ }^{1} \mathrm{H}$ NMR $\left(600 \mathrm{MHz}\right.$, DMSO- $d_{6}$; for NMR numbering, see Scheme S1): $\delta 12.57$ (br s, $1 \mathrm{H}$, IDO$\mathrm{COOH}), 9.27(\mathrm{t}, J=9.4 \mathrm{~Hz}, 1 \mathrm{H}, \mathrm{DACH}-1), 8.48$ (br s, $1 \mathrm{H}, \mathrm{DACH}-$ 1), 8.33 (br s, $1 \mathrm{H}, \mathrm{DACH}-1), 8.25(\mathrm{t}, J=9.7 \mathrm{~Hz}, 1 \mathrm{H}, \mathrm{DACH}-1), 7.49$ (d, $J=7.9 \mathrm{~Hz}, 1 \mathrm{H}, \mathrm{IDO}-5$ ), 7.37 (d, $J=8.2 \mathrm{~Hz}, 1 \mathrm{H}, \mathrm{IDO}-8$ ), $7.15-$
7.10 (m, 1H, IDO-7), 7.07 (s, 1H, IDO-2), 7.04-6.99 (m, 1H, IDO6), 6.99 (s, 2H, MAL-3), 6.63-6.09 (m, 1H, IDO-14), 4.31-4.14 (m, $1 \mathrm{H}$, IDO-12), 3.74 (s, 3H, IDO-10), 3.39-3.35 (m, 2H, MAL-4), $3.08(\mathrm{dd}, J=14.6,5.0 \mathrm{~Hz}, 1 \mathrm{H}, \mathrm{IDO}-11), 3.03(\mathrm{dd}, J=14.8,7.8 \mathrm{~Hz}$, $1 \mathrm{H}, \mathrm{IDO}-11), 2.58-2.51(\mathrm{~m}, 2 \mathrm{H}, 2 \times \mathrm{DACH}-2), 2.29-2.18(\mathrm{~m}, 2 \mathrm{H}$ MAL-8), $2.15-2.06$ (m, 2H, $2 \times$ DACH-3), $1.53-1.46$ (m, $2 \mathrm{H}, 2 \times$ DACH-4), 1.46-1.36 (m, 5H, MAL-5, MAL-7, 1× DACH-3), 1.36$1.27(\mathrm{~m}, 1 \mathrm{H}, \mathrm{DACH}-3), 1.20-1.07(\mathrm{~m}, 4 \mathrm{H}, 2 \times$ DACH-4, MAL-6). ${ }^{13} \mathrm{C}$ NMR (151 MHz, DMSO- $d_{6}$ ): $\delta 180.8$ (MAL-10), 173.8 (IDO13), 171.1 ( $2 \times$ MAL-2), 163.8 (IDO-15), 163.4, 163.3 ( $2 \times$ oxalate), 136.4 (IDO-9), 134.5 (2× MAL-3), 128.0 (IDO-2), 127.5 (IDO-4), 121.0 (IDO-7), 118.5 (IDO-6), 118.4 (IDO-5), 109.6 (IDO-8), 109.1 (IDO-3), 61.1, 60.9 (2× DACH-2), 55.2 (IDO-12), 36.9 (MAL-4), 35.5 (MAL-8), 32.3 (IDO-10), 30.9, 30.9 (2× DACH-3), 27.7 (MAL5), 26.6 (IDO-11), 25.6 (MAL-6), 24.8 (MAL-7), 23.5, 23.5 (2× $\mathrm{DACH}-4)$. MS $(\mathrm{m} / z)$ : calcd $\mathrm{C}_{31} \mathrm{H}_{39} \mathrm{~N}_{5} \mathrm{O}_{12} \mathrm{NaPt}(\mathrm{M}+\mathrm{Na})^{+}, 891.21$; found, 891.20. EA calcd $\mathrm{C}_{31} \mathrm{H}_{39} \mathrm{~N}_{5} \mathrm{O}_{12} \mathrm{Pt} \cdot 0.5 \mathrm{TFA} \cdot 1 \mathrm{H}_{2} \mathrm{O}: \mathrm{C}, 40.72 ; \mathrm{H}$, 4.43; N, 7.42. Found: C, 40.82; H, 4.34; N, 7.43.

(OC-6-44)-[(R)-2-Ammonio-3-(1-methyl-1H-indol-3-yl)propanoato][(1R,2R)-1,2-yclohexanediamino][6-(2,5-dioxo-2,5-dihydro-1H-pyrrol-1-yl)hexanoato]oxalatoplatinum(IV) Trifluoroacetate (MalEs/IdoEs). 4 (203 mg, $0.64 \mathrm{mmol}, 1.1$ equiv) and 5a (135 $\mathrm{mg}, 0.64 \mathrm{mmol}, 1.1$ equiv) were dissolved in DMF $(6 \mathrm{~mL})$, and TEA $(242 \mu \mathrm{L}, 1.73 \mathrm{mmol}, 3$ equiv) and TBTU (465 mg, $1.45 \mathrm{mmol}, 2.5$ equiv) were added. After $10 \mathrm{~min}$ at RT, $9(250 \mathrm{mg}, 0.58 \mathrm{mmol}, 1$ equiv) was added and stirred further at RT for $16 \mathrm{~h}$. The solvent was evaporated under reduced pressure, and the crude product was purified by preparative RP-HPLC [gradient: $35-50 \% \mathrm{MeCN}(+0.1 \%$ $\mathrm{HCOOH})$ in $\mathrm{H}_{2} \mathrm{O}(+0.1 \% \mathrm{HCOOH})$ over $\left.20 \mathrm{~min}\right]$ to obtain BocMalEs/IdoEs (140 mg, 52\%) as a yellow solid. Deprotection was performed according to general procedure B starting from BocMalEs/IdoEs (140 mg, $0.15 \mathrm{mmol}$ ). Preparative RP-HPLC conditions: $30 \% \mathrm{MeCN}(+0.1 \%$ TFA $)$ in $\mathrm{H}_{2} \mathrm{O}(+0.1 \%$ TFA); isocratic. Yield: $104 \mathrm{mg}(69 \%)$ of yellow solid. ${ }^{1} \mathrm{H}$ NMR $(600 \mathrm{MHz}$, DMSO- $d_{6}$; for NMR numbering, see Scheme $\left.\mathrm{S} 1\right): \delta 8.57-8.40(\mathrm{~m}$, $1 \mathrm{H}, \mathrm{DACH}-1), 8.36-8.24(\mathrm{~m}, 1 \mathrm{H}, \mathrm{DACH}-1), 8.24-8.13(\mathrm{~m}, 1 \mathrm{H}$, DACH-1), 8.02 (br s, 3H, IDO-14), 7.68-7.51 (m, 2H, $1 \times$ DACH-1, IDO-5), 7.43 (d, $J=8.3 \mathrm{~Hz}, 1 \mathrm{H}, \mathrm{IDO}-8), 7.21-7.15$ (m, 1H, IDO-7), $7.12(\mathrm{~s}, 1 \mathrm{H}, \mathrm{IDO}-2), 7.09-7.05(\mathrm{~m}, 1 \mathrm{H}, \mathrm{IDO}-6), 7.00$ (s, 2H, MAL3), 4.14-4.04 (m, 1H, IDO-12), 3.75 (s, 3H, IDO-10), 3.38-3.36 (m, 2H, MAL-4), 3.33-3.32 (m, 1H, IDO-11), 3.03 (dd, $J=15.3,8.3$ $\mathrm{Hz}, 1 \mathrm{H}, \mathrm{IDO}-11), 2.65-2.56(\mathrm{~m}, 2 \mathrm{H}, 2 \times \mathrm{DACH}-2), 2.32-2.22(\mathrm{~m}$, 2H, MAL-8), 2.21-2.13 (m, 1H, DACH-3), 2.10-2.02 (m, $1 \mathrm{H}$, DACH-3), $1.56-1.50(\mathrm{~m}, 2 \mathrm{H}, 2 \times \mathrm{DACH}-4), 1.50-1.39(\mathrm{~m}, 6 \mathrm{H}$, MAL-5, MAL-7-, 2× DACH-3), 1.24-1.12 (m, 3H, MAL-6, 1× DACH-4), $1.10-1.00(\mathrm{~m}, 1 \mathrm{H}, \mathrm{DACH}-4) .{ }^{13} \mathrm{C}$ NMR (151 MHz, DMSO- $\left.d_{6}\right): \delta 180.8$ (MAL-10), 174.1 (IDO-13), 171.1 (2× MAL-2), 163.7, 163.7 ( $2 \times$ oxalate), 157.9, 157.7 ( $2 \times$ TFA), 136.8 (IDO-9), 134.5 (MAL-3), 129.0 (IDO-2), 127.2 (IDO-4), 121.4 (IDO-7), 118.7 (IDO-6), 118.4 (IDO-5), 109.9 (IDO-8), 106.7 (IDO-3), 61.5, 60.4 (2× DACH-2), 53.2 (IDO-12), 36.9 (MAL-4), 35.4 (MAL-8), 32.4 (IDO-10), 31.0, 30.8 (2× DACH-3), 27.7 (MAL-5), 26.7 (IDO11), 25.6 (MAL-6), 24.8 (MAL-7), 23.6, 23.5 (2× DACH-4). MS $(m / z)$ : calcd $\mathrm{C}_{30} \mathrm{H}_{40} \mathrm{~N}_{5} \mathrm{O}_{10} \mathrm{Pt}(\mathrm{M}+\mathrm{H})^{+}$, 825.24; found, 825.16. EA calcd $\mathrm{C}_{30} \mathrm{H}_{39} \mathrm{~N}_{5} \mathrm{O}_{10} \mathrm{Pt} \cdot 1.5 \mathrm{TFA} \cdot 0.5 \mathrm{H}_{2} \mathrm{O}$ : C, 39.45; H, 4.16; N, 6.97\%. Found: C, 39.63; H, 4.11; N, 7.11.

(OC-6-34)-[(R)-2-Ammonio-3-(1-methyl-1H-indol-3-yl)propanoato $][(1 R, 2 R)-1,2$-cyclohexanediamino] [5-(2,5-dioxo-2,5-dihydro-1H-pyrrolidin-1-yl)pentylcarbamatoloxalatoplatinum(IV) Trifluoroacetate (SucCa/ldoEs). 4 (30 mg, $0.09 \mathrm{mmol}$ ) was dissolved in DMF $(2 \mathrm{~mL})$, and TEA $(20 \mu \mathrm{L}, 0.14 \mathrm{mmol}, 1.5$ equiv $)$ and TBTU $(33 \mathrm{mg}, 0.10 \mathrm{mmol}, 1.1$ equiv) were added. After $10 \mathrm{~min}$ at RT, $8 \mathbf{b}$ (60 mg, $0.09 \mathrm{mmol}, 1$ equiv) was added and stirred further at RT for $24 \mathrm{~h}$. The solvent was evaporated under reduced pressure, and the crude product was purified by preparative RP-HPLC [ $43 \% \mathrm{MeCN}$ $(+0.1 \% \mathrm{HCOOH})$ in $\mathrm{H}_{2} \mathrm{O}(+0.1 \% \mathrm{HCOOH})$; isocratic] to obtain Boc-SucCa/IdoEs (38 mg, 43\%) as a yellow solid. Deprotection was performed according to general procedure B starting from BocSucCa/IdoEs ( $31 \mathrm{mg}, 0.03 \mathrm{mmol}$ ). Preparative RP-HPLC conditions: $30 \% \mathrm{MeCN}\left(+0.1 \%\right.$ TFA) in $\mathrm{H}_{2} \mathrm{O}(+0.1 \% \mathrm{TFA})$; isocratic. 
Yield: $17 \mathrm{mg}$ (51\%) of yellow solid. ${ }^{1} \mathrm{H}$ NMR (600 MHz, DMSO- $d_{6}$; for NMR numbering, see Scheme S1): $\delta 9.93-9.47(\mathrm{~m}, 1 \mathrm{H}, \mathrm{DACH}-$ 1), $8.82-8.62$ (m, 1H, DACH-1), 8.09 (br s, $1 \mathrm{H}, \mathrm{DACH}-1), 8.02$ (br s, 3H, IDO-14), 7.67-7.56 (m, 2H, 1× DACH-1, IDO-5), 7.44 (d, $J$ $=8.3 \mathrm{~Hz}, 1 \mathrm{H}, \mathrm{IDO}-8), 7.21-7.17(\mathrm{~m}, 1 \mathrm{H}, \mathrm{IDO}-7), 7.14(\mathrm{~s}, 1 \mathrm{H}, \mathrm{IDO}-$ 2), $7.08(\mathrm{t}, J=7.4 \mathrm{~Hz}, 1 \mathrm{H}, \mathrm{IDO}-6), 6.87(\mathrm{t}, J=5.5 \mathrm{~Hz}, 1 \mathrm{H}$, SUC-9), 4.18-4.07 (m, 1H, IDO-12), 3.76 (s, 3H, IDO-10), 3.34-3.31 (m, $3 \mathrm{H}$, SUC-4, $1 \times$ IDO-11), 3.03 (dd, $J=15.2,8.2 \mathrm{~Hz}, 1 \mathrm{H}, \mathrm{IDO}-11)$, 2.96-2.84 (m, 2H, SUC-8), 2.68-2.58 (m, 6H, SUC-3, $2 \times$ DACH2), $2.19(\mathrm{~d}, J=11.2 \mathrm{~Hz}, 1 \mathrm{H}, \mathrm{DACH}-3), 2.10(\mathrm{~d}, J=9.8 \mathrm{~Hz}, 1 \mathrm{H}$, DACH-3), 1.54 (d, $J=11.3 \mathrm{~Hz}, 2 \mathrm{H}, 2 \times \mathrm{DACH}-4), 1.49-1.27$ (m, $6 \mathrm{H}, \mathrm{SUC}-5,2 \times \mathrm{DACH}-3$, SUC-7), 1.23-1.02 (m, 4H, $2 \times \mathrm{DACH}-4$, SUC-6). ${ }^{13} \mathrm{C}$ NMR (151 MHz, DMSO- $\left.d_{6}\right): \delta 177.8$ (SUC-2), 174.1 (IDO-13), 164.2 (SUC-10), 163.7, 163.7 ( $2 \times$ oxalate), 136.8 (IDO9), 129.0 (IDO-2), 127.2 (IDO-4), 121.4 (IDO-7), 118.7 (IDO-6), 118.4 (IDO-5), 109.8 (IDO-8), 106.7 (IDO-3), 61.4, 60.3 (2× DACH-2), 53.1 (IDO-12), 40.7 (SUC-8), 37.8 (SUC-4), 32.4 (IDO10), 31.0, 30.8 (2× DACH-3), 29.1 (SUC-7), 28.0 (SUC-3), 26.9 (SUC-5), 26.8 (IDO-11), 23.6, 23.6 (2× DACH-4), 23.5 (SUC-6). MS $(m / z)$ : calcd $\mathrm{C}_{30} \mathrm{H}_{42} \mathrm{~N}_{6} \mathrm{O}_{10} \mathrm{Pt}(\mathrm{M}+\mathrm{H})^{+}$, 842.27; found, 842.28. EA calcd $\mathrm{C}_{30} \mathrm{H}_{42} \mathrm{~N}_{6} \mathrm{O}_{10} \mathrm{Pt} \cdot 1.5 \mathrm{TFA} \cdot 0.5 \mathrm{H}_{2} \mathrm{O}: \mathrm{C}, 38.87 ; \mathrm{H}, 4.20 ; \mathrm{N}, 8.24$. Found: C, 38.66; H, 4.45; N, 8.25.

(OC-6-24)-[(R)-(1-Carboxy-2-(1-methyl-1H-indol-3-yl)ethyl)carbamato $][(1 R, 2 R)-1,2-c y c l o h e x a n e d i a m i n o][(5-(2,5-d i o x o p y r r o l i-$ din-1-yl)pentyl)carbamato]oxalatoplatinum(IV) (SucCa/IdoCa). In a dry flask, 9 (27 mg; $0.04 \mathrm{mmol})$ was dissolved in anh. DMF (1 mL), and $6 \mathbf{b}$ (12 mg; $0.04 \mathrm{mmol} ; 1.5$ equiv) was added. The reaction mixture was stirred under $\mathrm{Ar}$ at RT for $18 \mathrm{~h}$. The solvent was evaporated in vacuo to obtain crude $t$-butyl SucCa/IdoCa $(39 \mathrm{mg}$ ) which was used without further purification. Deprotection was performed according to general procedure B. Preparative RP-HPLC conditions: $30 \% \mathrm{MeCN}(+0.1 \%$ TFA $)$ in $\mathrm{H}_{2} \mathrm{O}(+0.1 \%$ TFA); isocratic. Yield: $15 \mathrm{mg}$ ( $41 \%$ over two steps) of yellow solid. ${ }^{1} \mathrm{H}$ NMR (600 MHz, DMSO- $d_{6}$; for NMR numbering, see Scheme S1): $\delta 12.59$ (br s, 1H, IDO-COOH), 9.88-9.49 (m, 1H, DACH-1), 9.29 (br s, $1 \mathrm{H}, \mathrm{DACH}-1$ ), 8.56 (br s, $1 \mathrm{H}, \mathrm{DACH}-1$ ), 8.32 (br s, $1 \mathrm{H}, \mathrm{DACH}-1$ ), $7.49(\mathrm{~d}, J=7.9 \mathrm{~Hz}, 1 \mathrm{H}$, IDO-5), $7.36(\mathrm{~d}, J=8.2 \mathrm{~Hz}, 1 \mathrm{H}$, IDO- 8$)$, 7.15-7.10 (m, 1H, IDO-7), 7.07 (s, 1H, IDO-2), $7.01(\mathrm{t}, J=7.3 \mathrm{~Hz}$, $1 \mathrm{H}$, IDO-6), 6.84-6.60 (m, 1H, SUC-9), 6.60-6.07 (m, 1H, IDO14), 4.32-4.12 (m, 1H, IDO-12), 3.73 (s, 3H, IDO-10), 3.32-3.29 (m, 2H, SUC-4), 3.08 (dd, $J=14.6,5.1 \mathrm{~Hz}, 1 \mathrm{H}, \mathrm{IDO}-11$ ), 3.03 (dd, $J$ $=14.6,7.7 \mathrm{~Hz}, 1 \mathrm{H}, \mathrm{IDO}-11), 2.95-2.78(\mathrm{~m}, 2 \mathrm{H}, \mathrm{SUC}-8), 2.61(\mathrm{~s}$, $4 \mathrm{H}$, SUC-3), 2.58-2.53 (m, 2H, DACH-2), 2.18-2.08 (m, $2 \mathrm{H}, 2 \times$ DACH-3) $1.54-1.46$ (m, 2H, 2× DACH-2), $1.44-1.25(\mathrm{~m}, 6 \mathrm{H}$, SUC-5, SUC-7, $2 \times$ DACH-3), 1.19-1.06 (m, 4H, $2 \times$ DACH-4, SUC-6). ${ }^{13} \mathrm{C}$ NMR (151 MHz, DMSO- $\left.d_{6}\right): \delta 177.8$ (SUC-2), 173.8 (IDO-13), 164.4 (SUC-10), 163.8 (IDO-15), 163.3 (oxalate), 136.4 (IDO-9), 128.0 (IDO-2), 127.5 (IDO-4), 121.0 (IDO-7), 118.5 (IDO-6), 118.4 (IDO-5), 109.6 (IDO-8), 109.1 (IDO-3), 61.0, 60.9 (2× DACH-2), 55.2 (IDO-12), 40.7 (SUC-8), 37.8 (SUC-4), 32.3 (IDO-10), 30.9 (2× DACH-3), 29.1 (SUC-7), 28.0 (SUC-3), 26.9 (SUC-5), 26.5 (IDO-11), 23.6 (SUC-6), 23.5 (2× DACH-4). MS $(m / z)$ : calcd $\mathrm{C}_{31} \mathrm{H}_{41} \mathrm{~N}_{6} \mathrm{O}_{12} \mathrm{Pt}(\mathrm{M}-\mathrm{H})^{-}$, 884.24; found, 884.40. EA calcd $\mathrm{C}_{31} \mathrm{H}_{42} \mathrm{~N}_{6} \mathrm{O}_{12} \mathrm{Pt} \cdot 0.5$ TFA. $0.5 \mathrm{H}_{2} \mathrm{O}: \mathrm{C}, 40.38 ; \mathrm{H}, 4.61 ; \mathrm{N}, 8.83$. Found: C, 40.14; H, 4.36; N, 8.69.

(OC-6-34)-[(R)-(1-Carboxy-2-(1-methyl-1H-indol-3-yl)ethyl)carbamato][( $1 R, 2 R)-1,2$-cyclohexanediamino] [6-(2,5-dioxopyrrolidin-1-yl)hexanoato]]oxalatoplatinum(IV) (SucEs/IdoCa). $5 \mathbf{b}(9 \mathrm{mg}$, $0.04 \mathrm{mmol}, 1.6$ equiv) was dissolved in DMF $(0.75 \mathrm{~mL})$. Subsequently, DIPEA ( $12 \mu \mathrm{L}, 0.07 \mathrm{mmol}, 2.5$ equiv) and TBTU (17 mg, $0.04 \mathrm{mmol}, 1.7$ equiv) were added. After $15 \mathrm{~min}$ of stirring at RT, 9 (20 mg, $0.03 \mathrm{mmol}, 1$ equiv) was added and stirred further at RT for $17 \mathrm{~h}$. The solvent was evaporated under reduced pressure, and the crude product was purified by preparative RP-HPLC $[44 \% \mathrm{MeCN}$ $(+0.1 \% \mathrm{HCOOH})$ in $\mathrm{H}_{2} \mathrm{O}(+0.1 \% \mathrm{HCOOH})$; isocratic] to obtain $t$ butyl SucEs/IdoCa (15 mg, 56\%) as a yellow solid. Deprotection was performed according to general procedure B starting from $t$-butyl SucEs/IdoCa $(75 \mathrm{mg}, 0.08 \mathrm{mmol})$. Preparative RP-HPLC conditions: $28 \% \mathrm{MeCN}(+0.1 \% \mathrm{HCOOH})$ in $\mathrm{H}_{2} \mathrm{O}(+0.1 \% \mathrm{HCOOH})$; isocratic. Yield: $40 \mathrm{mg}$ (55\%) of yellow solid. ${ }^{1} \mathrm{H}$ NMR $(600 \mathrm{MHz}$,
DMSO- $d_{6}$; for NMR numbering, see Scheme S1): $\delta 12.60(\mathrm{~s}, 1 \mathrm{H}$, IDO-COOH), 9.26 (t, $J=9.3 \mathrm{~Hz}, 1 \mathrm{H}, \mathrm{DACH}-1), 8.47$ (br s, $J=4.9$ $\mathrm{Hz}, 1 \mathrm{H}, \mathrm{DACH}-1), 8.32$ (br s, $1 \mathrm{H}, \mathrm{DACH}-1), 8.24(\mathrm{t}, J=9.6 \mathrm{~Hz}, 1 \mathrm{H}$, DACH-1), $7.49(\mathrm{~d}, J=7.9 \mathrm{~Hz}, 1 \mathrm{H}, \mathrm{IDO}-5), 7.36(\mathrm{~d}, J=8.2 \mathrm{~Hz}, 1 \mathrm{H}$, IDO-8), 7.15-7.10 (m, 1H, IDO-7), 7.07 (s, 1H, IDO-2), 7.01 (t, $J=$ $7.4 \mathrm{~Hz}, 1 \mathrm{H}, \mathrm{IDO}-6), 6.58$ (d, J= 7.9 Hz, 1H, IDO-14), 4.32-4.14 (m, 1H, IDO-12), 3.73 (s, 3H, IDO-10), 3.32-3.29 (m, 2H, ido-N-4), $3.08(\mathrm{dd}, J=14.7,5.0 \mathrm{~Hz}, 1 \mathrm{H}, \mathrm{IDO}-11), 3.02(\mathrm{dd}, J=14.8,7.8 \mathrm{~Hz}$, $1 \mathrm{H}, \mathrm{IDO}-11$ ), 2.60 (s, 4H, SUC-3), 2.57-2.52 (m, 2H, DACH-2), $2.28-2.18(\mathrm{~m}, 2 \mathrm{H}, \mathrm{SUC}-8), 2.16-2.05(\mathrm{~m}, 2 \mathrm{H}, 2 \times \mathrm{DACH}-3), 1.54-$ $1.46(\mathrm{~m}, 2 \mathrm{H}, 2 \times$ DACH-4), 1.46-1.36 (m, 5H, SUC-5, SUC-7, $1 \times$ DACH-3), $1.36-1.26(\mathrm{~m}, 1 \mathrm{H}, 1 \times \mathrm{DACH}-3), 1.20-1.05(\mathrm{~m}, 4 \mathrm{H}, 2 \times$ DACH-4, SUC-6). ${ }^{13} \mathrm{C}$ NMR $\left(151 \mathrm{MHz}\right.$, DMSO- $\left.d_{6}\right): \delta 180.9$ (SUC10), 177.8 (2× SUC-1), 173.9 (IDO-13), 163.8 (IDO-15), 163.4, 163.4 ( $2 \times$ oxalate), 136.5 (IDO-9), 128.1 (IDO-2), 127.6 (IDO-4), 121.1 (IDO-7), 118.6 (IDO-6), 118.4 (IDO-5), 109.6 (IDO-8), 109.1 (IDO-3), 61.2, 60.9 (2× DACH-2), 55.2 (IDO-12), 37.7 (SUC-4), 35.5 (SUC-8), 32.3 (IDO-10), 31.0, 30.9 (2× DACH-3), 28.0 (SUC3), 26.9 (SUC-7), 26.6 (IDO-11), 25.7 (SUC-6), 24.9 (SUC-7), 23.6, $23.5\left(2 \times\right.$ DACH-4). MS $(m / z)$ : calcd $\mathrm{C}_{31} \mathrm{H}_{41} \mathrm{~N}_{5} \mathrm{O}_{12} \mathrm{NaPt}(\mathrm{M}+\mathrm{Na})^{+}$, 893.23; found, 893.22. EA calcd $\mathrm{C}_{31} \mathrm{H}_{39} \mathrm{~N}_{5} \mathrm{O}_{12} \mathrm{Pt} \cdot 1.5 \mathrm{H}_{2} \mathrm{O}$ : C, 41.47; $\mathrm{H}, 4.94$; N, 7.80. Found: C, 41.53; H, 4.74; N, 7.69.

(OC-6-44)-[(R)-2-Ammonio-3-(1-methyl-1H-indol-3-yl)propanoato][(1R,2R)-1,2-cyclohexanediamino][6-(2,5-dioxopyrrolidin-1-yl)hexanoatoloxalatoplatinum(IV) Trifluoroacetate (SucEs/ IdoEs). 4 ( $81 \mathrm{mg}, 0.26 \mathrm{mmol}, 1.1$ equiv) and $5 \mathrm{~b}(54 \mathrm{mg}, 0.26 \mathrm{mmol}$, 1.1 equiv) were dissolved in DMF $(5 \mathrm{~mL})$. TEA $(97 \mu \mathrm{L}, 0.70 \mathrm{mmol}, 3$ equiv) and TBTU (186 mg, $0.58 \mathrm{mmol}, 2.5$ equiv) were added subsequently. After $15 \mathrm{~min}$ of stirring at RT, $9(100 \mathrm{mg}, 0.23 \mathrm{mmol}, 1$ equiv) was added and stirred further at RT for $17 \mathrm{~h}$. The solvent was evaporated under reduced pressure, and the crude product was purified by preparative RP-HPLC $[45 \% \mathrm{MeCN}(+0.1 \% \mathrm{HCOOH})$ in $\mathrm{H}_{2} \mathrm{O}(+0.1 \% \mathrm{HCOOH})$; isocratic] to obtain Boc-SucEs/IdoEs (37 $\mathrm{mg}, 34 \%$ ) as a yellow solid. Deprotection was performed according to general procedure B starting from Boc-SucEs/IdoEs $(35 \mathrm{mg}, 0.04$ mmol). Preparative RP-HPLC conditions: $25 \% \mathrm{MeCN}(+0.1 \% \mathrm{TFA})$ in $\mathrm{H}_{2} \mathrm{O}(+0.1 \% \mathrm{TFA})$; isocratic. Yield: $25 \mathrm{mg}(65 \%)$ of yellow solid. ${ }^{1} \mathrm{H}$ NMR $\left(600 \mathrm{MHz}\right.$, DMSO- $d_{6}$; for NMR numbering, see Scheme S1): $\delta 8.53-8.41(\mathrm{~m}, 1 \mathrm{H}, \mathrm{DACH}-1), 8.27(\mathrm{t}, J=9.4 \mathrm{~Hz}, 1 \mathrm{H}, \mathrm{DACH}-$ 1), 8.21 (br s, 1H, DACH-1), 8.09-7.94 (m, 3H, IDO-14), 7.67$7.54(\mathrm{~m}, 2 \mathrm{H}, \mathrm{DACH}-1, \mathrm{IDO}-5), 7.43(\mathrm{~d}, J=8.3 \mathrm{~Hz}, 1 \mathrm{H}$, IDO- 8$)$, 7.21-7.16 (m, 1H, IDO-7), 7.12 (s, 1H, IDO-2), 7.09-7.04 (m, 1H, IDO-6), 4.18-4.08 (m, 1H, IDO-12), 3.75 (s, 3H, IDO-10), 3.36$3.29(\mathrm{~m}, 3 \mathrm{H}$, SUC-4, $1 \times$ IDO-11), 3.03 (dd, $J=15.3,8.3 \mathrm{~Hz}, 1 \mathrm{H}$, IDO-11), 2.66-2.54 (m, 6H, SUC-3, DACH-2), 2.32-2.22 (m, $2 \mathrm{H}$, SUC-8), 2.17 (d, $J=10.8 \mathrm{~Hz}, 1 \mathrm{H}, \mathrm{DACH}-3), 2.11-2.01(\mathrm{~m}, 1 \mathrm{H}$, DACH-3), $1.58-1.50(\mathrm{~m}, 2 \mathrm{H}, 2 \times \mathrm{DACH}-4), 1.50-1.39(\mathrm{~m}, 6 \mathrm{H}$, SUC-5, SUC-7, $2 \times$ DACH-3), 1.23-1.12 (m, 3H, SUC-6, 1× DACH-4), $1.10-1.00(\mathrm{~m}, 1 \mathrm{H}, \mathrm{DACH}-4) .{ }^{13} \mathrm{C}$ NMR $(151 \mathrm{MHz}$, DMSO- $\left.d_{6}\right): \delta 180.8$ (SUC-10), 177.8 (SUC-2), 174.1 (IDO-13), 163.7, 163.7 ( $2 \times$ oxalate), 158.1, 157.9, 157.7, 157.5 (4× TFA), 136.8 (IDO-9), 129.0 (IDO-2), 127.2 (IDO-4), 121.4 (IDO-7), 118.7 (IDO-6), 118.4 (IDO-5), 109.9 (IDO-8), 106.7 (IDO-3), 61.5, 60.4 (2× DACH-2), 53.2 (IDO-12), 37.6 (SUC-4), 35.4 (SUC-8), 32.4 (IDO-10), 31.0, 30.8 (2× DACH-3), 28.0 (SUC-3), 26.9 (SUC-5), 26.7 (IDO-11), 25.6 (SUC-6), 24.9 (SUC-7), 23.6, 23.5 (2× DACH4). MS $(\mathrm{m} / z)$ : calcd $\mathrm{C}_{30} \mathrm{H}_{42} \mathrm{~N}_{5} \mathrm{O}_{10} \mathrm{Pt}(\mathrm{M}+\mathrm{H})^{+}$, 827.26; found, 827.23. EA calcd $\mathrm{C}_{30} \mathrm{H}_{41} \mathrm{~N}_{5} \mathrm{O}_{10} \mathrm{Pt} \cdot 1.5 \mathrm{TFA} \cdot 0.5 \mathrm{H}_{2} \mathrm{O}: \mathrm{C}, 39.37 ; \mathrm{H}, 4.35$; N, 6.96. Found: C, 39.37; H, 4.38; N, 7.19.

(OC-6-34)-Acetato[(1R,2R)-1,2-cyclohexanediamine]oxalato[(5(2,5-dioxopyrrolidin-1-yl)pentyl)carbamato]platinum(IV) (SucCal OAc). In a dry flask, $6 \mathbf{b}(67 \mathrm{mg}, 0.32 \mathrm{mmol}, 1.5$ equiv) was dissolved in anh. DMF ( $3 \mathrm{~mL})$, and $7 \mathbf{b}(97 \mathrm{mg}, 0.21 \mathrm{mmol}, 1$ equiv) was added. The reaction mixture was stirred under Ar at RT for $20 \mathrm{~h}$. The solvent was removed under reduced pressure, and the residue was taken up in $\mathrm{MeOH}$ and precipitated with $\mathrm{Et}_{2} \mathrm{O}$. The crude product was purified via preparative RP-HPLC $\left[15 \% \mathrm{MeCN}(+0.1 \% \mathrm{HCOOH})\right.$ in $\mathrm{H}_{2} \mathrm{O}$ $(+0.1 \% \mathrm{HCOOH})$; isocratic $]$ to obtain SucCa/OAc $(30 \mathrm{mg} ; 21 \%)$ as a white solid. ${ }^{1} \mathrm{H}$ NMR ( $500 \mathrm{MHz}$, DMSO- $d_{6}$; for NMR numbering, see Scheme S1): $\delta 10.02-9.43(\mathrm{~m}, 1 \mathrm{H}, \mathrm{DACH}-1), 8.81-7.95(\mathrm{~m}, 3 \mathrm{H}$, 
DACH-1), 6.87-6.21 (m, 1H, SUC-9), 3.31-3.28 (m, 2H, SUC-4), 2.95-2.77 (m, 2H, SUC-8), 2.61 (s, 4H, SUC-3), 2.60-2.53 (m, 2H, DACH-2), 2.13 (d, $J=8.8 \mathrm{~Hz}, 2 \mathrm{H}, \mathrm{DACH}-3), 1.95$ (s, 3H, acetate), $1.51(\mathrm{~d}, J=8.9 \mathrm{~Hz}, 2 \mathrm{H}, \mathrm{DACH}-4), 1.47-1.25$ (m, 6H, SUC-5, $2 \times$ DACH-3, SUC-7), $1.21-1.04$ (m, 4H, $2 \times$ DACH-4, SUC-6). ${ }^{13} \mathrm{C}$ NMR $\left(126 \mathrm{MHz}\right.$, DMSO- $\left.d_{6}\right): \delta 178.4($ acetate-C$=\mathrm{O}), 177.8$ (SUC2), 164.4 (SUC-10), 163.4, 163.3 (2x oxalate), 61.2, 60.9 (2X DACH-2), 40.6 (SUC-8), 37.8 (SUC-4), 31.0, 30.8 (2× DACH-3), 29.1 (SUC-7), 28.0 (SUC-3), 26.9 (SUC-5), 23.6 (SUC-6), 23.5 (DACH-4), 22.9 (acetate- $\left.\mathrm{CH}_{3}\right)$. MS $(\mathrm{m} / z)$ : calcd $\mathrm{C}_{20} \mathrm{H}_{30} \mathrm{~N}_{4} \mathrm{O}_{10} \mathrm{Pt}$ $(\mathrm{M}+\mathrm{H})^{+}$, 684.18; found, 684.18. EA calcd $\mathrm{C}_{20} \mathrm{H}_{32} \mathrm{~N}_{4} \mathrm{O}_{10} \mathrm{Pt} \cdot \mathrm{H}_{2} \mathrm{O}: \mathrm{C}$, 34.24; H, 4.88; N, 7.99. Found: C, 34.47; H, 4.80; N, 8.28.

(OC-6-44)-Acetato[(1R,2R)-1,2-cyclohexanediamino][3-(1-methyl-1H-indol-3-yl)propanoato]oxalatoplatinum(IV) (OAC/IPAEs). IPA (11 mg, $0.06 \mathrm{mmol}, 1.1$ equiv) was dissolved in DMF $(1 \mathrm{~mL})$, and TEA (10.4 $\mu \mathrm{L}, 0.06 \mathrm{mmol}, 1.5$ equiv) and TBTU (20 mg; 0.06 mmol; 1.3 equiv) were added. After $10 \mathrm{~min}$ at RT, $6 \mathbf{b}(24 \mathrm{mg}, 0.05$ mmol, 1 equiv) was added and stirred further at RT for $16 \mathrm{~h}$. The solvent was evaporated under reduced pressure, and the crude product was purified by preparative RP-HPLC $[31 \% \mathrm{MeCN}(+0.1 \%$ $\mathrm{HCOOH})$ in $\mathrm{H}_{2} \mathrm{O}(+0.1 \% \mathrm{HCOOH})$ isocratic] to obtain OAc/ IPAEs ( $7 \mathrm{mg} ; 20 \%$ ) as a white solid. ${ }^{1} \mathrm{H}$ NMR (500 MHz, DMSO- $d_{6}$; for NMR numbering, see Scheme S1): $\delta 8.31$ (br s, $4 \mathrm{H}, \mathrm{DACH}-1)$, $7.48(\mathrm{~d}, J=7.9 \mathrm{~Hz}, 1 \mathrm{H}$, IDO-5), 7.35 (d, $J=8.2 \mathrm{~Hz}, 1 \mathrm{H}$, IDO- 8$)$, $7.12(\mathrm{t}, J=7.6 \mathrm{~Hz}, 1 \mathrm{H}, \mathrm{IDO}-7), 7.03(\mathrm{~s}, 1 \mathrm{H}, \mathrm{IDO}-2), 7.00(\mathrm{t}, J=7.4$ $\mathrm{Hz}, 1 \mathrm{H}, \mathrm{IDO}-6), 3.70$ (s, 3H, IDO-10), 2.87 (t, $J=7.5 \mathrm{~Hz}, 2 \mathrm{H}$, IDO11), 2.64-2.60 (m, $2 \mathrm{H}$, IDO-12), $2.57-2.53(\mathrm{~m}, 1 \mathrm{H}, \mathrm{DACH}-2)$, 2.44-2.38 (m, 1H, DACH-2), 2.13-2.01 (m, 2H, DACH-3), 1.96 (s, $3 \mathrm{H}$, acetate), 1.49-1.24 (m, 4H, $2 \times \mathrm{DACH}-4,2 \times \mathrm{DACH}-3), 1.18-$ 1.07 (m, 1H, DACH-4), 1.03-0.93 (m, 1H, DACH-4); ${ }^{13} \mathrm{C}$ NMR $\left(126 \mathrm{MHz}, \mathrm{DMSO}-d_{6}\right): \delta 180.6($ acetate$-\mathrm{C}=\mathrm{O}), 178.5($ IDO-13), 163.5 (oxalate), 136.6 (IDO-9), 127.2 (IDO-4), 126.6 (IDO-2), 121.1 (IDO-7), 118.4 (IDO-5), 118.3 (IDO-6), 112.8 (IDO-3), 109.5 (IDO-8), 61.2, 61.0 (2× DACH-2), 36.4 (IDO-12), 32.2 (IDO-10), 30.9, 30.8 (2× DACH-3), 23.5, $23.4(2 \times \mathrm{DACH}-4), 23.0$ (acetate$\left.\mathrm{CH}_{3}\right), 20.9$ (IDO-11). MS $(\mathrm{m} / z)$ : calcd $\mathrm{C}_{22} \mathrm{H}_{28} \mathrm{~N}_{3} \mathrm{O}_{8} \mathrm{Pt}(\mathrm{M}-\mathrm{H})^{-}$, 657.15; found, 657.16.

UHPLC-Reduction Experiments. The platinum(IV)-succinimide complexes were dissolved in 2\% DMF in phosphate buffer (500 $\mathrm{mM}, \mathrm{pH} 7.4$ ) to a final concentration of $2 \mathrm{mM}$. The solutions were then mixed $1: 1$ with a $20 \mathrm{mM}$ stock of L-ascorbic acid in phosphate buffer $(500 \mathrm{mM}, \mathrm{pH} 7.4)$ to obtain final concentrations of $1 \mathrm{mM}$ complex, $10 \mathrm{mM}$ L-ascorbic acid, and 1\% DMF. The samples were incubated at $20{ }^{\circ} \mathrm{C}$ and measured on a Dionex UltiMate $3000 \mathrm{RS}$ UPLC system with a Waters Acquity UPLC BEH C18 column $(3 \times$ $50 \mathrm{~mm}$, pore size $1.7 \mu \mathrm{m}$ ) and absorption detection at $220 \mathrm{~nm}$. Data points were taken at $t=0$ and every $30 \mathrm{~min}$ for $6 \mathrm{~h}$.

SEC-ICP-MS Studies. FCS was purchased from Sigma-Aldrich and buffered with $150 \mathrm{mM}$ phosphate buffer ( $\mathrm{pH}$ 7.4) to guarantee a stable $\mathrm{pH}$. The maleimide-bearing platinum(IV) complexes were dissolved in $10 \%$ DMF in $150 \mathrm{mM}$ phosphate buffer ( $\mathrm{pH} 7.4$ ) to 1 $\mathrm{mM}$ and diluted 1:10 in serum to obtain a final concentration of 100 $\mu \mathrm{M}$. The samples were then incubated in the autosampler at $37^{\circ} \mathrm{C}$ for $24 \mathrm{~h}$ and analyzed every $1 \mathrm{~h}$. Between each sample, a pure water blank was measured. For SEC-ICP-MS measurements, an Agilent 1260 Infinity system coupled to an Agilent 7800 ICP-MS equipped with a dynamic reaction cell was used. Oxygen (purity 5.5, Messer Austria $\mathrm{GmbH}$, Gumpoldskirchen, Austria) was used as reaction gas. HPLC parameters are given in Table S4, and ICP-MS operation parameters are given in Table S5.

Cell Culture. The human SKOV3 (ATCC HTB-77, ovarian adenocarcinoma) and HCT116 (ATCC CCL-247, colorectal carcinoma) cells were maintained in McCoy's 5A (Sigma-Aldrich, MO, USA). Murine CT26 (ATCC CRL-2638, colon carcinoma) and murine GL261 (glioblastoma, kindly provided by T. Felzmann, Vienna, Austria) were kept in Dulbecco's modified Eagle's medium (DMEM)/F12 (1:1). Human OVCAR (ATCC HTB-161, ovarian adenocarcinoma), murine $\mathrm{AB} 12$ (mesothelioma), murine $\mathrm{AE} 17$ (mesothelioma), and the human melanoma (VM1, VM7, and VM15, established at our institute ${ }^{47}$ ) cancer cell lines were maintained in RPMI-1640. ID8 (ovarian adenocarcinoma, kindly provided by F. Roby, Kansas, USA) was kept in DMEM (supplemented with $5 \mu \mathrm{g} / \mathrm{mL}$ insulin, $5 \mu \mathrm{g} / \mathrm{mL}$ transferrin, and 5 $\mathrm{ng} / \mathrm{mL} \mathrm{Na}_{2} \mathrm{SeO}_{3}$ ), and murine K7M2 (ATCC CRL-2836, osteosarcoma) was kept in DMEM medium. All media were supplemented with $10 \%$ FBS (PAA, Linz, Austria) in a humidified atmosphere at 37 ${ }^{\circ} \mathrm{C}$ and $5 \% \mathrm{CO}_{2}$.

Cytotoxicity Assay. The cells were seeded at 3500-6000 cells/ well in 96-well plates depending on the proliferation rate of the respective cell line and allowed to recover for $24 \mathrm{~h}$. Subsequently, the cells were treated at indicated concentrations for 48 or $72 \mathrm{~h}$. Cells were additionally incubated with 5-fold equimolar concentrations of ascorbic acid to increase the reduction rate of the compounds. Cell viability was measured by the MTT-based vitality assay (EZ4U; Biomedica, Vienna, Austria), following the manufacturer's recommendations. Full dose-response curves were generated using GraphPad Prism software to calculate $\mathrm{IC}_{50}$ values (drug concentrations at $50 \%$ reduced cell viability compared to control).

pH2AX Signal Detection and Quantification. HCT116 cells were seeded on polytetrafluoroethylene-printed spot slides (E6342406, Science Services GmbH, Munich, Germany) at a density of 4000 cells/spot. On the next day, cells were exposed to the compounds for $24 \mathrm{~h}$, at $50 \mu \mathrm{M}$ and fixed in a $4 \%$ formaldehyde solution in phosphatebuffered saline (PBS) with a $\mathrm{pH}$ adjusted to 7.4 (158127, Merck, Darmstadt, Germany) for $15 \mathrm{~min}$ at RT. Spots were washed thrice with $\mathrm{PBS}$ each for $5 \mathrm{~min}$, and samples were then incubated in a blocking buffer [PBS, 5\% albumin (Carl Roth, Karlsruhe, Germany), $0.3 \%$ Triton X-100 (T8787, Merck, Darmstadt, Germany)] for $1 \mathrm{~h}$ at RT. Next, samples were incubated with a primary antibody solution of phospho-histone H2A.X (Ser139) (clone 20E3, \#9718, Cell Signaling, Danvers, USA) at a dilution of 1:200 in an antibody dilution buffer [PBS with 1\% albumin (Carl Roth, Karlsruhe, Germany) and 0.3\% Triton X-100 (T8787, Merck, Darmstadt, Germany)] for $1 \mathrm{~h}$ at RT. Subsequently, samples were washed twice with PBS (5 min each), incubated with goat anti-rabbit antibody linked to Alexa Fluor 488 (A11008, Thermo Fisher Scientific, Massachusetts, USA), and diluted 1:500 in antibody dilution buffer for $1 \mathrm{~h}$ at RT. Next, samples were incubated with rhodamine-labeled wheat germ agglutinin (RL-1022, Vector Laboratories, California, USA) at a concentration for $5 \mu \mathrm{g} / \mathrm{mL}$ for $15 \mathrm{~min}$ at RT, and spots were washed twice in PBS, embedded in vectashield mounting medium with DAPI (VECH-1200, SzaboScandic, Vienna, Austria), and analyzed using a LSM700 confocal microscope (Zeiss Axio Observer.Z1, inverse, 63× plan-apochromat NA 1.4 Oil DIC objective). Per condition, five representative images were taken (16-bit, $101.61 \times 101.61 \mu \mathrm{m}$ ). Images were analyzed using ImageJ software. Nuclear area was selected by applying default threshold to the DAPI channel of each image. Then, Alexa Fluor 488 signal (integrated density) was measured and normalized to nuclear area.

Cell Cycle Analysis. The cells were seeded at 600,000 cells/well in six-well plates and allowed to recover for $24 \mathrm{~h}$. On the next day, cells were exposed to the compounds for $24 \mathrm{~h}$, then trypsinized, and collected. Subsequently, cells were washed with PBS and centrifuged $(400 \mathrm{~g}, 5 \mathrm{~min})$, and the cell pellet was resuspended in $100 \mu \mathrm{L}$ of $0.9 \%$ $\mathrm{NaCl}$ solution. The cell suspension was then added dropwise to 1.8 $\mathrm{mL}$ of ice-cold $80 \%$ ethanol and incubated for $48 \mathrm{~h}$ at $-20{ }^{\circ} \mathrm{C}$. The fixated cells were centrifuged $(6200 \mathrm{~g}, 2 \mathrm{~min})$, and the cell pellet was diluted in $0.5 \mathrm{~mL}$ of PBS with $0.1 \mathrm{mg} / \mathrm{mL}$ RNAse A (R5503, Merck, Darmstadt, Germany), which was previously heat-activated (10 min at $96{ }^{\circ} \mathrm{C}$ ), and samples were incubated for $30 \mathrm{~min}$ at $37{ }^{\circ} \mathrm{C}$ to remove RNA content. Next, to stain DNA, propidium iodide (81845, Merck, Darmstadt, Germany) at a concentration of $5 \mu \mathrm{g} / \mathrm{mL}$ was added, samples were incubated for $30 \mathrm{~min}$ on ice and subsequently measured by flow cytometry.

ICP-MS Measurements of HCT116 Cells and Tumor Tissues. HCT116 cells were seeded at $6 \times 10^{5}$ cells/well in a sixwell plate and allowed to settle for $24 \mathrm{~h}$. Cells were exposed to drugs at $20 \mu \mathrm{M}$ for $3 \mathrm{~h}$ under normal cell culture conditions. Cells were washed twice with PBS and lysed at RT in $500 \mu \mathrm{L} \mathrm{HNO}_{3}(\geq 69 \%$, Rotipuran Supra, Carl Roth, Karlsruhe, Germany) for 1 h. $400 \mu \mathrm{L}$ of 
the lysate was transferred to $7.6 \mathrm{~mL}$ of ultrapure water $(18.2 \mathrm{M} \Omega \mathrm{cm}$, Milli-Q Advantage, Darmstadt, Germany).

For tissue digestion, approx. $25-50 \mathrm{mg}$ of tissue was weighed into perfluoralkoxy tubes, and $2 \mathrm{~mL}$ of $\mathrm{HNO}_{3}$ and $100 \mu \mathrm{L} \mathrm{H}_{2} \mathrm{O}_{2}(30 \%$, Suprapur, Merck, Darmstadt, Germany) were added. The solutions were placed on a hot plate and heated up for $7 \mathrm{~h}$ using a temperature program with a maximum of $200{ }^{\circ} \mathrm{C}$. The liquids were transferred to $15 \mathrm{~mL}$ tubes with the remaining solution being removed by washing twice with $4 \mathrm{~mL}$ of ultrapure water.

Platinum concentrations were measured using an Agilent 7800 ICP-QMS instrument (Agilent Technologies, Tokyo, Japan) equipped with an Agilent SPS 4 autosampler (Agilent Technologies, Tokyo, Japan) and a MicroMist nebulizer at a sample uptake rate of approx. $0.2 \mathrm{~mL} / \mathrm{min}$. The Agilent MassHunter software package (Workstation Software, Version C.01.04, 2018) was used for data evaluation. All of the measured samples were blank corrected (for the cell culture data, wells containing no cells were used). The instrumental parameters for the ICP-MS are summarized in Table S6. Elemental standard solutions were purchased from Labkings (Hilversum, The Netherlands). The instrument was tuned on a daily basis.

$\log D_{7.4}$ Determination by ICP-MS. $50 \mathrm{mM}$ stock solutions of the succinimide complexes in DMF were diluted in phosphate buffer (20 mM, pH 7.4, pre-saturated with $n$-octanol) to a final concentration of $50 \mu \mathrm{M}$ drug and $0.1 \%$ DMF. The platinum content of these aqueous solutions was measured by ICP-MS (see above). The solutions were mixed 1:1 with $n$-octanol and shaken on a $360^{\circ}$ rotatable rack for $3 \mathrm{~h}$. The solutions were centrifuged for $5 \mathrm{~min}(860 \mathrm{~g}$, $\mathrm{RT}$ ), the aqueous layers were carefully removed, and their Pt content was measured by ICP-MS. Experiments were performed and measured in duplicates, and averages were used for further calculations. $\log D_{7.4}$ values were calculated by the following equation

$$
\log D_{7.4}=\log \frac{[c(\text { Pt aqueous stock })-c(\text { Pt aqueous layer })]}{c(\text { Pt aqueous layer })}
$$

RNA Isolation and Detection of IDO Levels by Real-Time PCR. Total RNA was isolated from cells using the TRIzol reagent (15596-026, Thermo Fisher Scientific, Massachusetts, USA), according to the manufacturer's instructions. RNA was reverse transcribed to complementary DNA (cDNA) using RevertAid Reverse Transcriptase (EP0441, Thermo Fisher Scientific, Massachusetts, USA). The real-time PCR method is described elsewhere. ${ }^{58}$ In short, cDNA samples were diluted 1:25 and analyzed using Maxima SYBR Green/ROX qPCR Master Mix (2x) (K0221, Thermo Fisher Scientific, Massachusetts, USA) in a CFX96 Touch real-time PCR detection system (Bio-Rad Laboratories, California, USA) for their specific mRNA content using the following primer sequences purchased from Eurofins Genomics: human $\beta$-actin: fwd (5'-GGA TGC AGA AGG AGA TCA CTG-3'), rev ( $5^{\prime}$-CGA TCC ACA CGG AGT ACT TG-3'); human IDO: fwd (5'-GTC ATG GAG ATG TCC GTA AG-3'), rev (5'-CTT GGA GAG TTG GCA GTA AG$\left.3^{\prime}\right)$; murine $\beta$-actin: fwd $\left(5^{\prime}\right.$-ATG GAG GGG AAT ACA GCC- $\left.3^{\prime}\right)$, rev (5'-TTC TTT GCA GCT CCT TCG TT-3'); murine IDO transcript 1: fwd (5'-ATG TTG GCT TTG CTC TAC CA-3'), rev (5'-GAC CAC CTC AGG GTT TAG CG-3').

Long-Term Cytotoxicity Assay. SKOV3 cells were seeded in duplicates at 5000 cells/well in 24-well plates and allowed to recover for $24 \mathrm{~h}$. Subsequently, the cells were treated at the indicated concentrations for $168 \mathrm{~h}$. Cells were fixed with ice-cold methanol (20 min at $4{ }^{\circ} \mathrm{C}$ ), washed with PBS, and stained with crystal violet. Subsequently, colony formation was inspected, and the fluorescence signal was detected using Typhoon Trio imager (GE Healthcare, Little Chalfont, UK) at $610 / 30 \mathrm{~nm} \mathrm{BP}$ and analyzed by Image J software. Fluorescence values of empty wells were subtracted from each value, and full dose-response curves were generated to calculate $\mathrm{IC}_{50}$ values (drug concentrations at $50 \%$ reduced fluorescence intensity compared to control).

Reduction and 1-MDT Release in SKOV3 Lysates. SKOV3 cells were grown in four T225 $\mathrm{mm}^{2}$ cell culture flasks to reach a high cell number. On the day of cell lysate isolation, cells were washed with PBS, scraped from the surface, and centrifuged. Each cell pellet was lysed in $\sim 160 \mu \mathrm{L}$ lysis buffer ( $15 \mathrm{mM} \mathrm{NaCl} 0.5 \%$ Triton X, ultrapure) and incubated on ice for $1 \mathrm{~h}$. The samples were then centrifuged for $15 \mathrm{~min}$ at $14,000 \mathrm{rpm}\left(4^{\circ} \mathrm{C}\right)$, and the cleared lysate was pooled and kept at $-80{ }^{\circ} \mathrm{C}$ until analysis. Cell lysates were treated with $2 \mathrm{mM}$ stock solutions of respective complexes in 4\% DMF and phosphate buffer $(100 \mathrm{mM}, \mathrm{pH} 7.4)$ to obtain a final compound concentration of $100 \mu \mathrm{M}$ and incubated at $37^{\circ} \mathrm{C}$. After $0,4,24$, and $72 \mathrm{~h}$, three volume equivalents of cold $\mathrm{MeOH}$ were added to sample aliquots. Samples were stored at $4{ }^{\circ} \mathrm{C}$ for $10 \mathrm{~min}$ and centrifuged $\left(15,080 \mathrm{~g}, 4{ }^{\circ} \mathrm{C}, 10\right.$ min). LC-MS analysis of the supernatant was performed on an Agilent 1260 Infinity system using a Waters Atlantis T3 column (150 $\mathrm{mm} \times 4.6 \mathrm{~mm}$ ) and absorption detection at $230 \mathrm{~nm}$, coupled to a Bruker amaZon SL ESI-IT mass spectrometer. Milli-Q water, containing $0.1 \%$ formic acid, and acetonitrile, containing $0.1 \%$ formic acid, were used as eluents. A gradient of 1-99\% acetonitrile in $20 \mathrm{~min}$ was used.

Colorimetric Kyn Assay. SKOV3 cells were seeded at 5000 cells/ well in 96-well plates and allowed to recover for $24 \mathrm{~h}$. Cells were treated for $72 \mathrm{~h}$. Supernatants $(200 \mu \mathrm{L} /$ well $)$ and blank medium were transferred to microcentrifuge tubes, and cell viability was measured by MTT assay. To precipitate proteins, the supernatants were mixed with $100 \mu \mathrm{L} 30 \%(\mathrm{w} / \mathrm{v})$ trichloroacetic acid. N-Formyl-Kyn was hydrolyzed to Kyn by incubating the supernatants for $30 \mathrm{~min}$ in a thermoblock at $50{ }^{\circ} \mathrm{C}$ and $300 \mathrm{rpm}$. The supernatants were cleared by centrifugation $(10 \mathrm{~min}$ at $10,000 \mathrm{~g})$, and $100 \mu \mathrm{L}$ of the clear supernatants was transferred to a fresh 96-well plate in duplicates and incubated with $100 \mu \mathrm{L}$ Ehrlich's reagent [2\% 4-(dimethylamino)benzaldehyde (Sigma-Aldrich, D2004, MO, USA) in acetic acid (Merck, Darmstadt, Germany)] for $10 \mathrm{~min}$ at RT. For the washout experiments, cells were seeded in quintuplicates. $72 \mathrm{~h}$ after treatment, the cell supernatant was exchanged with serum-free medium. After 24 $\mathrm{h}$ incubation, the supernatant was analyzed, as described above. The absorption of Kyn was measured at $490 \mathrm{~nm}$ (reference $620 \mathrm{~nm}$ ), and the absorbance of blank medium was subtracted. The Kyn concentrations were calculated using a standard curve [generated from L-Kyn (Sigma-Aldrich, K8625, MO, USA) dilution series in blank medium] and normalized to cell viability.

Animals. 8-12 week old $\mathrm{Balb} / \mathrm{c}$ and SCID mice (Harlan Laboratories, San Pietro Al Natisone, Italy) were kept in a pathogen-free environment. Every procedure was carried out under sterile conditions and according to the regulations of the Ethics Committee for the Care and Use of Laboratory Animals at the Medical University Vienna.

Organ Distribution in SKOV3-Bearing SCID Mice. SKOV3 cells $\left(1.5 \times 10^{6}\right.$ cells in $50 \mu \mathrm{L}$ serum-free medium $)$ were injected subcutaneously into the right flank of male SCID mice. When the tumors reached a volume of at least $\sim 340 \mathrm{~mm}^{3}$, the mice $(n=2$ per group) were treated once with the compounds iv at concentrations equimolar to $9 \mathrm{mg} / \mathrm{kg}$ oxaliplatin (MalEs/IdoCa $19.7 \mathrm{mg} / \mathrm{kg}$, MalCa/IdoCa $20.5 \mathrm{mg} / \mathrm{kg}$, MalEs/IdoEs $21.4 \mathrm{mg} / \mathrm{kg}$, and MalCa/ IdoEs $21.5 \mathrm{mg} / \mathrm{kg}$ ) in $20 \%$ propylene glycol (PG). OAc/OAc (12.1 $\mathrm{mg} / \mathrm{kg}$ ) was applied in $0.9 \% \mathrm{NaCl}$ and oxaliplatin $(9.0 \mathrm{mg} / \mathrm{kg})$ in $5 \%$ glucose. After $24 \mathrm{~h}$, the animals were anesthetized and blood drawn by heart puncture. Then, the animals were sacrificed by cervical dislocation, and tumors and organs were collected for the measurement with ICP-MS. For plasma isolation, blood was collected in ethylenediaminetetraacetic acid (EDTA)-coated tubes and centrifuged for $10 \mathrm{~min}$ at $900 \mathrm{~g}$ at $4{ }^{\circ} \mathrm{C}$. Plasma was transferred to a new tube and centrifuged once more to remove residual red blood cells.

Detection of Trp and Its Metabolites in Cell Culture and in Tumor Tissue by LC-HRMS. Sample Preparation. The cell supernatant was analyzed using adapted protocols from Simón-Manso et al. ${ }^{59}$ SKOV3 cells were seeded at 5000 cells/well in a 96-well plate. $24 \mathrm{~h}$ after seeding, cells were treated for $72 \mathrm{~h}$. The medium was exchanged to serum-free medium, and cells were incubated for $24 \mathrm{~h}$. To $50 \mu \mathrm{L}$ of cell supernatant or blank medium, $50 \mu \mathrm{L}$ of fully ${ }^{13} \mathrm{C}$ internal standard (labeled yeast extract prepared in $2 \mathrm{~mL}$ of $\mathrm{H}_{2} \mathrm{O}$; ISOtopic solutions e.U., Vienna, Austria) and $400 \mu \mathrm{L}$ of $\mathrm{MeOH}$ 
(LC-MS grade, Sigma-Aldrich, Vienna, Austria) were added for protein precipitation $\left(-20^{\circ} \mathrm{C}\right.$ overnight $)$ and centrifugation $(14,000 \mathrm{~g}$, $4{ }^{\circ} \mathrm{C}, 15 \mathrm{~min}$ ). $100 \mu \mathrm{L}$ of aliquots was dried for direct LC-HRMS analysis.

To $50 \mathrm{mg}$ of tumor tissue, $50 \mu \mathrm{L}$ of fully ${ }^{13} \mathrm{C}$ internal standard (labeled yeast extract prepared in $2 \mathrm{~mL}$ of $\mathrm{H}_{2} \mathrm{O}$; ISOtopic solutions e.U., Vienna, Austria) and $950 \mu \mathrm{L}$ of $80 \% \mathrm{MeOH}$ (LC-MS grade, Sigma-Aldrich, Vienna, Austria) were added and homogenized in a Dounce-type glass tissue grinder. The homogenate was collected, the tissue homogenizer was washed twice with $400 \mu \mathrm{L} 80 \% \mathrm{MeOH}$ (LCMS grade, Sigma-Aldrich, Vienna, Austria), and the washing solution was added to the homogenate. The samples were vortexed, centrifuged $\left(14,000 \mathrm{~g}, 4{ }^{\circ} \mathrm{C}, 20 \mathrm{~min}\right)$, and kept on dry ice until further processing. $500 \mu \mathrm{L}$ of tumor sample aliquots was dried for direct LC-HRMS analysis.

LC-HRMS Analysis. All samples were resuspended in $100 \mu \mathrm{L}$ of water (supernatant sample: same volume; tumor samples 5-fold concentration) and measured using a 12 min method based on reversed-phase chromatography (column: HSS T3, $1.8 \mu \mathrm{m}, 2.1 \times 150$ $\mathrm{mm}$, Waters) and high-resolution mass spectrometry (Orbitrap HF, Thermo). For quantification, multi-point calibration with external standard mixes (Kyn, Trp, and kynurenic acid) using co-eluting ${ }^{13} \mathrm{C}$ internal standards was performed and analyzed by Skyline 20.2.0.286. For 1-MDT, relative quantification based on ${ }^{13} \mathrm{C} \operatorname{Trp}$ normalization was performed.

Anticancer Activity Experiment. CT26 cells $\left(5 \times 10^{5}\right.$ cells in 50 $\mu \mathrm{L}$ of serum-free medium) were injected subcutaneously into the right flank of $\mathrm{Balb} / \mathrm{c}$ mice. On day 3, when the tumors were palpable, the mice ( $n=4$ per group) were treated with the compounds iv at concentrations equimolar to $9 \mathrm{mg} / \mathrm{kg}$ oxaliplatin (MalEs/IdoEs 23 $\mathrm{mg} / \mathrm{kg}$ in $10 \% \mathrm{PG}, \mathrm{MalCa} / \mathrm{IdoEs} 22.2 \mathrm{mg} / \mathrm{kg}$ in $15 \% \mathrm{PG}$, MalCa/ IdoCa $20.6 \mathrm{mg} / \mathrm{kg}$ in $15 \% \mathrm{PG}$, and MalEs/IdoCa $21 \mathrm{mg} / \mathrm{kg}$ in $15 \%$ PG/PBS) twice a week (Mon/Thu or Tue/Fri) for 2 weeks. Every day, the animals were monitored for body weight and the enhanced stress level, and the tumor size was measured using a caliper according to the formula length $\times$ width $^{2} / 2$.

Sample Preparation of Murine Tissue for Flow Cytometry. CT2 6 cells $\left(5 \times 10^{5}\right.$ cells in $50 \mu \mathrm{L}$ of serum-free RPMI medium $)$ were injected into the right flank of female Balb/c mice ( $n=4$ per group). On day 7 , when the tumors reached a mean tumor volume of $\sim 170$ $\mathrm{mm}^{3}$, mice were treated once iv with MalEs/IdoCa at a concentration equimolar to $9 \mathrm{mg} / \mathrm{kg}$ (dissolved in 20\% PG in PBS) or solvent only. After $24 \mathrm{~h}$, the animals were sacrificed, and tumor tissues and the tumor-draining lymph nodes were isolated. Tissues were collected in a tube with $750 \mu \mathrm{L}$ of ice-cold PBS containing 5\% FBS and cut into small pieces. Samples were digested using PBS containing $50 \mathrm{mg} / \mathrm{mL}$ collagenase (C2139, Merck, Darmstadt, Germany) and $50 \mathrm{mg} / \mathrm{mL}$ DNase I (DN25, Darmstadt, Germany) and filtered several times through a $70 \mu \mathrm{m}$ cell strainer (734-2761, VWR, Pennsylvania, USA). The samples were centrifuged, and cell pellets were treated with ammonium-chloride-potassium (ACK)-buffer $\left(150 \mathrm{mM} \mathrm{NH}_{4} \mathrm{Cl}, 10\right.$ $\mathrm{mM} \mathrm{KHCO}_{3}, 127 \mu \mathrm{M}$ EDTA, $\mathrm{pH}$ 7.2-7.4) to lyse red blood cells and centrifuged in a Würzburg buffer (PBS containing 5\% FBS, $5 \mathrm{mM}$ EDTA, $20 \mu \mathrm{g} / \mathrm{mL}$ DNase I).

Human PBMC Isolation. Blood was drawn from healthy donors and collected in EDTA-coated tubes. Blood was diluted in PBS-2 mM EDTA (Titriplex III, Merck, Darmstadt, Germany) 1:2 and carefully layered on top of Ficoll-Paque solution (Merck, Darmstadt, Germany) in a $50 \mathrm{~mL}$ falcon tube. Subsequently, blood was centrifuged for $40 \mathrm{~min}$, at $400 \mathrm{~g}$, at $20^{\circ} \mathrm{C}$ without active deceleration to obtain a buffy coat layer containing PBMC. Upper layer, containing serum, was aspirated, and the buffy coat layer was collected and washed in PBS containing $2 \mathrm{mM}$ EDTA. PBMCs were diluted in RPMI-1640 supplemented with 10\% FBS. For later analysis, PBMCs were frozen in RPMI-1640-40\% FBS-15\% DMSO and stored in liquid nitrogen.

Immune Co-culture and Sample Preparation for Flow Cytometry. PBMCs were thawed and slowly dropped into warm medium at a rate of $1 \mathrm{drop} / 5 \mathrm{~s}$. PBMCs were then centrifuged (10 min, 400g) and washed with warm AIM V medium (12055091,
Thermo Fisher Scientific, Massachusetts, USA). PBMCs were cocultured with SKOV3 at a ratio of 2:1 (PBMC/SKOV3) in 12-well CytoOne plates (CC7682-7512, Starlab, Hamburg, Germany). In the presence of IL-2 (SRP3085, Merck, Darmstadt, Germany) at a concentration of $80 \mathrm{ng}$ per $10^{6}$, PBMCs were added. To induce $\mathrm{T}_{\text {res }}$ differentiation, OKT3 monoclonal CD3 antibody (317302, BioLegend, California, USA) and TGF- $\beta 1$ CHO (AF-100-21C-10 $\mu \mathrm{g}$, Eubio, Vienna, Austria) were added at concentrations of $4 \mu \mathrm{g}$ and 10 ng per $10^{6} \mathrm{PBMC}$, respectively. Cells were incubated with drugs at nontoxic concentrations of $10 \mu \mathrm{M}$ for oxaliplatin and $50 \mu \mathrm{M}$ for prodrugs. After 3 days, $250 \mu \mathrm{L}$ of fresh AIM V medium was added, and cells were incubated for another two days. On the day of measurement, supernatant, containing PBMC, was collected.

Flow Cytometry. Cells were washed with PBS and stained using the Aqua Zombie Fixable Viability Kit (423101, BioLegend, California, USA), according to the manufacturer's instructions. Cells were then stained with fluorescent dye-labeled antibodies, according to the manufacturer's instructions (Table S7). For nuclear FOXP3 staining, cells were fixated using a True-Nuclear Transcription Factor Buffer Set (424401, BioLegend, California, USA), in accordance with manufacturer's instructions. Single stains for each antibody using the AbC Total Antibody Compensation Bead Kit (A10497, Thermo Fisher) were performed to generate compensation matrices. Sample acquisition was performed using an LSRFortessa X-20 cell analyzer (BD Biosciences, New Jersey, USA). Data analysis was performed using FlowJo software (FlowJo LLC, Oregon, USA) after processing with the flowAI plugin to remove unwanted events resulting from changes in the flow rate. ${ }^{60}$ The cleaned up data were analyzed using the gating strategy, as shown in Figure S15 for murine tissue and Figure S16 for human co-culture experiment.

Statistical Analysis. All data are presented as mean \pm SD. Comparison between groups was analyzed by unpaired two-tailed Student's $t$-test or multi comparison (ANOVA) with Dunnett's or Bonferroni post-hoc-test. Statistical analysis was performed using Prism 8 (GraphPad) $(* p<0.05, * * p<0.01, * * * p<0.001$, and $* * * * p$ $<0.0001)$.

\section{ASSOCIATED CONTENT}

\section{Supporting Information}

The Supporting Information is available free of charge at https://pubs.acs.org/doi/10.1021/acs.jmedchem.1c00770.

${ }^{1} \mathrm{H}$ and ${ }^{13} \mathrm{C}$ NMR spectra and HPLC traces of final compounds, stability data, reduction kinetics, additional cytotoxicity data, DNA damage induction, cell cycle analysis, Kyn levels in supernatant, 1-MDT levels in tumor tissue, and additional in vivo data (PDF) Molecular formula strings (CSV)

\section{AUTHOR INFORMATION}

\section{Corresponding Authors}

Petra Heffeter - Institute of Cancer Research and Comprehensive Cancer Center, Medical University of Vienna, 1090 Vienna, Austria; Research Cluster "Translational Cancer Therapy Research", 1090 Vienna, Austria; Email: petra.heffeter@meduniwien.ac.at

Christian R. Kowol - Faculty of Chemistry, Institute of Inorganic Chemistry, University of Vienna, 1090 Vienna, Austria; Research Cluster "Translational Cancer Therapy Research", 1090 Vienna, Austria; 이이.org/0000-00028311-1632; Email: christian.kowol@univie.ac.at

\section{Authors}

Philipp Fronik - Faculty of Chemistry, Institute of Inorganic Chemistry, University of Vienna, 1090 Vienna, Austria

Isabella Poetsch - Faculty of Chemistry, Institute of Inorganic Chemistry, University of Vienna, 1090 Vienna, Austria; 
Institute of Cancer Research and Comprehensive Cancer Center, Medical University of Vienna, 1090 Vienna, Austria; Research Cluster "Translational Cancer Therapy Research", 1090 Vienna, Austria

Alexander Kastner - Faculty of Chemistry, Institute of Inorganic Chemistry, University of Vienna, 1090 Vienna, Austria

Theresa Mendrina - Institute of Cancer Research and Comprehensive Cancer Center, Medical University of Vienna, 1090 Vienna, Austria

Sonja Hager - Institute of Cancer Research and Comprehensive Cancer Center, Medical University of Vienna, 1090 Vienna, Austria

Katharina Hohenwallner - Faculty of Chemistry, Institute of Analytical Chemistry, University of Vienna, 1090 Vienna, Austria

Hemma Schueffl - Institute of Cancer Research and Comprehensive Cancer Center, Medical University of Vienna, 1090 Vienna, Austria; 이이.org/0000-0002-9959-9716

Dietmar Herndler-Brandstetter - Institute of Cancer Research and Comprehensive Cancer Center, Medical University of Vienna, 1090 Vienna, Austria

Gunda Koellensperger - Faculty of Chemistry, Institute of Analytical Chemistry, University of Vienna, 1090 Vienna, Austria; (1) orcid.org/0000-0002-1460-4919

Evelyn Rampler - Faculty of Chemistry, Institute of Analytical Chemistry, University of Vienna, 1090 Vienna, Austria; (1) orcid.org/0000-0002-9429-7663

Joanna Kopecka - Department of Oncology, University of Torino, 10126 Torino, Italy

Chiara Riganti - Department of Oncology, University of Torino, 10126 Torino, Italy; (1) orcid.org/0000-0001-97874836

Walter Berger - Institute of Cancer Research and Comprehensive Cancer Center, Medical University of Vienna, 1090 Vienna, Austria; Research Cluster "Translational Cancer Therapy Research", 1090 Vienna, Austria; (1) orcid.org/0000-0003-0014-1658

Bernhard K. Keppler - Faculty of Chemistry, Institute of Inorganic Chemistry, University of Vienna, 1090 Vienna, Austria; Research Cluster "Translational Cancer Therapy Research", 1090 Vienna, Austria

Complete contact information is available at:

https://pubs.acs.org/10.1021/acs.jmedchem.1c00770

\section{Author Contributions}

${ }^{\#}$ P.F. and I.P. have contributed equally.

\section{Notes}

The authors declare no competing financial interest.

${ }^{\mathbb{T}}$ P.H. and C.R.K. have shared last authorship.

\section{ACKNOWLEDGMENTS}

This manuscript is dedicated to Professor Wolfgang Kaim on the occasion of his 70th birthday. We gratefully acknowledge the Austrian Science Fund (FWF) grant P28853 (to C.R.K.) and FG3 (to P.H.), the Fellinger Cancer Research Foundation (Fellinger Krebsforschung; to D.H.-B.), and Italian Association for Cancer Research (AIRC; IG21408 to C.R.) for financial support. S.H. is a recipient of a DOC Fellowship of the Austrian Academy of Sciences. Part of the research has been performed in a short-term scientific mission (STSM) in the course of EU-funded COST action CA17104. We thank
Gerhart Zeitler and Lisa Mayr for their help with the animal experiments. We thank Tatjana Schafarik for ICP-MS measurements.

\section{ABBREVIATIONS}

1-MDT, 1-methyl-D-tryptophan; 1-MLT, 1-methyl-L-tryptophan; 1-MT, 1-methyltryptophan; DIPEA, N,N-diisopropylethylamine; EPR, enhanced permeability and retention; FCS, fetal calf serum; ICP-MS, inductively coupled plasma mass spectrometry; IDO, indoleamine 2,3-dioxygenase; IPA, 3-(1methyl-1H-indol-3-yl)propanoic acid; Kyn, kynurenine; LCHRMS, liquid chromatography-high resolution mass spectrometry; $\mathrm{MeCN}$, acetonitrile; $\mathrm{MeOH}$, methanol; MTT, 3(4,5-dimethylthiazol-2-yl)-2,5-diphenyltetrazolium bromide; OAc, acetate; PBMCs, peripheral blood mononuclear cells; PBS, phosphate-buffered saline; PG, propylene glycol; PTFE, polytetrafluoroethylene; SEC-ICP-MS, size exclusion chromatography-inductively coupled plasma mass spectrometry; TBTU, 2-(1H-benzotriazole-1-yl)-1,1,3,3-tetramethylaminium tetrafluoroborate; TEA, triethylamine; $\mathrm{T}_{\text {reg, }}$, regulatory $\mathrm{T}$ cell

\section{REFERENCES}

(1) Rosenberg, B.; Van Camp, L.; Krigas, T. Inhibition of Cell Division in Escherichia Coli by Electrolysis Products from a Platinum Electrode. Nature 1965, 205, 698-699.

(2) Muggia, F. M.; Bonetti, A.; Hoeschele, J. D.; Rozencweig, M.; Howell, S. B. Platinum Antitumor Complexes: 50 Years since Barnett Rosenberg's Discovery. J. Clin. Oncol. 2015, 33, 4219-4226.

(3) Englinger, B.; Pirker, C.; Heffeter, P.; Terenzi, A.; Kowol, C. R.; Keppler, B. K.; Berger, W. Metal Drugs and the Anticancer Immune Response. Chem. Rev. 2019, 119, 1519-1624.

(4) Deo, K. M.; Ang, D. L.; McGhie, B.; Rajamanickam, A.; Dhiman, A.; Khoury, A.; Holland, J.; Bjelosevic, A.; Pages, B.; Gordon, C.; Aldrich-Wright, J. R. Platinum Coordination Compounds with Potent Anticancer Activity. Coord. Chem. Rev. 2018, 375, 148-163.

(5) Heffeter, P.; Jungwirth, U.; Jakupec, M.; Hartinger, C.; Galanski, M.; Elbling, L.; Micksche, M.; Keppler, B.; Berger, W. Resistance against Novel Anticancer Metal Compounds: Differences and Similarities. Drug Resist. Updates 2008, 11, 1-16.

(6) Thommen, D. S.; Schumacher, T. N. T Cell Dysfunction in Cancer. Cancer Cell 2018, 33, 547-562.

(7) Yentz, S.; Smith, D. Indoleamine 2,3-Dioxygenase (Ido) Inhibition as a Strategy to Augment Cancer Immunotherapy. Biodrugs 2018, 32, 311-317.

(8) Coletti, A.; Greco, F. A.; Dolciami, D.; Camaioni, E.; Sardella, R.; Pallotta, M. T.; Volpi, C.; Orabona, C.; Grohmann, U.; Macchiarulo, A. Advances in Indoleamine 2,3-Dioxygenase 1 Medicinal Chemistry. MedChem Comm 2017, 8, 1378-1392.

(9) Wirthgen, E.; Leonard, A. K.; Scharf, C.; Domanska, G. The Immunomodulator 1-Methyltryptophan Drives Tryptophan Catabolism toward the Kynurenic Acid Branch. Front. Immunol. 2020, 11, 313.

(10) Hou, D.-Y.; Muller, A. J.; Sharma, M. D.; DuHadaway, J.; Banerjee, T.; Johnson, M.; Mellor, A. L.; Prendergast, G. C.; Munn, D. H. Inhibition of Indoleamine 2,3-Dioxygenase in Dendritic Cells by Stereoisomers of 1-Methyl-Tryptophan Correlates with Antitumor Responses. Cancer Res. 2007, 67, 792-801.

(11) Merlo, L. M. F.; Pigott, E.; DuHadaway, J. B.; Grabler, S.; Metz, R.; Prendergast, G. C.; Mandik-Nayak, L. Ido2 Is a Critical Mediator of Autoantibody Production and Inflammatory Pathogenesis in a Mouse Model of Autoimmune Arthritis. J. Immunol. 2014, 192, 2082-2090.

(12) Muller, A. J.; DuHadaway, J. B.; Donover, P. S.; Sutanto-Ward, E.; Prendergast, G. C. Inhibition of Indoleamine 2,3-Dioxygenase, an Immunoregulatory Target of the Cancer Suppression Gene Bin 1, Potentiates Cancer Chemotherapy. Nat. Med. 2005, 11, 312-319. 
(13) Lu, J.; Liu, X.; Liao, Y.-P.; Salazar, F.; Sun, B.; Jiang, W.; Chang, C. H.; Jiang, J.; Wang, X.; Wu, A. M.; Meng, H.; Nel, A. E. NanoEnabled Pancreas Cancer Immunotherapy Using Immunogenic Cell Death and Reversing Immunosuppression. Nat. Commun. 2017, 8, 1811.

(14) Wang, N.; Wang, Z.; Xu, Z.; Chen, X.; Zhu, G. A CisplatinLoaded Immunochemotherapeutic Nanohybrid Bearing Immune Checkpoint Inhibitors for Enhanced Cervical Cancer Therapy. Angew. Chem., Int. Ed. 2018, 57, 3426-3430.

(15) Du, W.; Chen, C.; Sun, P.; Zhang, S.; Zhang, J.; Zhang, X.; Liu, Y.; Zhang, R.; Yan, C.; Fan, C.; Wu, J.; Jiang, X. Eliciting an Immune Hot Tumor Niche with Biomimetic Drug-Based Multi-Functional Nanohybrids Augments Immune Checkpoint Blockade-Based Breast Cancer Therapy. Nanoscale 2020, 12, 3317-3329.

(16) Awuah, S. G.; Zheng, Y.-R.; Bruno, P. M.; Hemann, M. T.; Lippard, S. J. A Pt(Iv) Pro-Drug Preferentially Targets Indoleamine2,3-Dioxygenase, Providing Enhanced Ovarian Cancer ImmunoChemotherapy. J. Am. Chem. Soc. 2015, 137, 14854-14857.

(17) Crist, R. M.; Grossman, J. H.; Patri, A. K.; Stern, S. T.; Dobrovolskaia, M. A.; Adiseshaiah, P. P.; Clogston, J. D.; McNeil, S. E. Common Pitfalls in Nanotechnology: Lessons Learned from Nci's Nanotechnology Characterization Laboratory. Integr. Biol. 2013, 5, 66-73.

(18) Gibson, D. Multi-Action Pt(Iv) Anticancer Agents; Do We Understand How They Work? J. Inorg. Biochem. 2019, 191, 77-84.

(19) Kenny, R. G.; Marmion, C. J. Toward Multi-Targeted Platinum and Ruthenium Drugs-a New Paradigm in Cancer Drug Treatment Regimens? Chem. Rev. 2019, 119, 1058-1137.

(20) Petruzzella, E.; Braude, J. P.; Aldrich-Wright, J. R.; Gandin, V.; Gibson, D. A Quadruple-Action Platinum(Iv) Prodrug with Anticancer Activity against Kras Mutated Cancer Cell Lines. Angew. Chem., Int. Ed. 2017, 56, 11539-11544.

(21) Kratz, F. Albumin as a Drug Carrier: Design of Prodrugs, Drug Conjugates and Nanoparticles. J. Controlled Release 2008, 132, 171183.

(22) Hoogenboezem, E. N.; Duvall, C. L. Harnessing Albumin as a Carrier for Cancer Therapies. Adv. Drug Delivery Rev. 2018, 130, 7389.

(23) Palm, W.; Thompson, C. B. Nutrient Acquisition Strategies of Mammalian Cells. Nature 2017, 546, 234-242.

(24) Chatterjee, M.; Ben-Josef, E.; Robb, R.; Vedaie, M.; Seum, S.; Thirumoorthy, K.; Palanichamy, K.; Harbrecht, M.; Chakravarti, A.; Williams, T. M. Caveolae-Mediated Endocytosis Is Critical for Albumin Cellular Uptake and Response to Albumin-Bound Chemotherapy. Cancer Res. 2017, 77, 5925-5937.

(25) Sleep, D. Albumin and Its Application in Drug Delivery. Expert Opin. Drug Delivery 2015, 12, 793-812.

(26) Cecco, S.; Aliberti, M.; Baldo, P.; Giacomin, E.; Leone, R. Safety and Efficacy Evaluation of Albumin-Bound Paclitaxel. Expert Opin. Drug Saf. 2014, 13, 511-520.

(27) Sachdev, E.; Sachdev, D.; Mita, M. Aldoxorubicin for the Treatment of Soft Tissue Sarcoma. Expert Opin. Invest. Drugs 2017, 26, 1175-1179.

(28) Larsen, M. T.; Kuhlmann, M.; Hvam, M. L.; Howard, K. A. Albumin-Based Drug Delivery: Harnessing Nature to Cure Disease. Mol. Cell. Ther. 2016, 4, 3.

(29) Mayr, J.; Heffeter, P.; Groza, D.; Galvez, L.; Koellensperger, G.; Roller, A.; Alte, B.; Haider, M.; Berger, W.; Kowol, C. R.; Keppler, B. K. An Albumin-Based Tumor-Targeted Oxaliplatin Prodrug with Distinctly Improved Anticancer Activity in Vivo. Chem. Sci. 2017, 8, 2241-2250.

(30) Pichler, V.; Mayr, J.; Heffeter, P.; Dömötör, O.; Enyedy, É. A.; Hermann, G.; Groza, D.; Köllensperger, G.; Galanksi, M.; Berger, W.; Keppler, B. K.; Kowol, C. R. Maleimide-Functionalised Platinum(Iv) Complexes as a Synthetic Platform for Targeted Drug Delivery. Chem. Commun. 2013, 49, 2249-2251.

(31) Chen, S.; Yao, H.; Zhou, Q.; Tse, M.-K.; Gunawan, Y. F.; Zhu, G. Stability, Reduction, and Cytotoxicity of Platinum(Iv) Anticancer
Prodrugs Bearing Carbamate Axial Ligands: Comparison with Their Carboxylate Analogues. Inorg. Chem. 2020, 59, 11676-11687.

(32) Göschl, S.; Varbanov, H. P.; Theiner, S.; Jakupec, M. A.; Galanski, M.; Keppler, B. K. The Role of the Equatorial Ligands for the Redox Behavior, Mode of Cellular Accumulation and Cytotoxicity of Platinum(Iv) Prodrugs. J. Inorg. Biochem. 2016, 160, 264-274.

(33) Feng, B.; Zhou, F.; Hou, B.; Wang, D.; Wang, T.; Fu, Y.; Ma, Y.; Yu, H.; Li, Y. Binary Cooperative Prodrug Nanoparticles Improve Immunotherapy by Synergistically Modulating Immune Tumor Microenvironment. Adv. Mater. 2018, 30, No. e1803001.

(34) Shen, F.; Feng, L.; Zhu, Y.; Tao, D.; Xu, J.; Peng, R.; Liu, Z. Oxaliplatin-/Nlg919 Prodrugs-Constructed Liposomes for Effective Chemo-Immunotherapy of Colorectal Cancer. Biomaterials 2020, 255, 120190.

(35) Bernardim, B.; Cal, P. M. S. D.; Matos, M. J.; Oliveira, B. L.; Martínez-Sáez, N.; Albuquerque, I. S.; Perkins, E.; Corzana, F.; Burtoloso, A. C. B.; Jiménez-Osés, G.; Bernardes, G. J. L. Stoichiometric and Irreversible Cysteine-Selective Protein Modification Using Carbonylacrylic Reagents. Nat. Commun. 2016, 7, 13128.

(36) Gibson, D. Platinum(Iv) Anticancer Prodrugs-Hypotheses and Facts. Dalton Trans. 2016, 45, 12983-12991.

(37) Höfer, D.; Varbanov, H. P.; Hejl, M.; Jakupec, M. A.; Roller, A.; Galanski, M.; Keppler, B. K. Impact of the Equatorial Coordination Sphere on the Rate of Reduction, Lipophilicity and Cytotoxic Activity of Platinum(Iv) Complexes. J. Inorg. Biochem. 2017, 174, 119-129.

(38) Kizu, R.; Nakanishi, T.; Miyazaki, M.; Tashiro, T.; Noji, M.; Matsuzawa, A.; Eriguchi, M.; Takeda, Y.; Akiyama, N.; Kidani, Y. An Orally Active Antitumor Cyclohexanediamine-Pt (Iv) Complex: Trans, Cis, Cis-Bis (N-Valerato)(Oxalato)(1r, 2r-Cyclohexane Diamine) Pt (Iv). Anticancer Drugs 1996, 7, 248-256.

(39) Zhang, J. Z.; Bonnitcha, P.; Wexselblatt, E.; Klein, A. V.; Najajreh, Y.; Gibson, D.; Hambley, T. W. Facile Preparation of Mono-, Di- and Mixed-Carboxylato Platinum(Iv) Complexes for Versatile Anticancer Prodrug Design. Chem.-Eur. J. 2013, 19, 16721676.

(40) Zhang, J. Z.; Wexselblatt, E.; Hambley, T. W.; Gibson, D. Pt(Iv) Analogs of Oxaliplatin That Do Not Follow the Expected Correlation between Electrochemical Reduction Potential and Rate of Reduction by Ascorbate. Chem. Commun. 2012, 48, 847-849.

(41) Neumann, W.; Crews, B. C.; Sárosi, M. B.; Daniel, C. M.; Ghebreselasie, K.; Scholz, M. S.; Marnett, L. J.; Hey-Hawkins, E. Conjugation of Cisplatin Analogues and Cyclooxygenase Inhibitors to Overcome Cisplatin Resistance. ChemMedChem 2015, 10, 183-192.

(42) Wang, Q.; Huang, Z.; Ma, J.; Lu, X.; Zhang, L.; Wang, X.; George Wang, P. Design, Synthesis and Biological Evaluation of a Novel Series of Glycosylated Platinum(Iv) Complexes as Antitumor Agents. Dalton Trans. 2016, 45, 10366-10374.

(43) Jungwirth, U.; Xanthos, D. N.; Gojo, J.; Bytzek, A. K.; Körner, W.; Heffeter, P.; Abramkin, S. A.; Jakupec, M. A.; Hartinger, C. G.; Windberger, U.; Galanski, M.; Keppler, B. K.; Berger, W. Anticancer Activity of Methyl-Substituted Oxaliplatin Analogs. Mol. Pharmacol. 2012, 81, 719-728.

(44) Platts, J. A.; Oldfield, S. P.; Reif, M. M.; Palmucci, A.; Gabano, E.; Osella, D. The Rp-Hplc Measurement and Qspr Analysis of Logpo/W Values of Several Pt(Ii) Complexes. J. Inorg. Biochem. 2006, 100, 1199-1207.

(45) Lai, Y.-H.; Kuo, C.; Kuo, M. T.; Chen, H. H. W. Modulating Chemosensitivity of Tumors to Platinum-Based Antitumor Drugs by Transcriptional Regulation of Copper Homeostasis. Int. J. Mol. Sci. 2018, 19, 1486.

(46) Litzenburger, U. M.; Opitz, C. A.; Sahm, F.; Rauschenbach, K. J.; Trump, S.; Winter, M.; Ott, M.; Ochs, K.; Lutz, C.; Liu, X.; Anastasov, N.; Lehmann, I.; Höfer, T.; von Deimling, A.; Wick, W.; Platten, M. Constitutive Ido Expression in Human Cancer Is Sustained by an Autocrine Signaling Loop Involving Il-6, Stat3 and the Ahr. Oncotarget 2014, 5, 1038-1051.

(47) Mathieu, V.; Pirker, C.; Martin de Lassalle, E.; Vernier, M.; Mijatovic, T.; DeNeve, N.; Gaussin, J.-F.; Dehoux, M.; Lefranc, F.; Berger, W.; Kiss, R. The Sodium Pump Alphal Sub-Unit: A Disease 
Progression-Related Target for Metastatic Melanoma Treatment. J. Cell. Mol. Med. 2009, 13, 3960-3972.

(48) Baguley, B. C.; Marshall, E. S.; Whittaker, J. R.; Dotchin, M. C.; Nixon, J.; McCrystal, M. R.; Finlay, G. J.; Matthews, J. H. L.; Holdaway, K. M.; van Zijl, P. Resistance Mechanisms Determining the in Vitro Sensitivity to Paclitaxel of Tumour Cells Cultured from Patients with Ovarian Cancer. Eur. J. Cancer 1995, 31, 230-237.

(49) Campia, I.; Buondonno, I.; Castella, B.; Rolando, B.; Kopecka, J.; Gazzano, E.; Ghigo, D.; Riganti, C. An Autocrine Cytokine/Jak/ Stat-Signaling Induces Kynurenine Synthesis in Multidrug Resistant Human Cancer Cells. PLoS One 2015, 10, No. e0126159.

(50) Curti, A.; Trabanelli, S.; Onofri, C.; Aluigi, M.; Salvestrini, V.; Ocadlikova, D.; Evangelisti, C.; Rutella, S.; De Cristofaro, R.; Ottaviani, E.; Baccarani, M.; Lemoli, R. M. Indoleamine 2,3Dioxygenase-Expressing Leukemic Dendritic Cells Impair a Leukemia-Specific Immune Response by Inducing Potent $\mathrm{T}$ Regulatory Cells. Haematologica 2010, 95, 2022-2030.

(51) Qian, F.; Villella, J.; Wallace, P. K.; Mhawech-Fauceglia, P.; Tario, J. D., Jr.; Andrews, C.; Matsuzaki, J.; Valmori, D.; Ayyoub, M.; Frederick, P. J.; Beck, A.; Liao, J.; Cheney, R.; Moysich, K.; Lele, S.; Shrikant, P.; Old, L. J.; Odunsi, K. Efficacy of Levo-1-Methyl Tryptophan and Dextro-1-Methyl Tryptophan in Reversing Indoleamine-2,3-Dioxygenase-Mediated Arrest of T-Cell Proliferation in Human Epithelial Ovarian Cancer. Cancer Res. 2009, 69, 5498-5504. (52) Munn, D. H.; Mellor, A. L. Indoleamine 2,3-Dioxygenase and Tumor-Induced Tolerance. J. Clin. Invest. 2007, 117, 1147-1154.

(53) Larsen, M. T.; Mandrup, O. A.; Schelde, K. K.; Luo, Y.; Sørensen, K. D.; Dagnæs-Hansen, F.; Cameron, J.; Stougaard, M.; Steiniche, T.; Howard, K. A. Fcrn Overexpression in Human Cancer Drives Albumin Recycling and Cell Growth; a Mechanistic Basis for Exploitation in Targeted Albumin-Drug Designs. J. Controlled Release 2020, 322, 53-63.

(54) Hanahan, D.; Weinberg, R. A. The Hallmarks of Cancer. Cell 2000, 100, 57-70.

(55) Hanahan, D.; Weinberg, R. A. Hallmarks of Cancer: The Next Generation. Cell 2011, 144, 646-674.

(56) Kidani, Y.; Inagaki, K.; Iigo, M.; Hoshi, A.; Kuretani, K. Antitumor Activity of 1, 2-Diaminocyclohexaneplatinum Complexes against Sarcoma-180 Ascites Form. J. Med. Chem. 1978, 21, 13151318.

(57) Maertens, F.; Van den Bogaert, A.; Compernolle, F.; Hoornaert, G. J. Intramolecular Ritter Reactions of 2-(2-Cyanoethyl)Tetrahydrocyclopenta[B]Indole and -Carbazole Derivatives. Eur. J. Org. Chem. 2004, 2004, 4648-4656.

(58) Ponchel, F.; Toomes, C.; Bransfield, K.; Leong, F. T.; Douglas, S. H.; Field, S. L.; Bell, S. M.; Combaret, V.; Puisieux, A.; Mighell, A. J.; Robinson, P. A.; Inglehearn, C. F.; Isaacs, J. D.; Markham, A. F. Real-Time Pcr Based on Sybr-Green I Fluorescence: An Alternative to the Taqman Assay for a Relative Quantification of Gene Rearrangements, Gene Amplifications and Micro Gene Deletions. BMC Biotechnol. 2003, 3, 18.

(59) Simón-Manso, Y.; Lowenthal, M. S.; Kilpatrick, L. E.; Sampson, M. L.; Telu, K. H.; Rudnick, P. A.; Mallard, W. G.; Bearden, D. W.; Schock, T. B.; Tchekhovskoi, D. V.; Blonder, N.; Yan, X.; Liang, Y.; Zheng, Y.; Wallace, W. E.; Neta, P.; Phinney, K. W.; Remaley, A. T.; Stein, S. E. Metabolite Profiling of a Nist Standard Reference Material for Human Plasma (Srm 1950): Gc-Ms, Lc-Ms, Nmr, and Clinical Laboratory Analyses, Libraries, and Web-Based Resources. Anal. Chem. 2013, 85, 11725-11731.

(60) Monaco, G.; Chen, H.; Poidinger, M.; Chen, J.; de Magalhães, J. P.; Larbi, A. Flowai: Automatic and Interactive Anomaly Discerning Tools for Flow Cytometry Data. Bioinformatics 2016, 32, 2473-2480. 


\section{Supporting Information}

\section{Structure-activity relationships of triple-action platinum(IV) prodrugs with albumin-binding properties and immunomodulating ligands}

Philipp Fronik ${ }^{a \#}$, Isabella Poetsch ${ }^{a b c \#}$, Alexander Kastner ${ }^{a}$, Theresa Mendrina ${ }^{b}$, Sonja Hager ${ }^{b}$, Katharina Hohenwallner $^{d}$, Hemma Schueffl ${ }^{b}$, Dietmar Herndler-Brandstetter ${ }^{b}$, Gunda Koellensperger ${ }^{d}$, Evelyn Rampler $^{d}$, Joanna Kopecka ${ }^{e}$, Chiara Riganti ${ }^{\mathrm{e}}$, Walter Berger ${ }^{b c}$, Bernhard K. Keppler ${ }^{a c}$, Petra Heffeter ${ }^{b c^{*}}$, and Christian R. Kowol ${ }^{a c^{*}}$

a University of Vienna, Faculty of Chemistry, Institute of Inorganic Chemistry, Waehringer Strasse 42, 1090 Vienna, Austria.

b Institute of Cancer Research and Comprehensive Cancer Center, Medical University of Vienna, Borschkegasse 8a, 1090 Vienna, Austria.

'Research Cluster "Translational Cancer Therapy Research", 1090 Vienna, Austria

d University of Vienna, Faculty of Chemistry, Institute of Analytical Chemistry, Waehringer Strasse 38, 1090 Vienna, Austria

e University of Torino, Department of Oncology, University of Torino, via Santena 5/bis, 10126, Torino, Italy

\# These authors have contributed equally 


\section{Table of contents}

$\begin{array}{lll}\text { Figures S1-S2: } & \text { SEC-ICP-MS supporting information } & \text { Page S3-S4 } \\ \text { Figures S3-S4: } & \text { Stability data of compounds } & \text { Page S5 } \\ \text { Figures S5-S16: } & \text { Biological data } & \text { Page S6-S16 } \\ \text { Figures S17-S24: } & \text { NMR characterization } & \text { Page S17-S24 } \\ \text { Figures S25-S32: } & \text { UHPLC chromatograms } & \text { Page S25-S27 } \\ \text { Tables S1-S3 } & \text { Additional IC50 values } & \text { Page S28-S29 } \\ \text { Table S4 } & \text { Pt ratio in tissue samples } & \text { Page S30 } \\ \text { Tables S5-S8: } & \text { Materials and methods } & \text { Page S31-S33 } \\ \text { Scheme S1: } & \text { NMR numbering scheme } & \text { Page S34 }\end{array}$




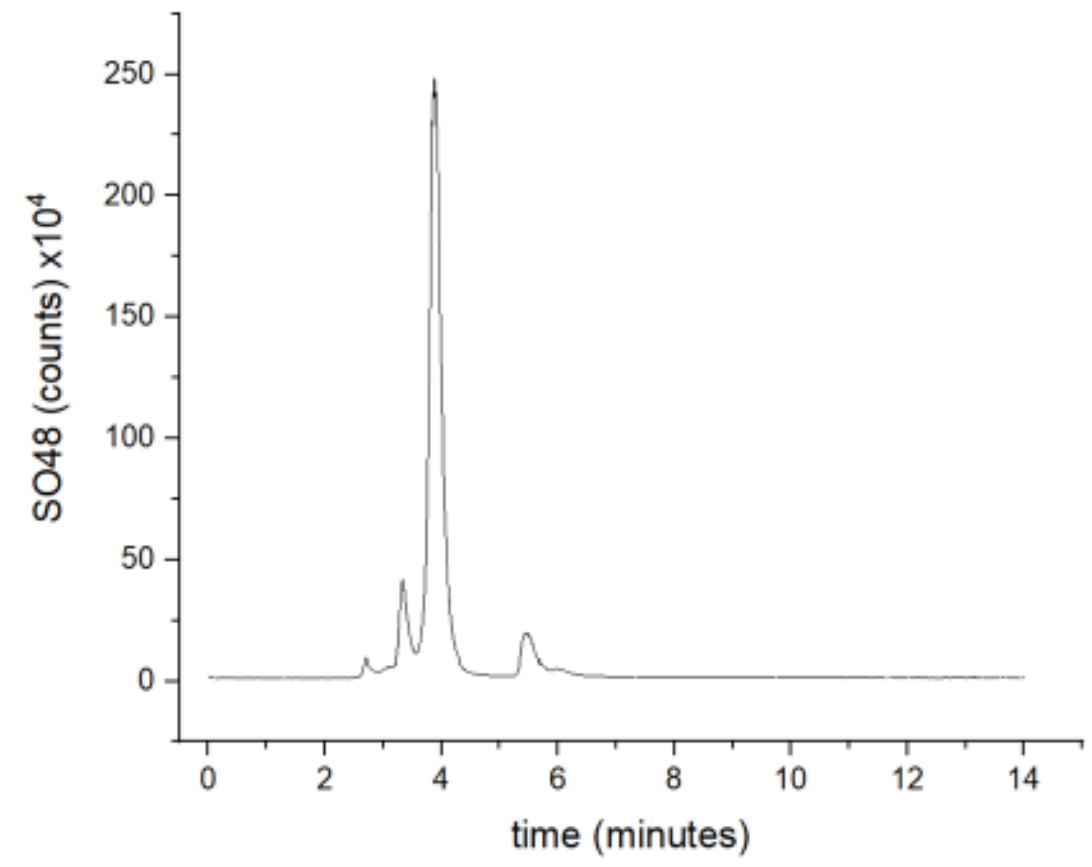

Figure S1: Sulfur trace of fetal calf serum (+150 mM phosphate buffer, $p H$ 7.4), measured by ICP-MS. 

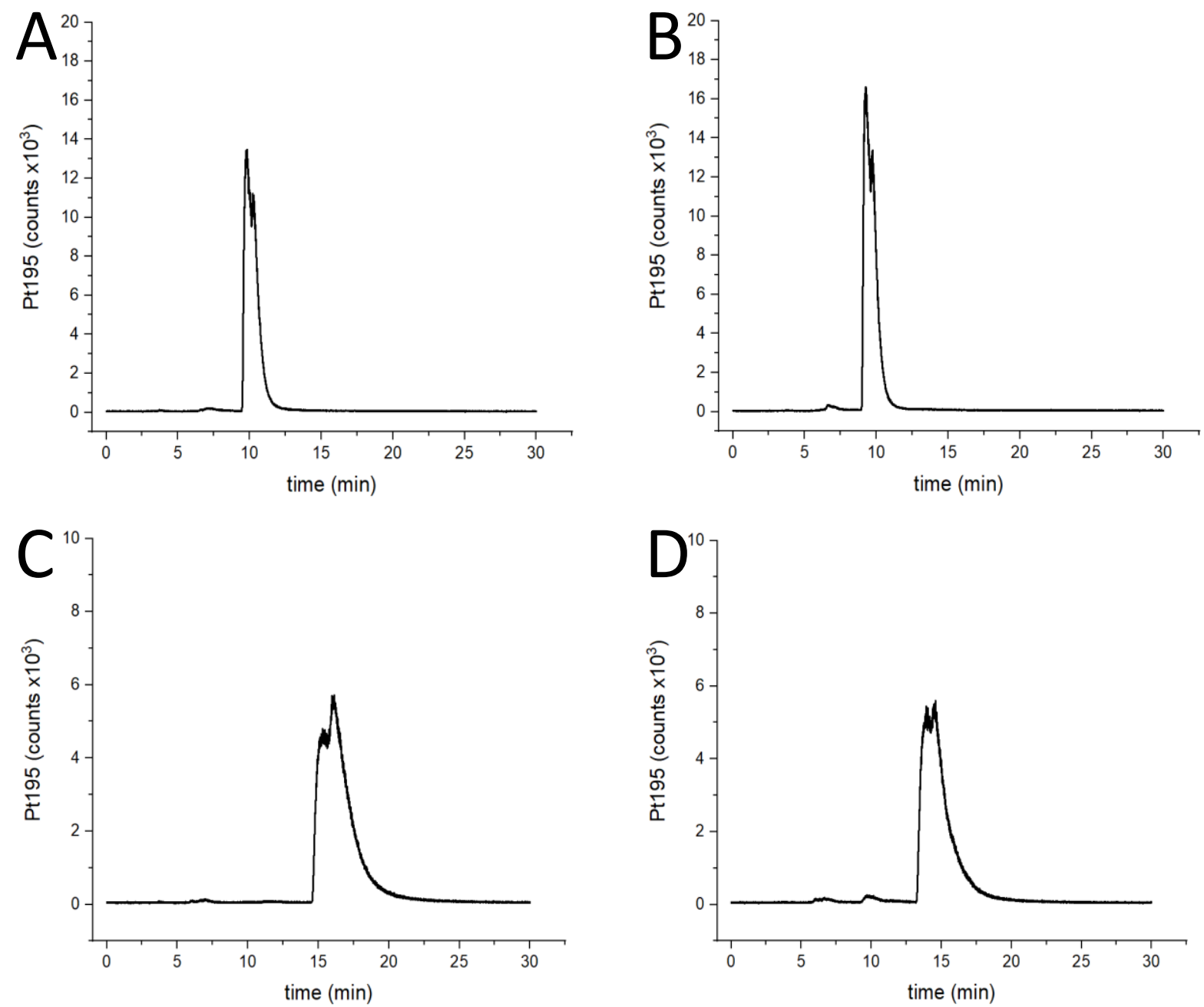

Figure S2: SEC-ICP-MS traces of complexes (A) SucEs/IdoCa, (B) SucCa/IdoCa, (C) SucCa/IdoEs and (D) SucEs/IdoEs after incubation in fetal calf serum ( $+150 \mathrm{mM}$ phosphate buffer, $p H 7.4)$ at $37^{\circ} \mathrm{C}$. No significant binding to albumin ( $t_{R} \sim 4 \mathrm{~min}$ ) could be observed for any of the compounds. 

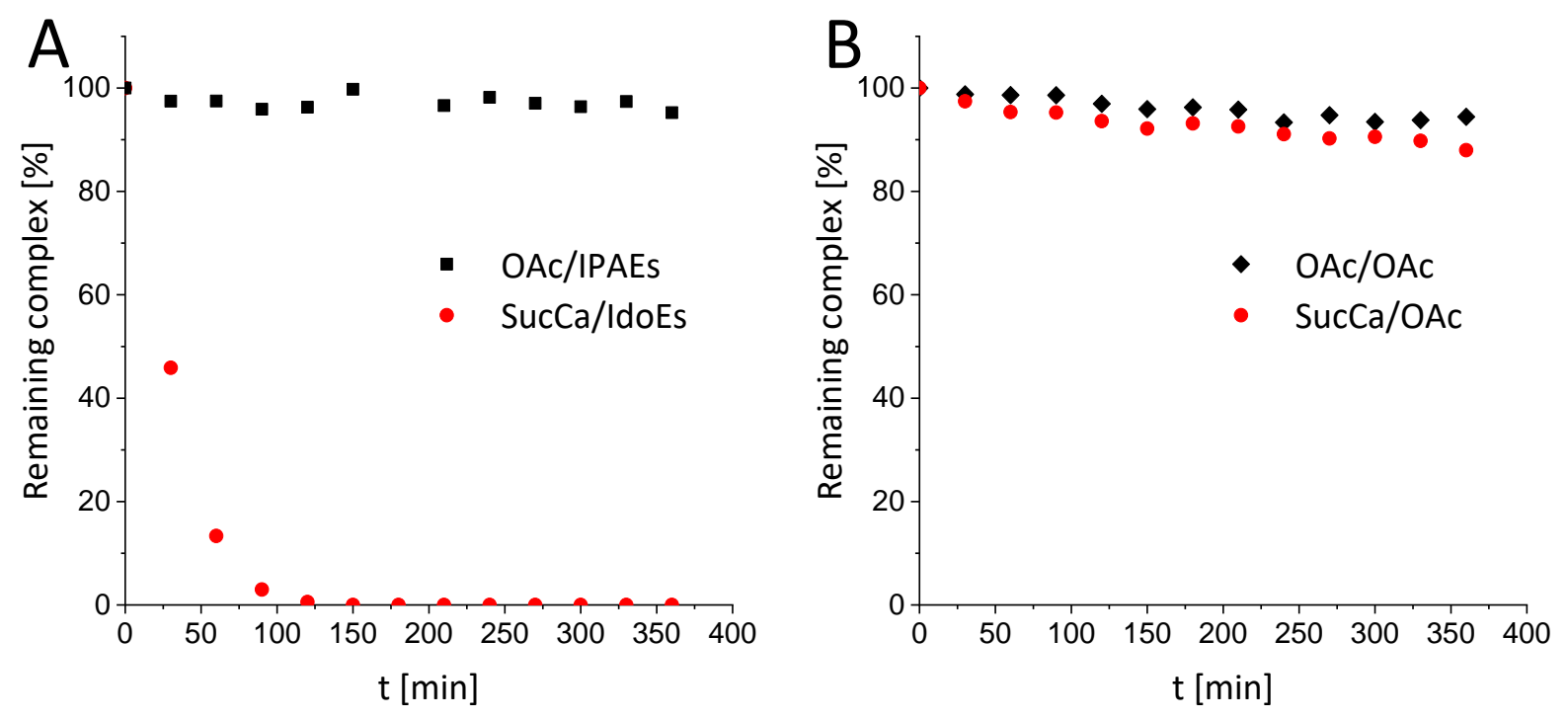

Figure S3: Reduction kinetics of reference compounds with $A A$ at $20^{\circ} \mathrm{C}$, measured by UHPLC and UV absorption at $220 \mathrm{~nm}$. A: Comparison of OAC/IPAEs with amino-group containing SucCa/IdoEs; B: Reductive stability of reference compounds with no $1 M D T$-like ligand. AUC-values were normalized to $t=0$. Experimental conditions: $1 \mathrm{mM}$ complex, $10 \mathrm{mM}$ AA in 1\% DMF and $500 \mathrm{mM}$ phosphate buffer $(\mathrm{pH}$ 7.4).

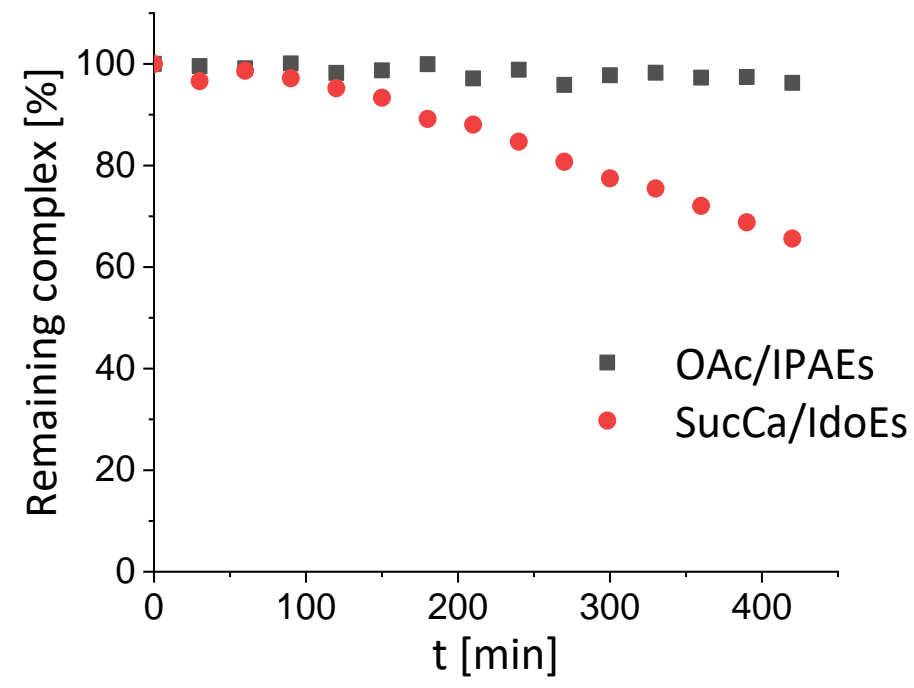

Figure S4: Reduction kinetics of OAc/IPAEs and SucCa/IdoEs in the presence of dithiothreitol (DTT) at $20^{\circ} \mathrm{C}$, measured by UHPLC. The complex OAC/IPAEs does not have a free amino group on its 1-MDT-like ligand and is stable under these conditions, whereas SucCa/IdoEs is readily reduced. Experimental conditions: $1 \mathrm{mM}$ complex, $10 \mathrm{mM}$ DTT in 1\% DMF and $500 \mathrm{mM}$ phosphate buffer ( $\mathrm{pH}$ 7.4). 

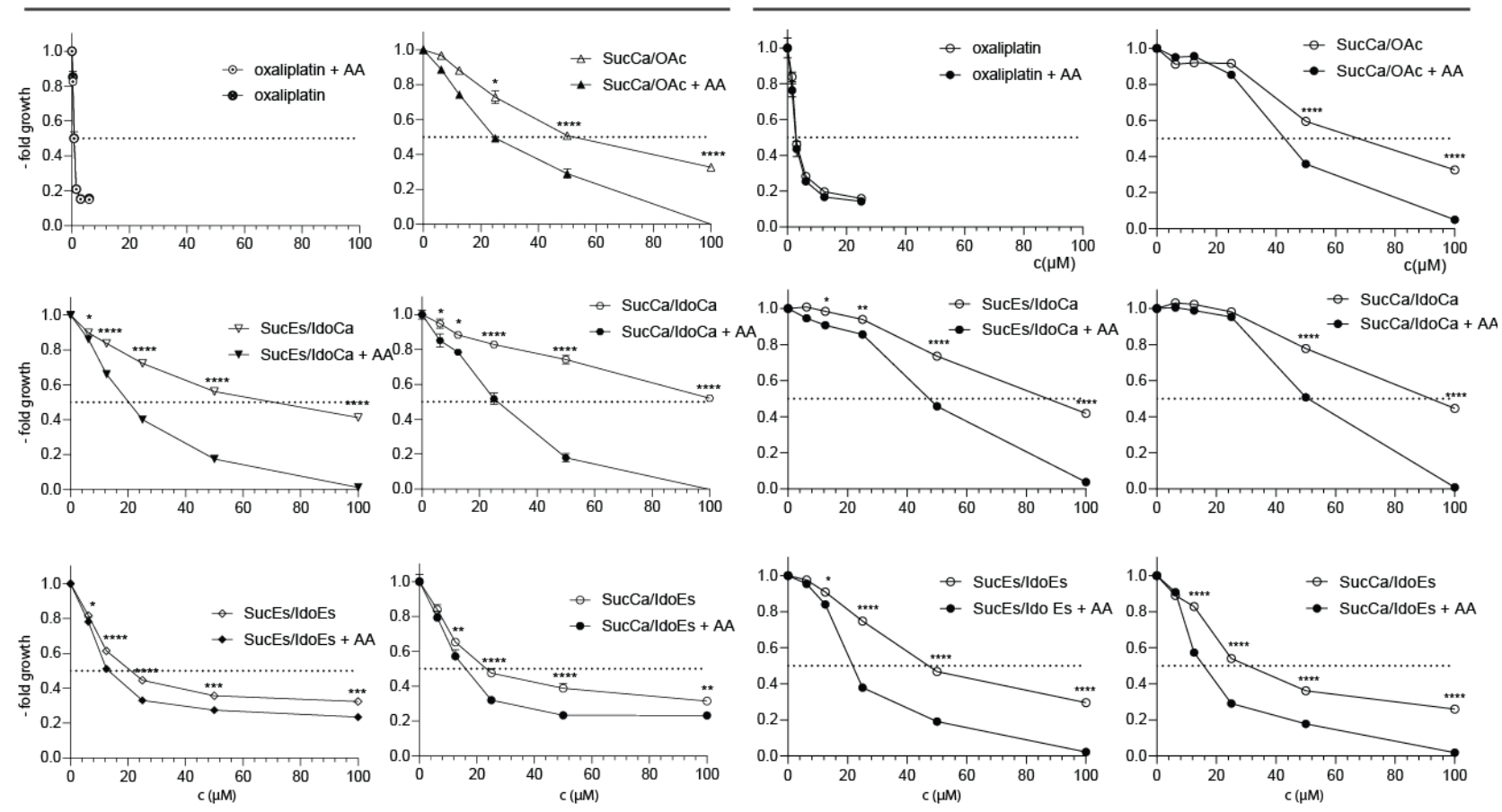

Figure S5: Cytotoxicity determination. HCT116 or CT26 cancer cells were treated for 72 h with increasing drug concentrations in the presence or absence of 5-fold equimolar amount of AA. The viability of the cells was analyzed by MTT assay. Data shown are mean + /- standard deviation of triplicates from one exemplary experiment. Significance was calculated using multiple comparisons (two-way ANOVA) * $p<0.05, * * p<0.01, * * * p<0.001, * * * * p<0.0001$. 
A
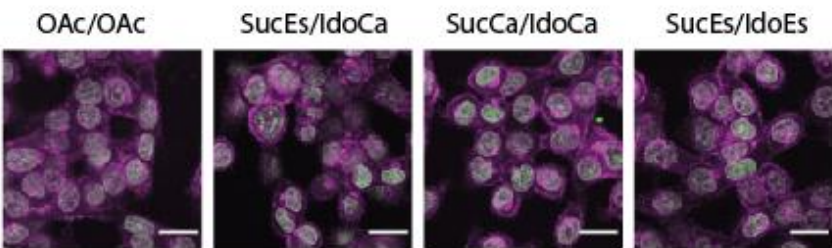

SucCa/IdoEs
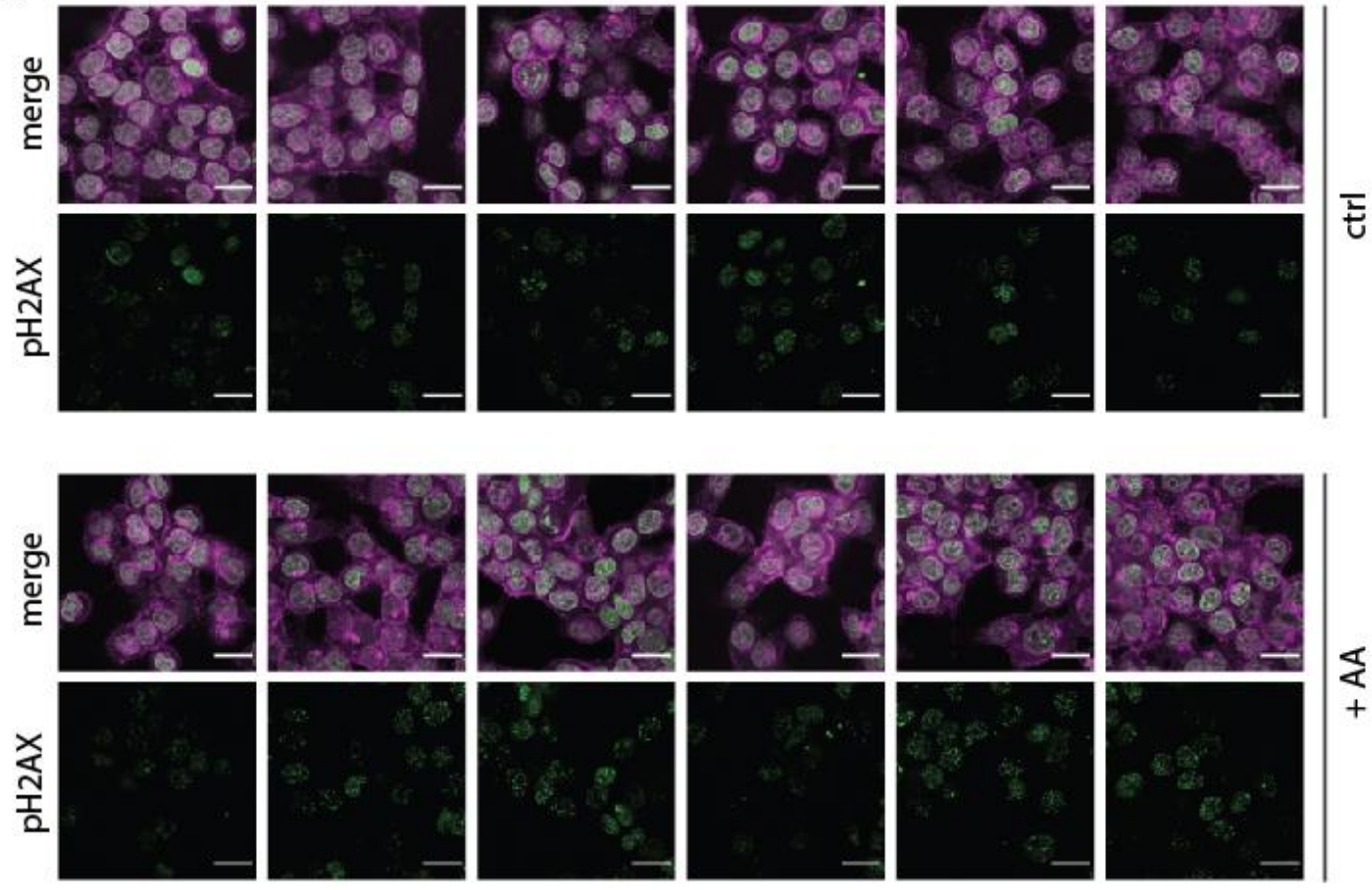

B
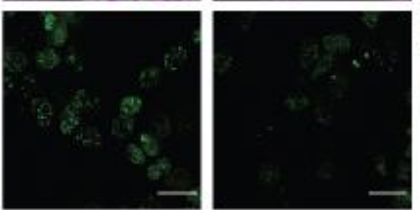

$\frac{\mathbb{4}}{+}$
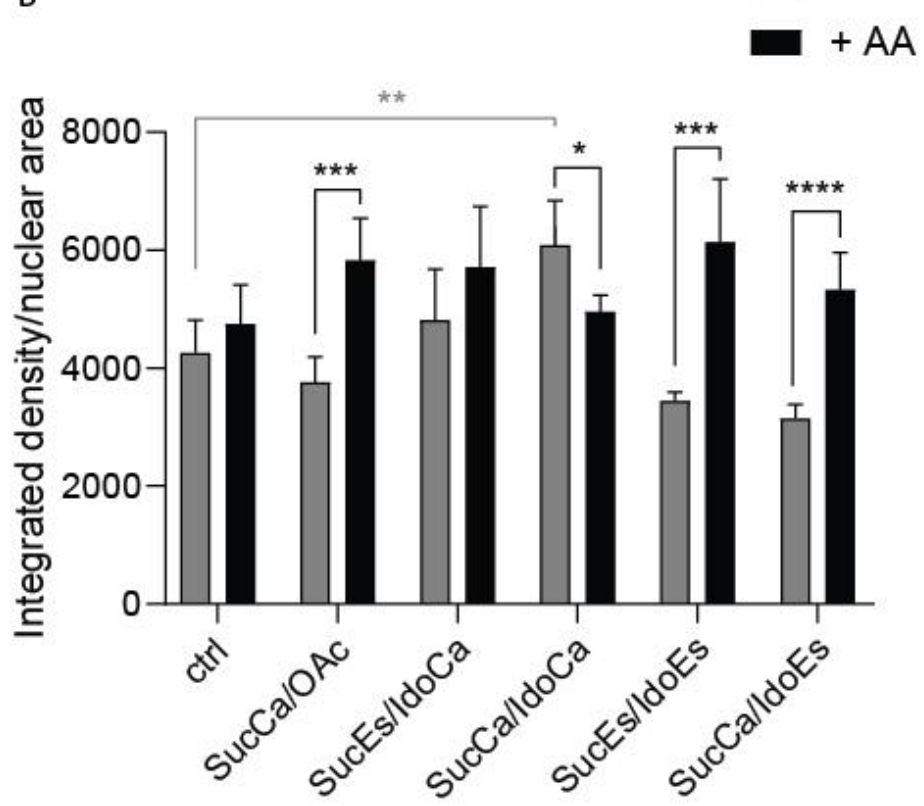

Figure S6: DNA damage levels. HCT116 cells were treated with the respective drugs at $50 \mu M$ for $24 h$ in the absence or presence of 5-fold excess AA. (A) Cells were fixed and stained with TRITC-phalloidin (magenta), DAPI (white) and $\mathrm{pH} 2 \mathrm{AX}$ antibody (green). Shown are representative fluorescence images (scale bar $20 \mu \mathrm{m}$ ). (B) $\mathrm{pH} 2 \mathrm{AX}$ fluorescence intensity signals were quantified and are depicted as mean $\pm S D$ from five images. Significance compared to control (ctrl) was calculated by mixed-effects analysis and Sidak's multiple comparisons test. Significance comparing conditions with and without $A A$ was calculated by multiple $t$ tests. ${ }^{*} p<0.05,{ }^{* *} p<0.01,{ }^{* * *} p<0.001,{ }^{* * * *} p<0.0001$ 
A

\begin{tabular}{|c|c|c|c|c|c|c|c|}
\hline & ctrl & oxaliplatin & SucCa/OAc & SucEs/ldoCa & SucCa/ldoCa & SucEs/ldoEs & SucCa/ldoEs \\
\hline - & 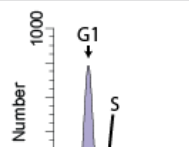 & 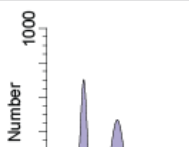 & 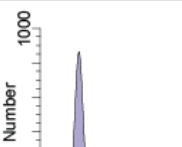 & 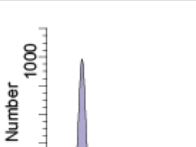 & 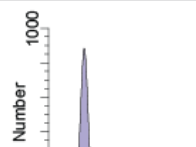 & 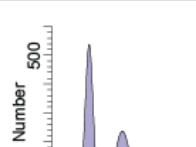 & 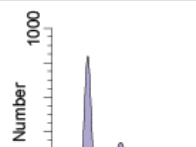 \\
\hline & 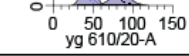 & 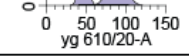 & ${ }^{0} \begin{array}{c}50100 \\
y \\
y\end{array}$ & 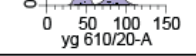 & 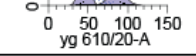 & 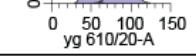 & 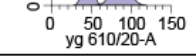 \\
\hline$+A A$ & 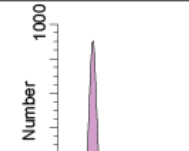 & 橡 & 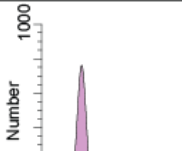 & $\stackrel{8}{7}_{7}$ & 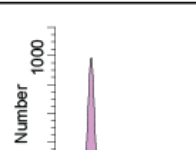 & $=$ & $=$ \\
\hline & ${ }^{5} \begin{array}{c}50 \\
\text { yg } 610120-\mathrm{A}\end{array}$ & $\begin{array}{c}50 \\
0 \\
y=6100 \\
y\end{array}$ & $\begin{array}{c}50100150 \\
y=6101 / 20-A\end{array}$ & $\begin{array}{l}50100150 \\
0 \\
y g\end{array}$ & $\begin{array}{c}0 \quad 50100150 \\
\text { yg } 610 / 20-A\end{array}$ & $\begin{array}{c}50100 \\
y_{y}^{5} 6101 / 20-A\end{array}$ & $\begin{array}{c}50100150 \\
0 \\
y=610120-A\end{array}$ \\
\hline
\end{tabular}

B

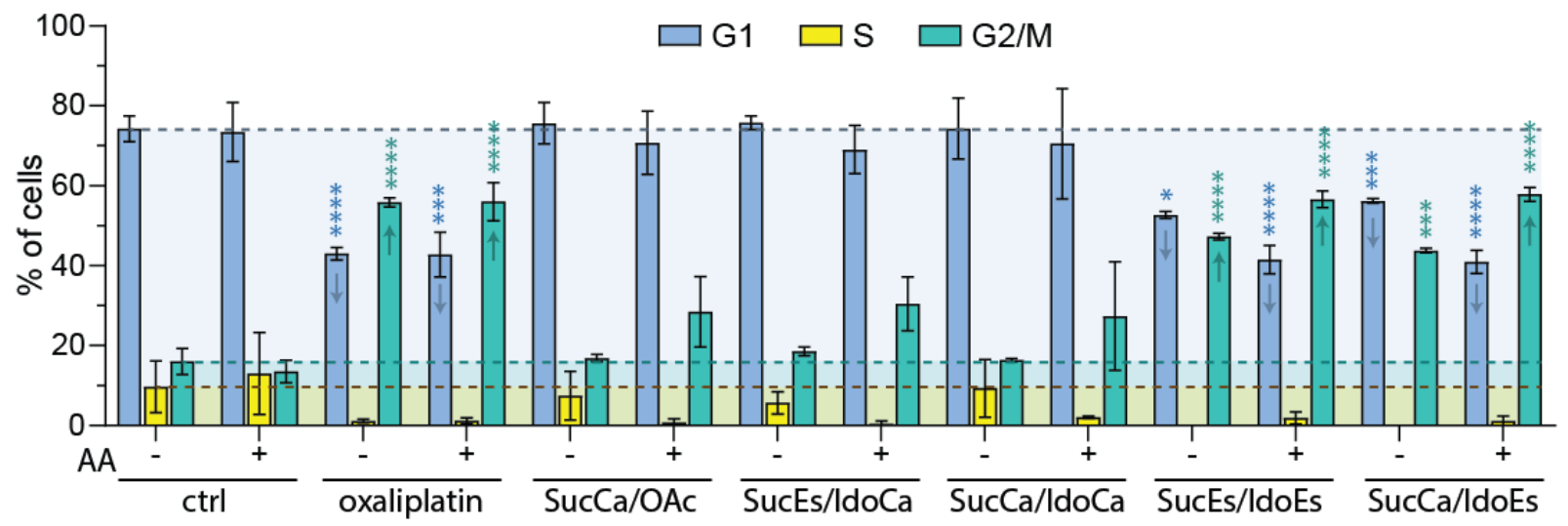

Figure S7: Cell cycle analysis. HCT116 cells were treated with the respective drugs at $50 \mu M(10 \mu M$ in case of oxaliplatin) for $24 \mathrm{~h}$ in the absence or presence of 5-fold excess AA. Cells were analyzed through flow cytometry and cell cycle phases were allocated according to the DNA content. (A) Exemplary histogram of cell cycle distribution. (B) Graph shows percentage of cell cycle distribution. Bars depict mean $\pm S D$ from two independent experiments. Statistical significance compared to respective control was calculated by 2 way ANOVA and Tukey's multiple comparisons test. ${ }^{*} p<0.05,{ }^{* * *} p<0.001,{ }^{* * * *} p$ $<0.0001$. 
A

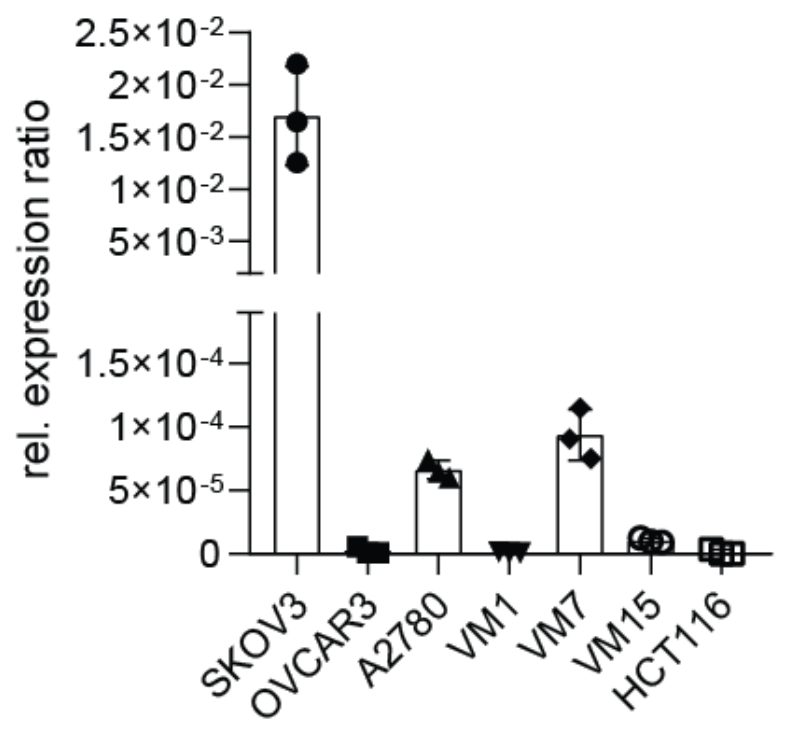

B

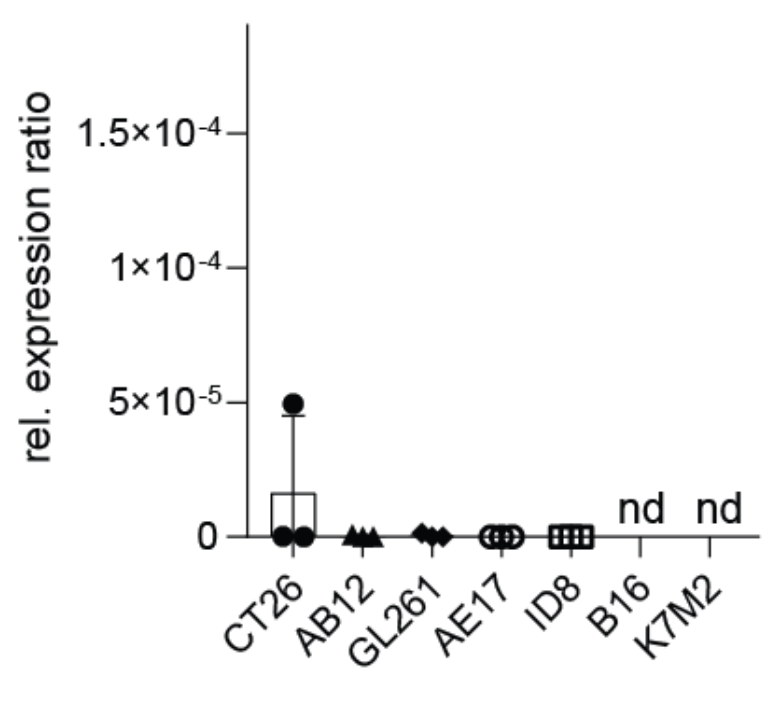

Figure S8: $m R N A$ levels of IDO transcript in $(A)$ human cell lines or $(B)$ murine cell lines normalized to the mRNA level of the housekeeping gene B-actin.

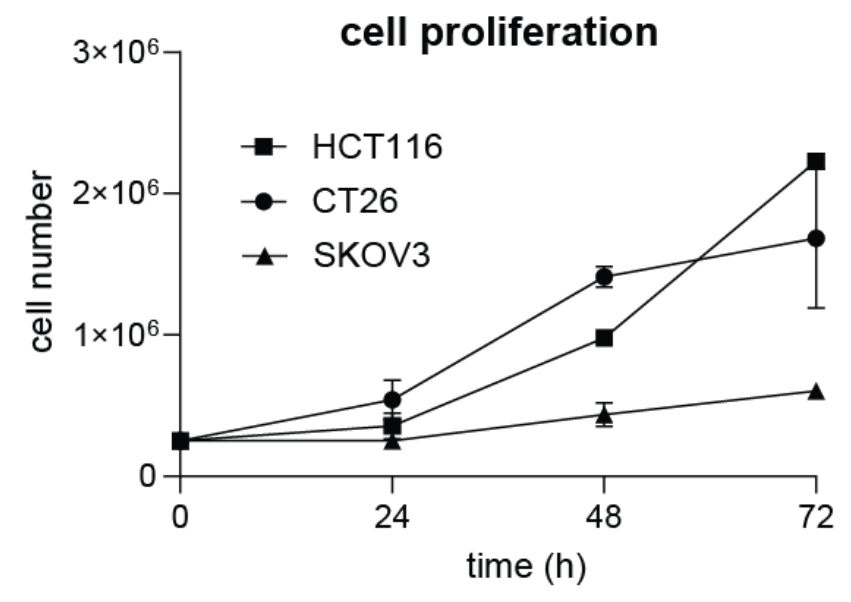

Figure S9: Proliferation rate of different cancer cell models: 250000 cells were seeded and counted every $24 \mathrm{~h}$ to determine cell proliferation. Data is presented as mean +/-SD from 2 individual experiments. 

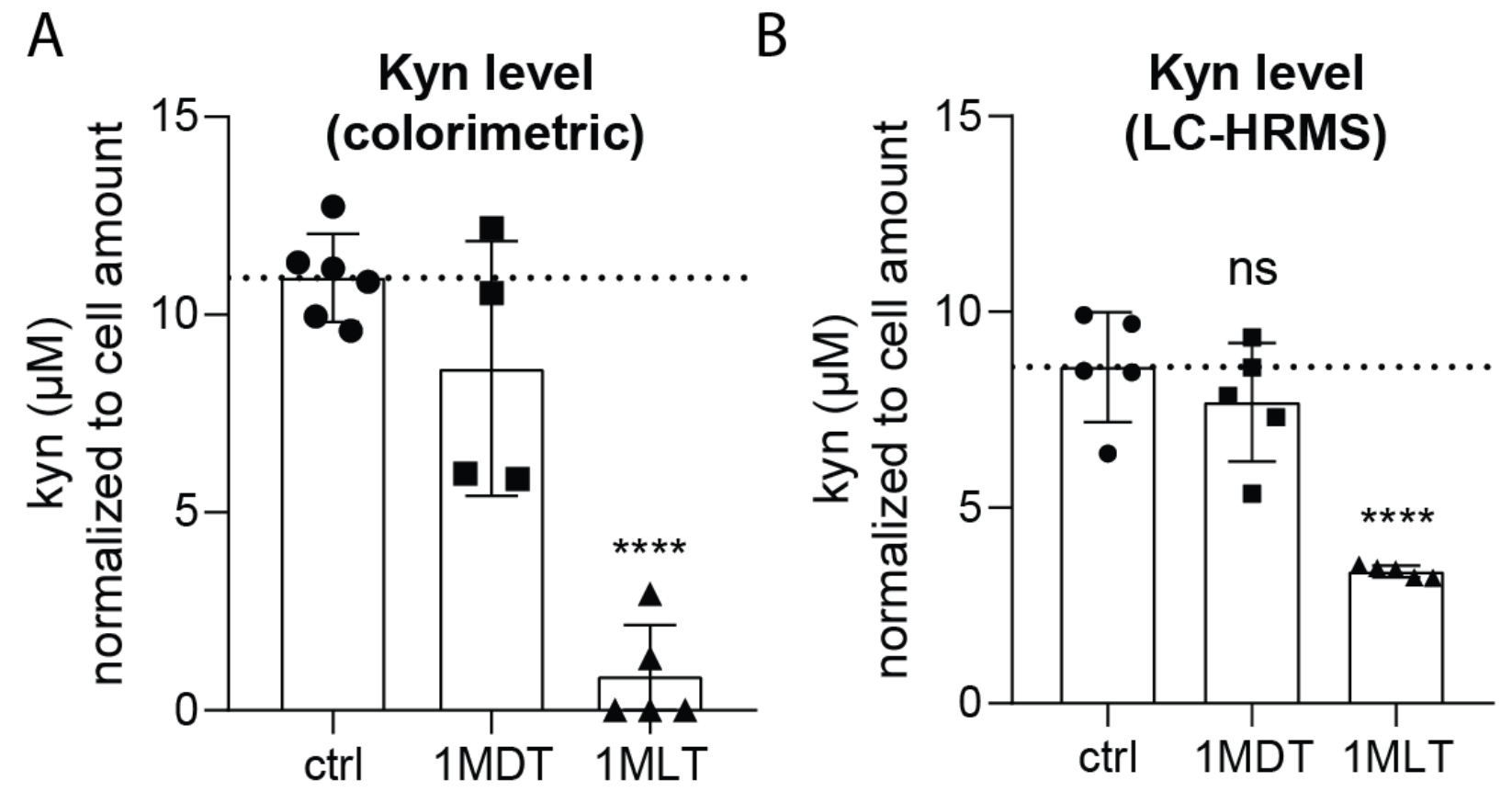

Figure S10: (A) Colorimetric measurement of Kyn in cell supernatants from SKOV3 cells after $72 \mathrm{~h}$ treatment at sub-toxic concentrations $(2 \mathrm{mM})$. Values were normalized to cell amount based on their metabolic capacity (B) LC-HRMS measurement of the supernatants from (A) to detect Kyn levels. Values were normalized to cell amount based on their metabolic capacity. Data is presented as mean +/- SD from 5 replicates. Significance was calculated by multiple comparison analysis (one-way ANOVA) and Dunnett Post-Hoc-test * $p<0.05,{ }^{* *} p<0.01,{ }^{* * *} p<0.001, * * * *<0.0001$. 
A

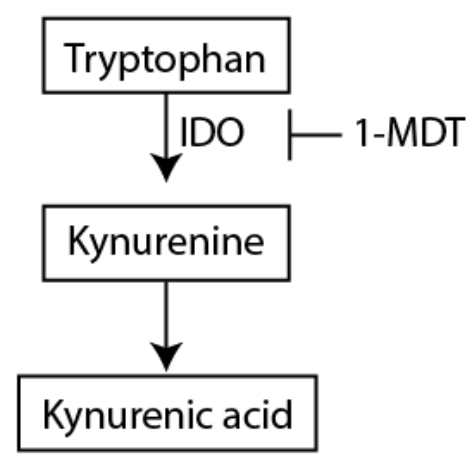

C

\section{Trp:Kyn}

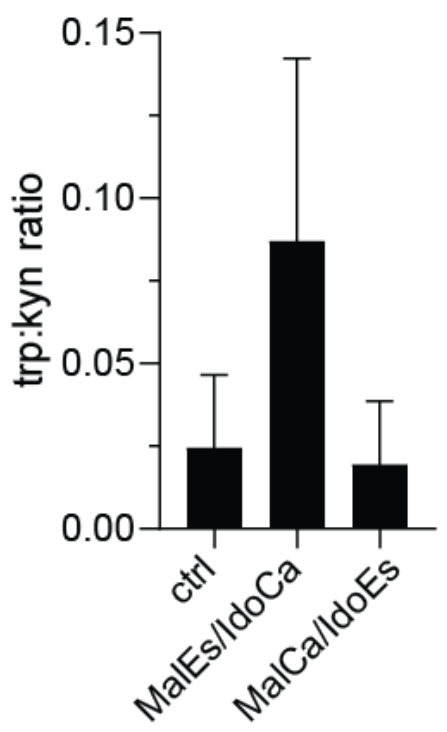

B

1-MDT release

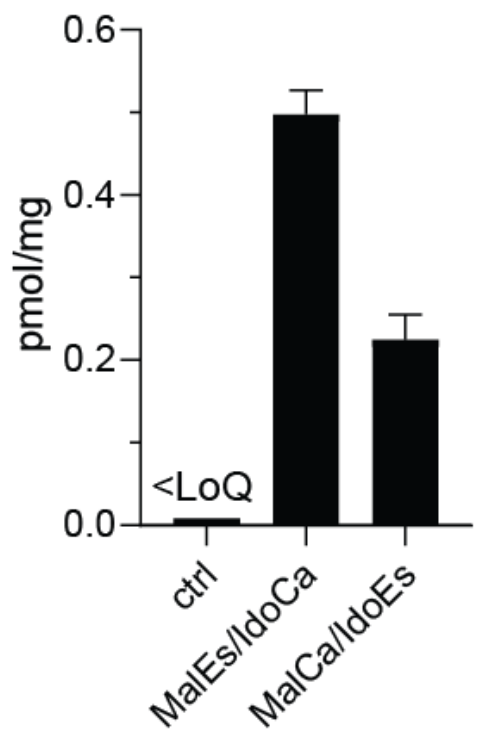

D

$$
\text { Kynurenic acid }
$$

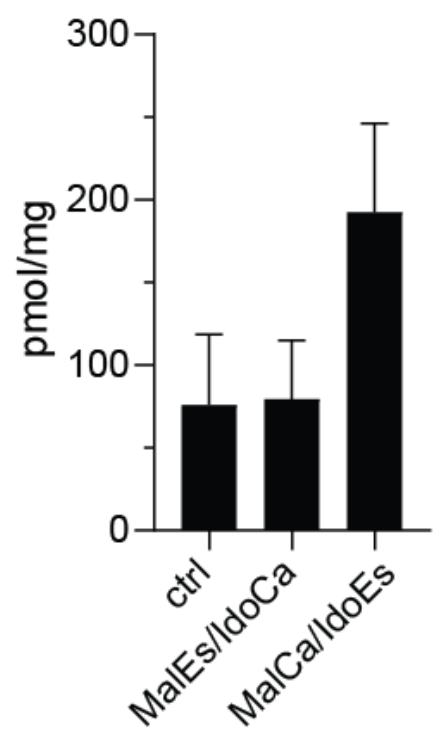

Figure S11: Inhibition of kynurenine pathway in tumor tissue. (A) Scheme shows downstream catabolites of IDO activity. (B) Relative quantification by LC-HRMS of 1-MDT levels from tumor tissue. (C) Ratio of tryptophan to kynurenine level in tumor tissue. Significance of the quantified metabolites by LC-HRMS was calculated by ordinary one-way ANOVA and Tukey's multiple comparisons test. ${ }^{* *} p<0.01$, *** $p<0.001$ (D) Downstream catabolite of IDO activity. Bars indicate mean \pm SD from 2 biological replicates. 

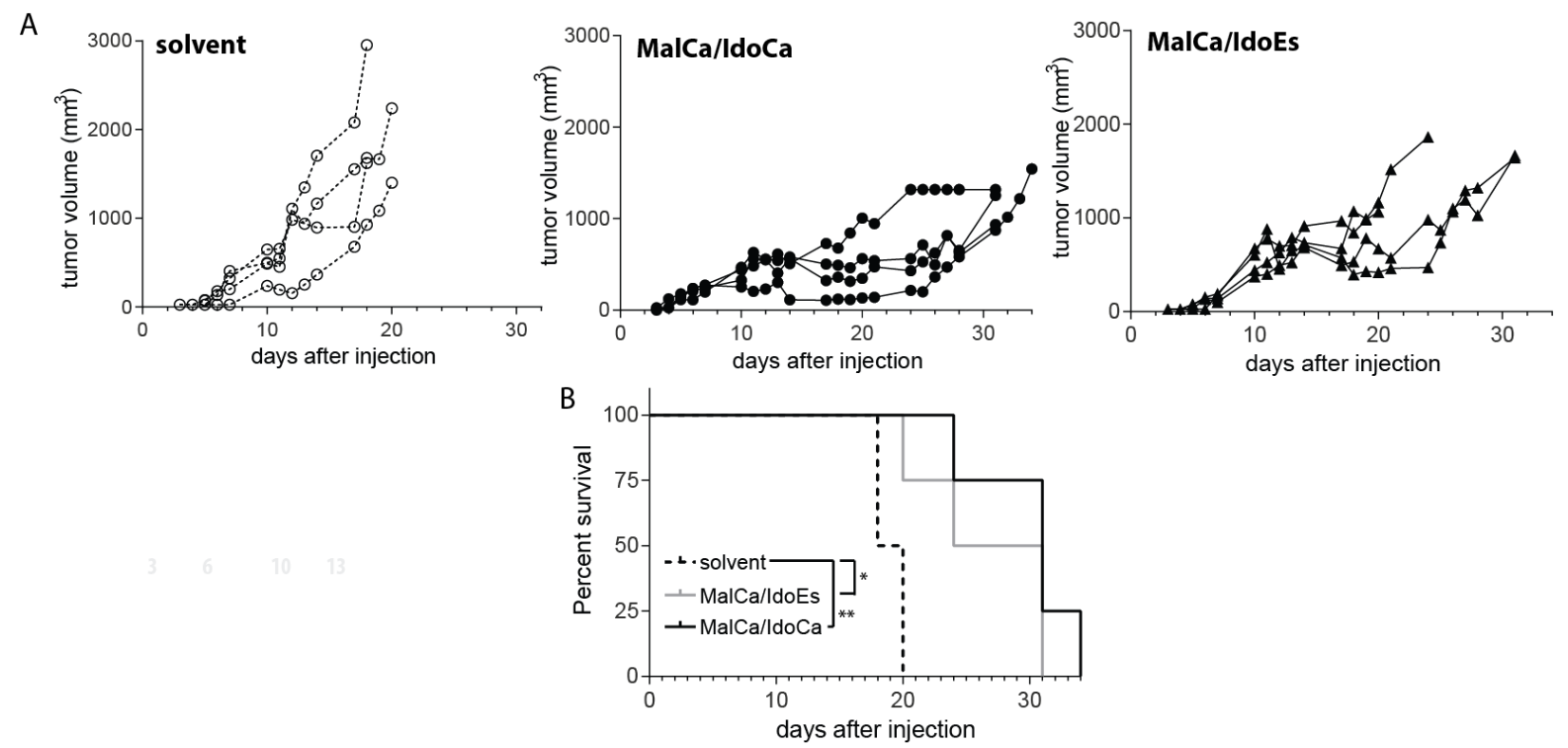

Figure S12: (A) Therapy of CT26-bearing Balb/c mice treated (i.v.) with MalCa/IdoCa or MalCa/IdoEs at concentrations equimolar to $9 \mathrm{mg} / \mathrm{kg}$ oxaliplatin. Tumor growth was measured daily. Each graph shows individual values from one treatment group. (B) Kaplan-Meier blot from (A). Significance was calculated using Log-rank (Mantel-Cox) test. 

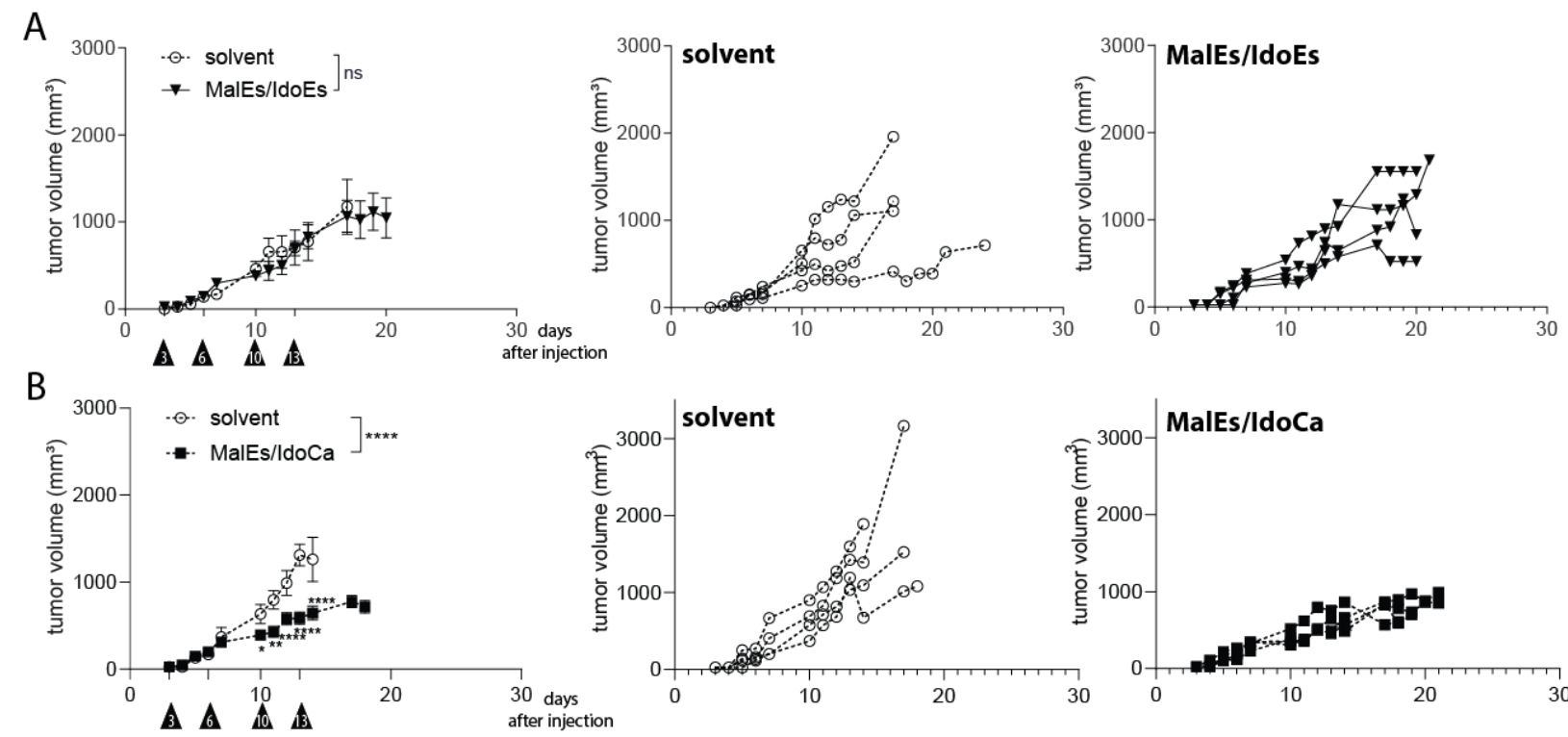

C

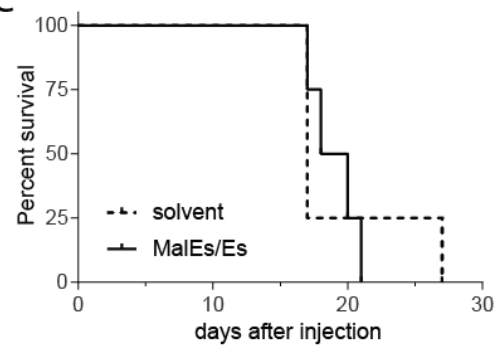

D

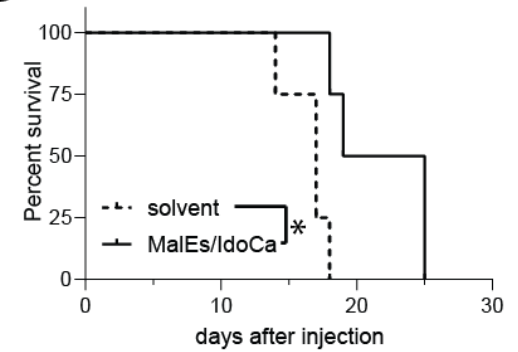

Figure S13: Therapy of CT26 bearing Balb/c mice treated (i.v.) with MalEs/IdoEs (A) or MalEs/IdoCa (B) at concentrations equimolar to $9 \mathrm{mg} / \mathrm{kg}$ oxaliplatin. Tumor growth was measured daily. Left graph shows mean \pm SEM, black arrows indicate treatments. Significance was calculated in comparison to the solvent group and within each group by multiple comparison analysis and 2-way ANOVA, respectively. ${ }^{*} p<0.05$, ${ }^{* *} p<0.01,{ }^{* *} p<0.001,{ }^{* * *} p<0.0001$. Middle and right graphs show individual values from each one treatment group. (C) and (D) show respective Kaplan-Meier blot from (A) and (B). Significance was calculated using Log-rank (Mantel-Cox) test. 
A

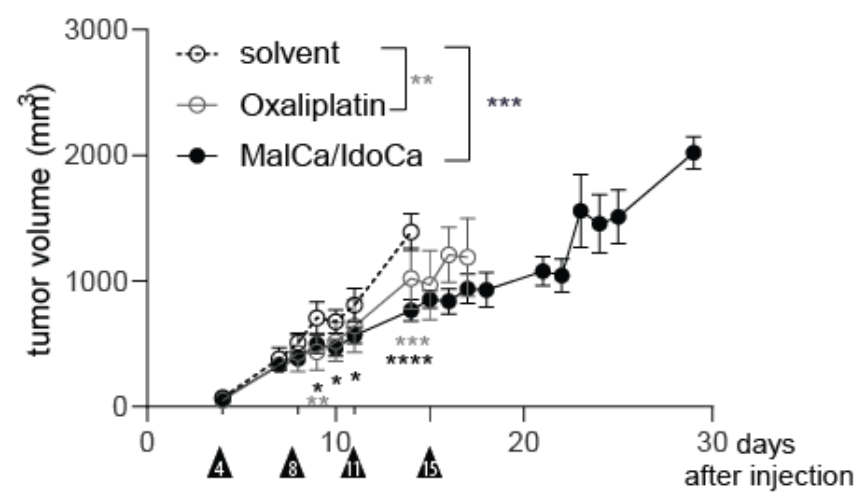

B
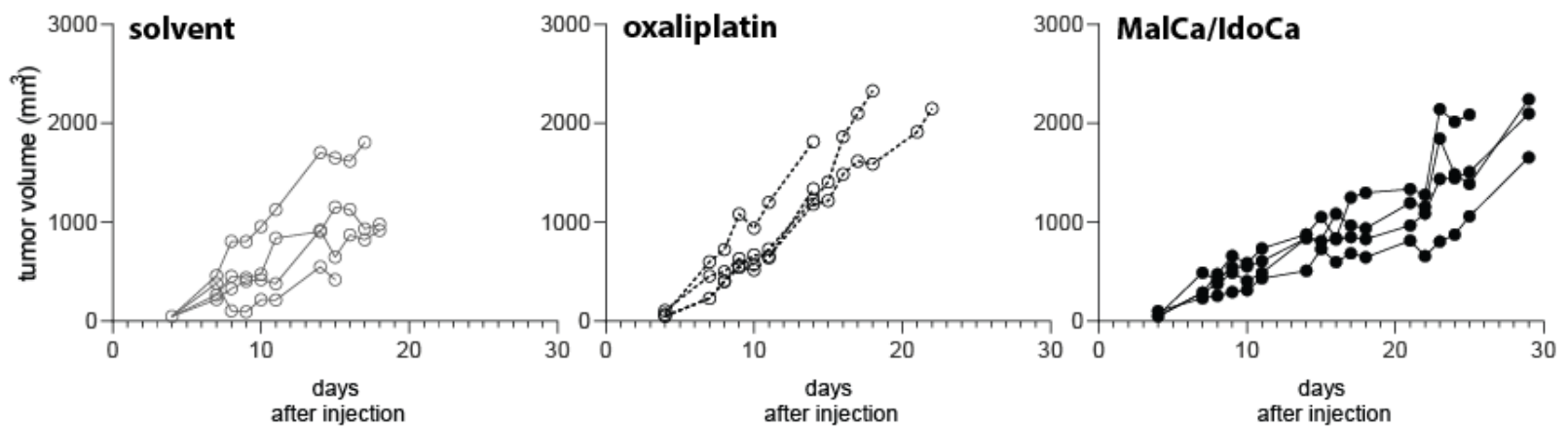

C

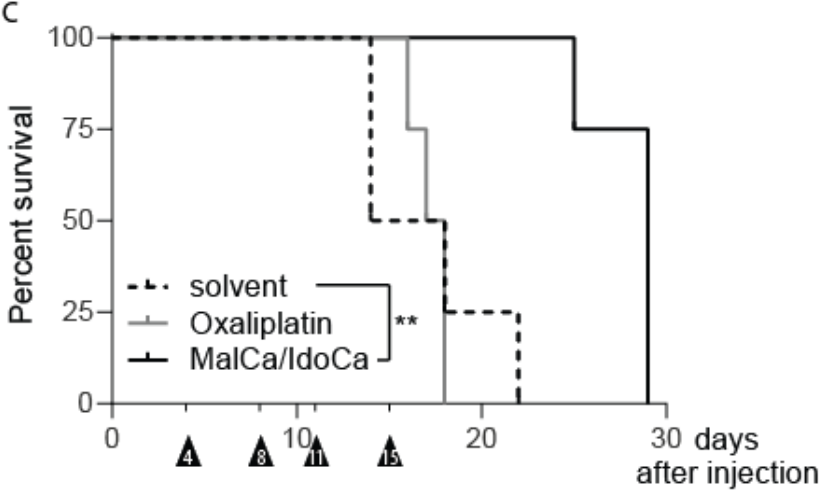

Figure S14: Therapy of CT26-bearing Balb/c mice treated (i.v.) with oxaliplatin or MalCa/IdoCa at concentrations equimolar to $9 \mathrm{mg} / \mathrm{kg}$ oxaliplatin. (A) Tumor growth was measured daily and is shown as mean \pm SEM. Black arrows indicate treatments. Significance was calculated in comparison to the solvent group and within each group by multiple comparison analysis and 2-way ANOVA, respectively. Significance between curves was calculated using paired t test. ${ }^{*} p<0.05,{ }^{* *} p<0.01,{ }^{* * *} p<0.001,{ }^{* * * *}$ $p<0.0001$. (B) shows individual values from (A) from each treatment group. (C) Kaplan-Meier-curve showing survival of the mice. Significance was calculated using Log-rank (Mantel-Cox) test compared to solvent group. 

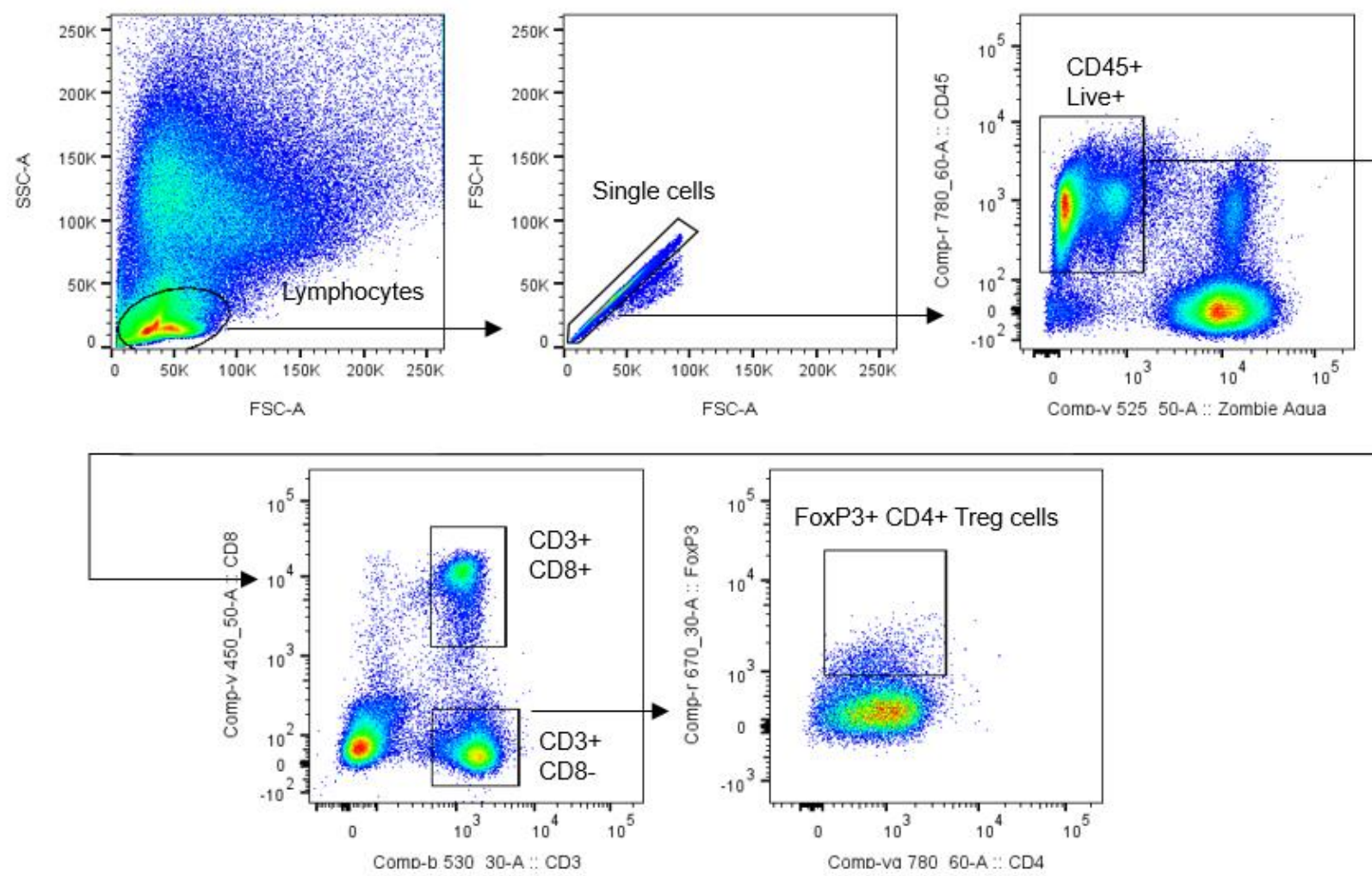

Figure S15: Gating strategy of $C D 8^{+} T$ cells, $C D 4^{+} T$ cells and FoxP3 ${ }^{+} C D 4^{+}$Treg from the mouse experiment (tumor-draining lymph nodes). 

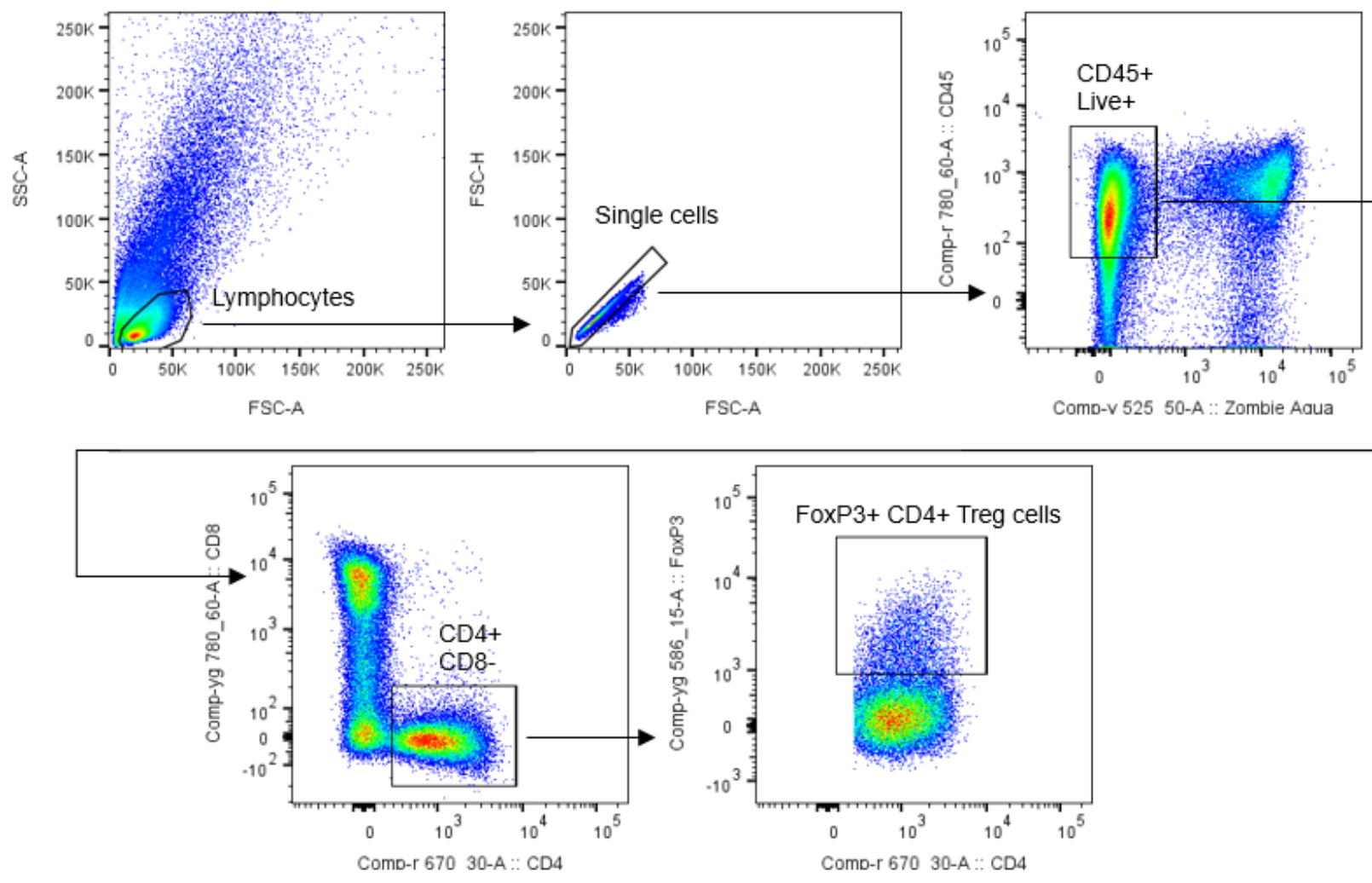

Figure S16: Gating strategy of human FoxP $3^{+} \mathrm{CD}^{+}$Treg from the human PBMC - SKOV3 tumor cell coculture experiment. 

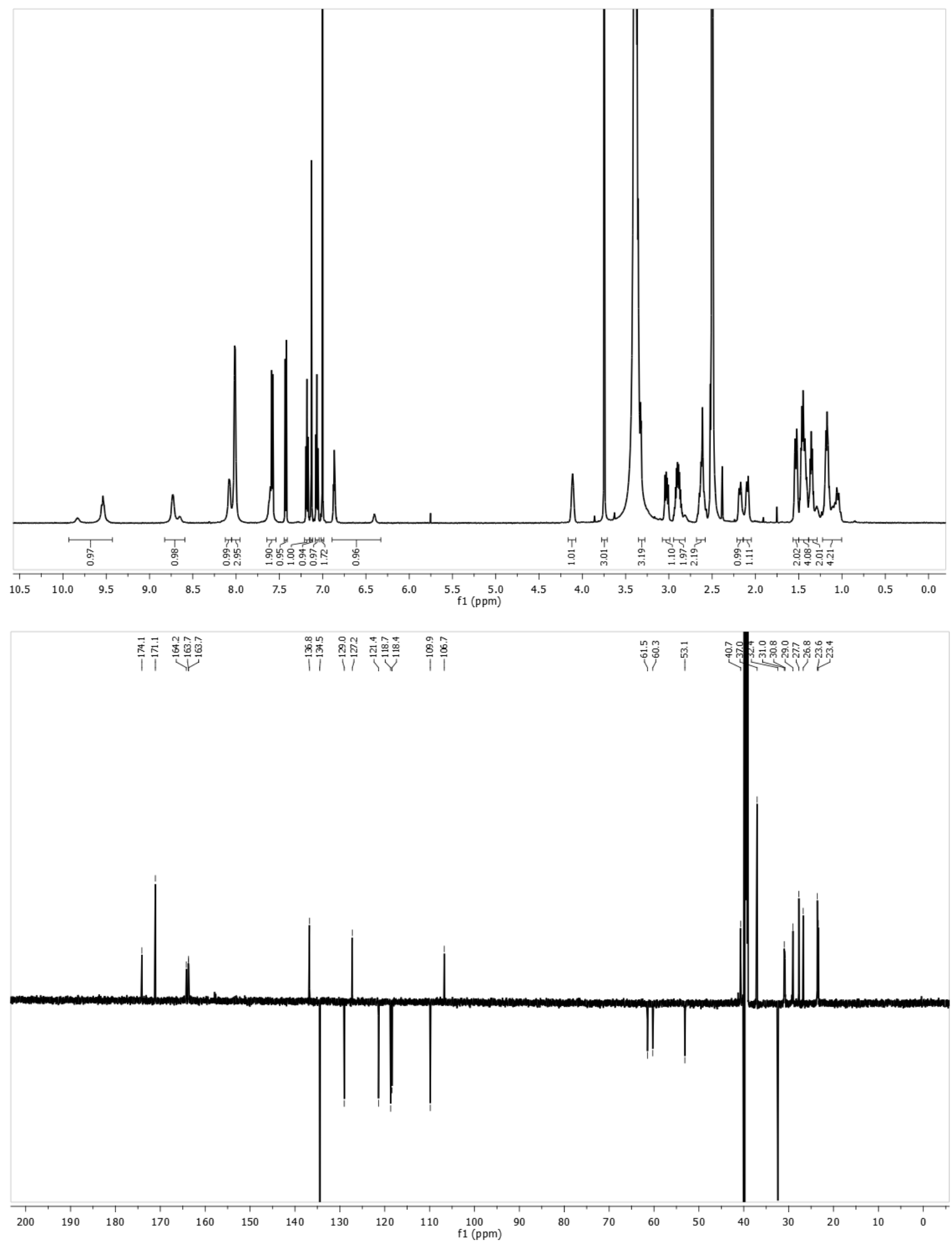

Figure S17: ${ }^{1} \mathrm{H}$ - and ${ }^{13} \mathrm{C}-\mathrm{NMR}$ spectra of MalCa/IdoEs in DMSO-d $d_{6}$. The ${ }^{1} \mathrm{H}$-peaks at $\sim 9.7, \sim 8.7$ and $\sim 6.7$ ppm are split due to the different orientations of the carbamate moiety at the platinum core. 

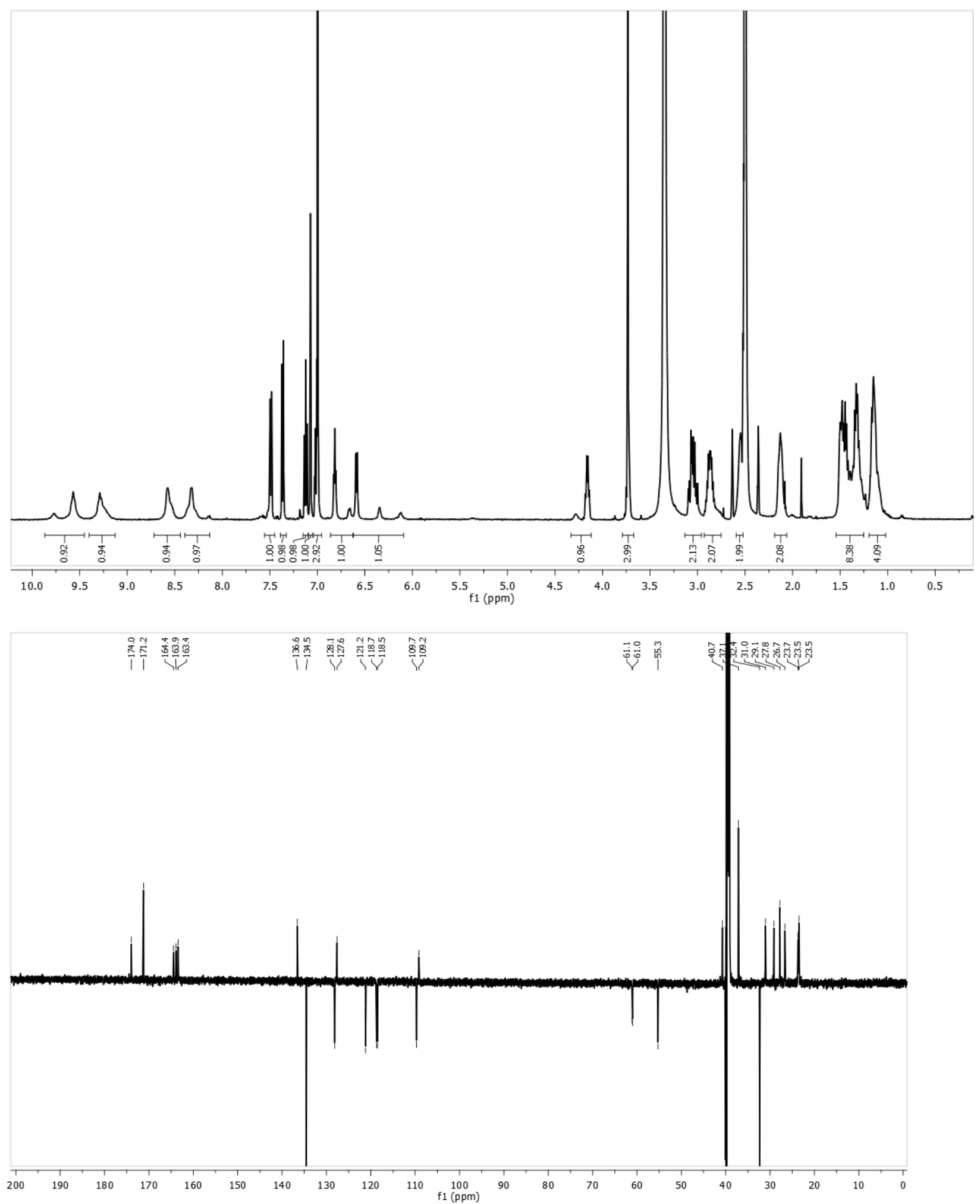

Figure S18: ${ }^{1} \mathrm{H}$ - and ${ }^{13} \mathrm{C}-\mathrm{NMR}$ spectra of MalCa/IdoCa in DMSO- $d_{6}$. The ${ }^{1} \mathrm{H}$-peaks at $\sim 9.7, \sim 8.3$ and in the range between 6.1 and $6.8 \mathrm{ppm}$ are split due to the different orientations of the carbamate moieties at the platinum core. 

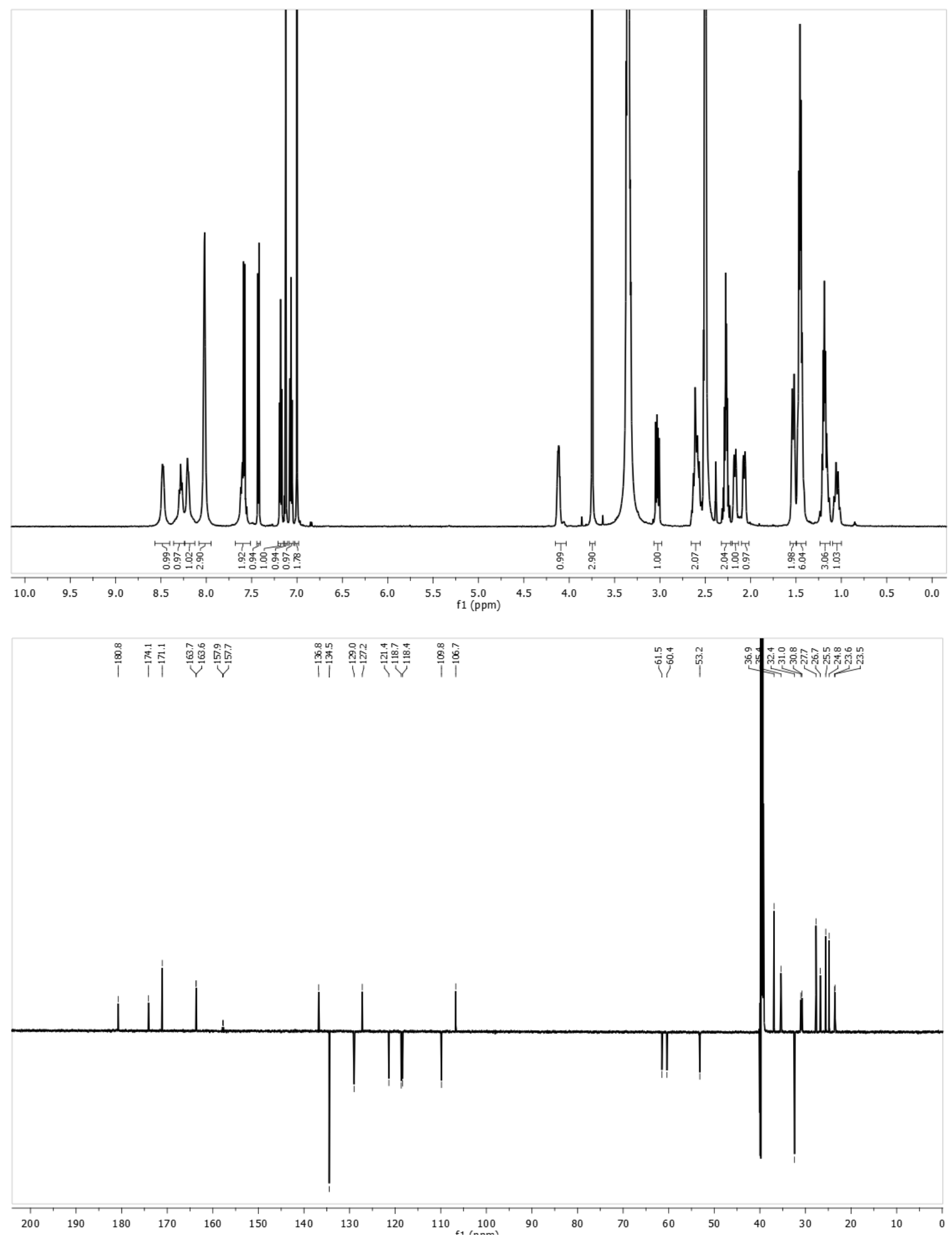

Figure S19: ${ }^{1} \mathrm{H}$ - and ${ }^{13} \mathrm{C}-\mathrm{NMR}$ spectra of MalEs/IdoEs in DMSO-d $\mathrm{d}_{6}$. 

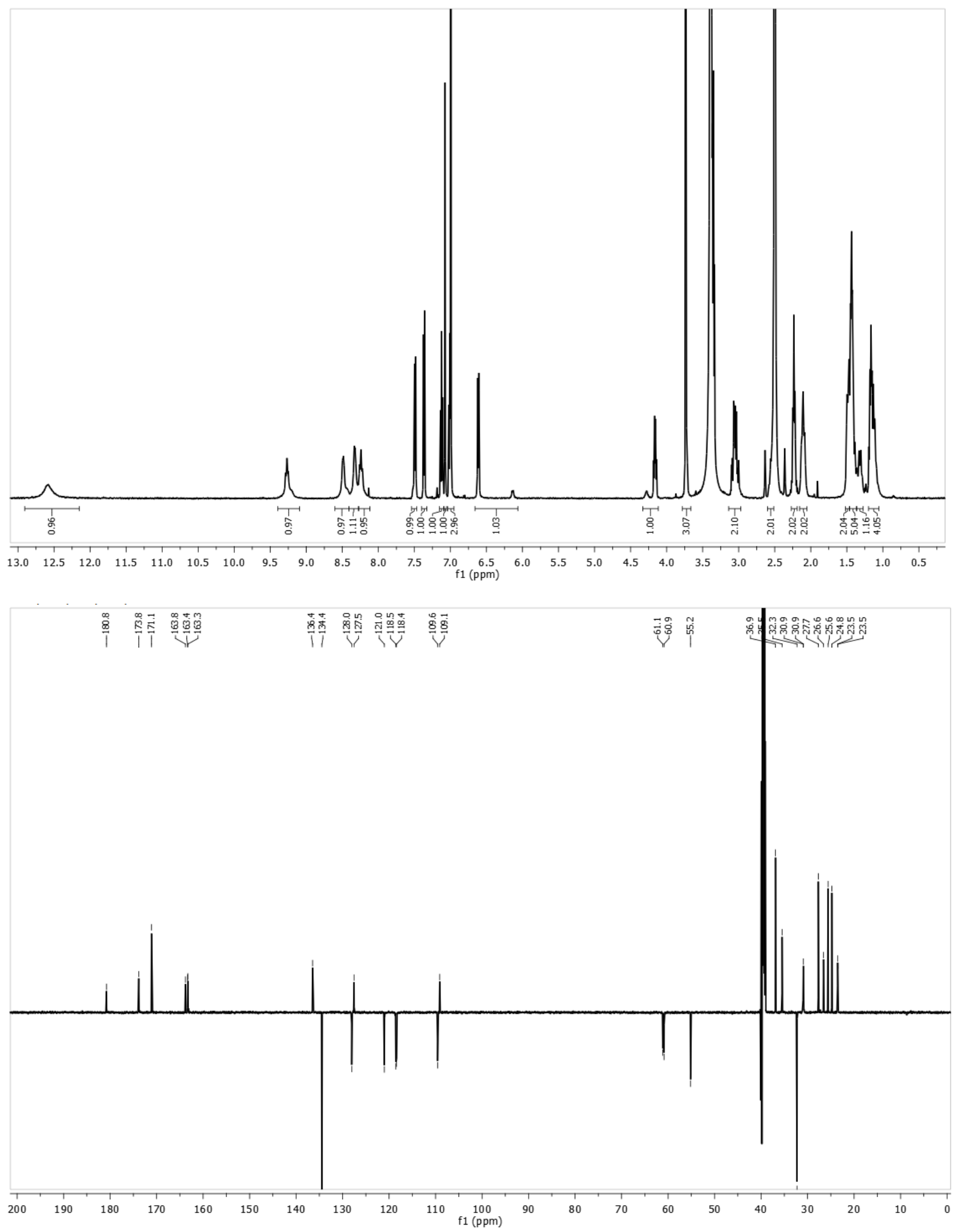

Figure S20: ${ }^{1} \mathrm{H}$ - and ${ }^{13} \mathrm{C}-\mathrm{NMR}$ spectra of MaIEs/IdoCa in DMSO-d $\mathrm{d}_{6}$. The ${ }^{1} \mathrm{H}$-peak at $~ 6.4 \mathrm{ppm}$ is split due to the different orientations of the carbamate moiety at the platinum core. 

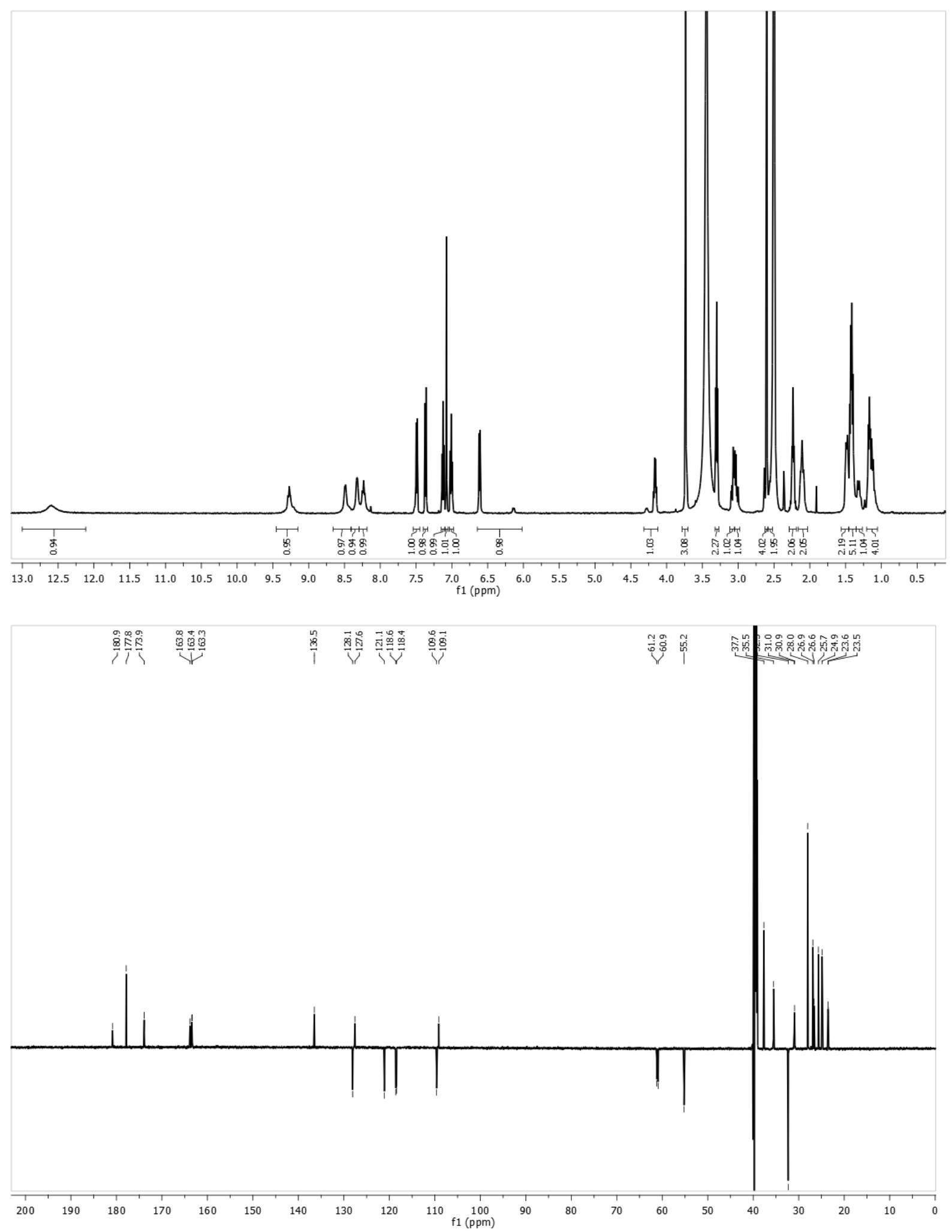

Figure S21: ${ }^{1} \mathrm{H}$ - and ${ }^{13} \mathrm{C}-\mathrm{NMR}$ spectra of SucEs/IdoCa in DMSO-d 6 . The ${ }^{1} \mathrm{H}$-peak at $\sim 6.4 \mathrm{ppm}$ is split due to the different orientations of the carbamate moiety at the platinum core. 

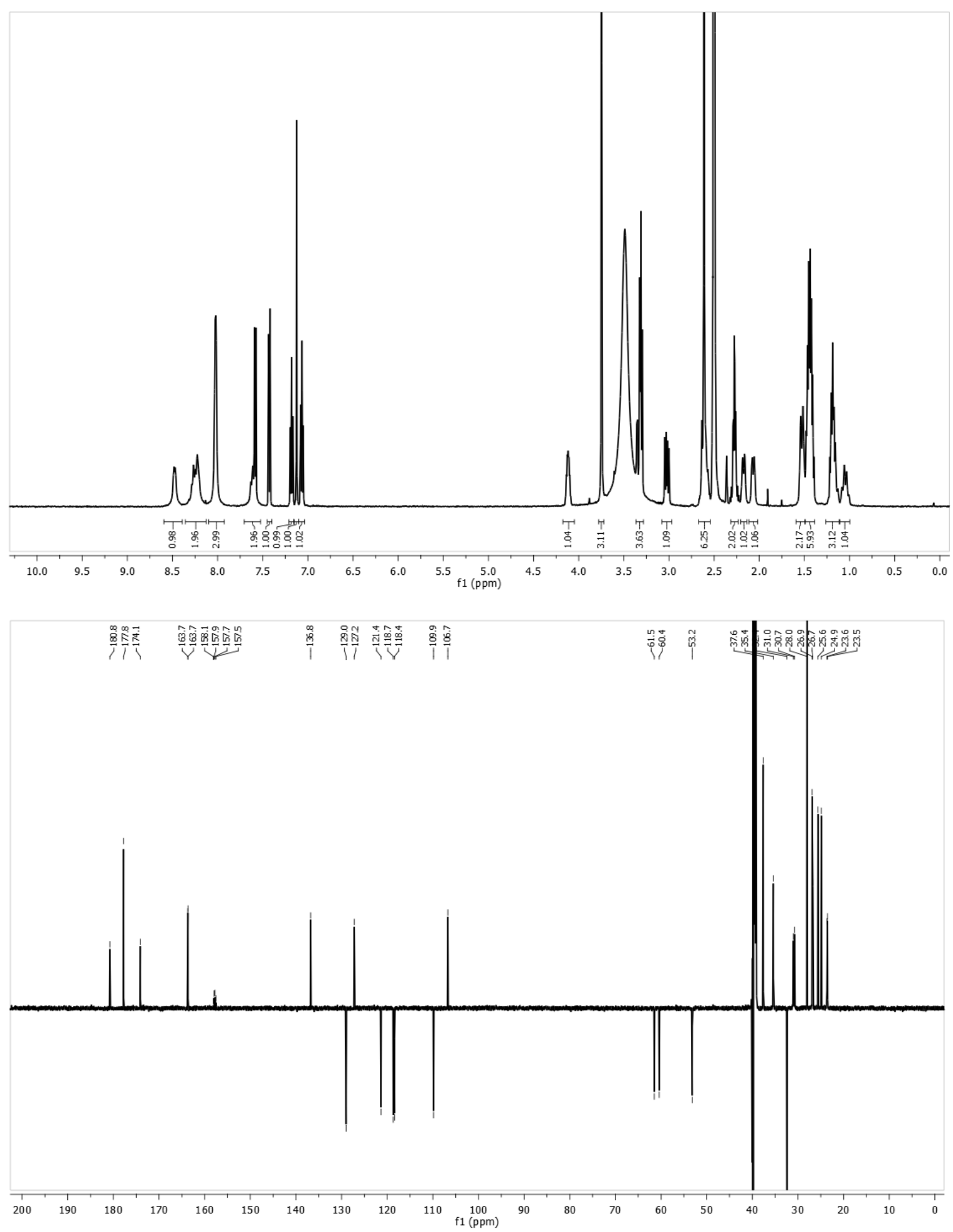

Figure S22: ${ }^{1} \mathrm{H}$ - and ${ }^{13} \mathrm{C}-\mathrm{NMR}$ spectra of SucEs/IdoEs in DMSO-d $d_{6}$. 

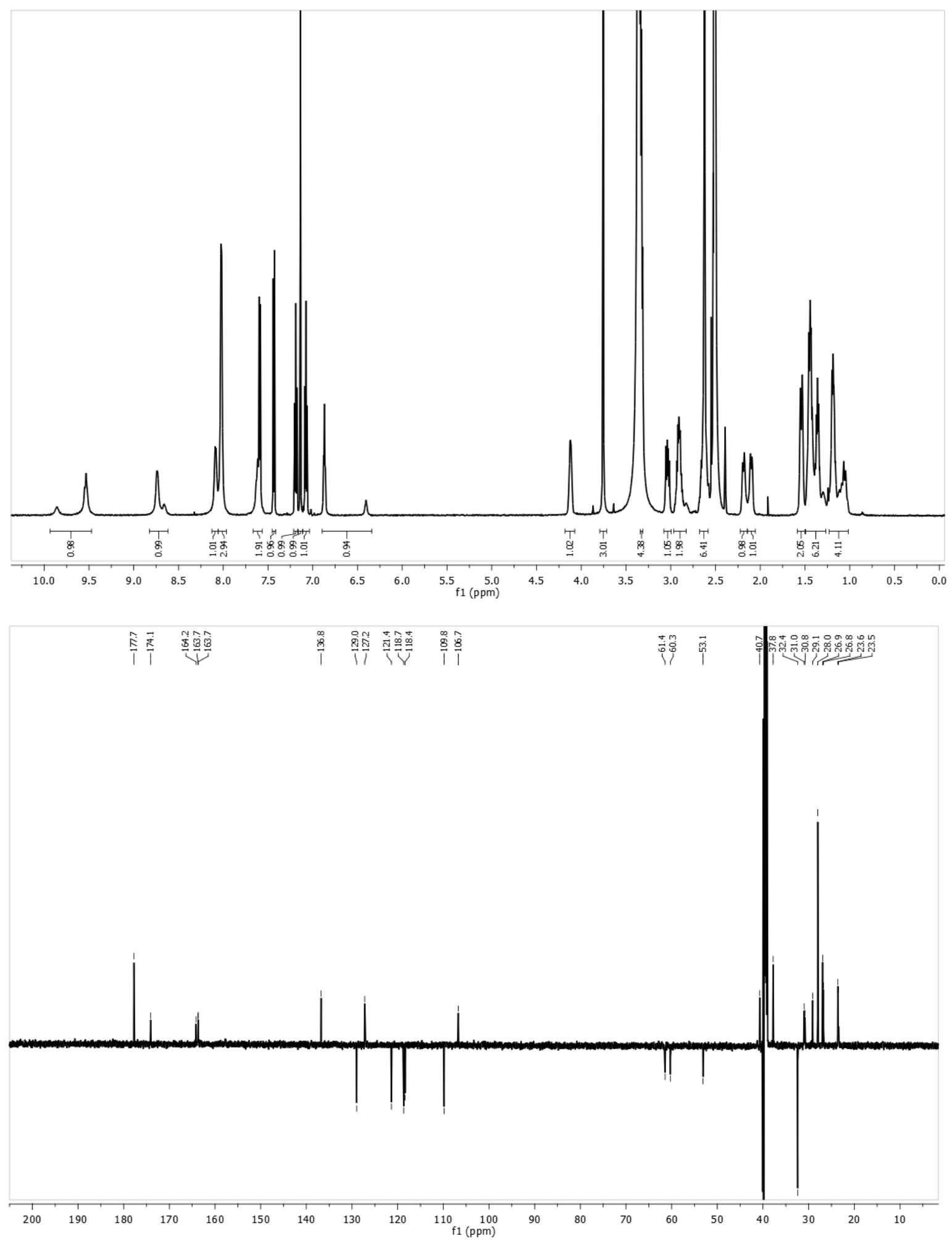

Figure S23: ${ }^{1} \mathrm{H}$ - and ${ }^{13} \mathrm{C}-\mathrm{NMR}$ spectra of SucCa/IdoEs in DMSO-d $d_{6}$. The ${ }^{1} \mathrm{H}$-peaks at $\sim 9.7, \sim 8.7$ and $\sim 6.7 \mathrm{ppm}$ are split due to the different orientations of the carbamate moiety at the platinum core. 

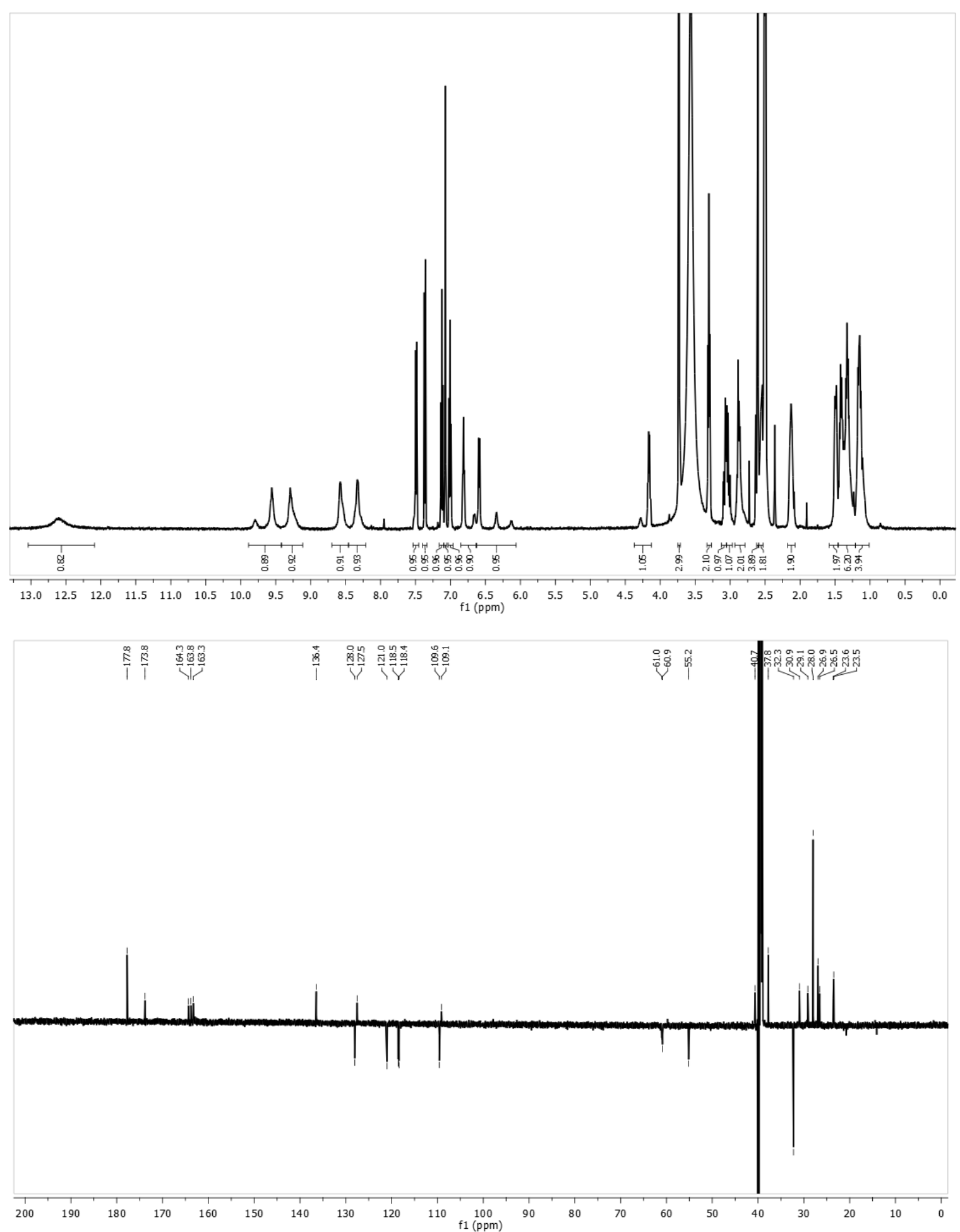

Figure S24: ${ }^{1} \mathrm{H}$ - and ${ }^{13} \mathrm{C}-\mathrm{NMR}$ spectra of SucCa/IdoCa in DMSO-d $\mathrm{d}_{6}$. The ${ }^{1} \mathrm{H}$-peaks at $\sim 9.7$ and in the range between 6.1 and $6.8 \mathrm{ppm}$ are split due to the different orientations of the carbamate moieties at the platinum core. 


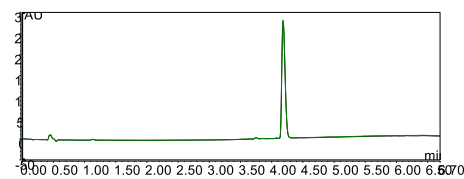

Figure S25: UHPLC-chromatogram of MalEs/IdoEs at $254 \mathrm{~nm}$.

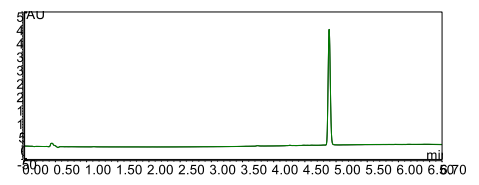

Figure S26: UHPLC-chromatogram of MalCa/ldoCa at $254 \mathrm{~nm}$.

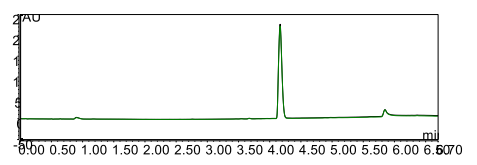

Figure S27: UHPLC-chromatogram of MalCa/IdoEs at $254 \mathrm{~nm}$. 


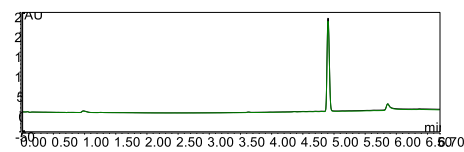

Figure S28: UHPLC-chromatogram of MalEs/IdoCa at $254 \mathrm{~nm}$.

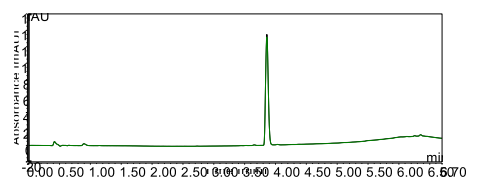

Figure S29: UHPLC-chromatogram of SucEs/IdoEs at $254 \mathrm{~nm}$.

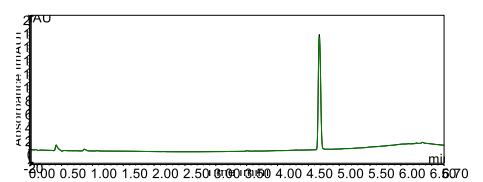

Figure S30: UHPLC-chromatogram of SUCEs/IdoCa at $254 \mathrm{~nm}$. 


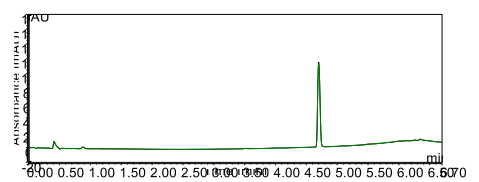

Figure S31: UHPLC-chromatogram of SucCa/IdoCa at $254 \mathrm{~nm}$.

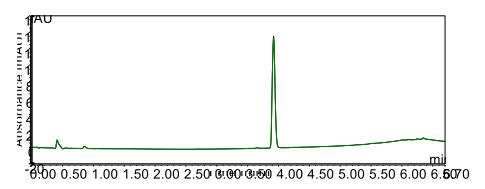

Figure S32: UHPLC-chromatogram of SucCa/IdoEs at $254 \mathrm{~nm}$. 
Table S1: Cytotoxicity determined by MTT assay in murine CT26 and human HCT116 colon cancer cells after $72 \mathrm{~h}$ incubation with and without 5 eq. AA.

\begin{tabular}{lccccccccc}
\hline \multicolumn{10}{c}{ CT26 - IC 5 values $(\boldsymbol{\mu M}) \mathbf{~} \mathbf{7 2} \mathbf{~ h}$} \\
\hline & \multicolumn{7}{c}{-} & \multicolumn{7}{c}{$+\mathbf{5}$ eq. AA } \\
\hline mean & & SD & mean & & SD & ratio \\
\hline oxaliplatin & 1.90 & \pm & 0.34 & 2.11 & \pm & 0.69 & 0.90 \\
OAc/OAc & 42.34 & \pm & 10.99 & 33.54 & \pm & 2.85 & 1.26 \\
SucCa/OAc & 55.17 & \pm & 12.64 & 40.39 & \pm & 5.62 & 1.37 \\
SucEs/IdoCa & 90.46 & \pm & 3.14 & 46.03 & \pm & 3.86 & 1.97 \\
SucCa/IdoCa & 82.49 & \pm & 8.19 & 43.65 & \pm & 6.11 & 1.89 \\
SucEs/IdoEs & 44.94 & \pm & 4.81 & 18.13 & \pm & 3.48 & 2.48 \\
SucCa/IdoEs & 31.86 & \pm & 6.11 & 16.94 & \pm & 3.21 & 1.88 \\
\hline
\end{tabular}

\begin{tabular}{lcccccccc}
\hline \multicolumn{7}{c}{ HCT116 } & - IC $_{50}$ values $(\boldsymbol{\mu M}) \mathbf{~} \mathbf{7 2} \mathbf{~ h}$ \\
\hline & \multicolumn{7}{c}{-} & \multicolumn{7}{c}{$\mathbf{+ 5}$ eq. AA } \\
\hline mean & & SD & mean & & SD & ratio \\
\hline oxaliplatin & 0.76 & \pm & 0.16 & 0.74 & \pm & 0.14 & 1.02 \\
OAc/OAc & 14.33 & \pm & 2.50 & 11.50 & \pm & 0.92 & 1.25 \\
SucCa/OAc & 42.02 & \pm & 7.39 & 21.79 & \pm & 2.38 & 1.93 \\
SucEs/IdoCa & 82.11 & \pm & 10.02 & 20.82 & \pm & 2.03 & 3.94 \\
SucCa/IdoCa & & $>100$ & & 24.74 & \pm & 2.49 & $\geq 4$ \\
SucEs/IdoEs & 5.45 & \pm & 1.42 & 4.89 & \pm & 1.10 & 1.12 \\
SucCa/IdoEs & 7.23 & \pm & 1.72 & & 5.35 & \pm & 1.28 & 1.35 \\
\hline
\end{tabular}


Table S2: Cytotoxicity determined by MTT assay in human embryonic kidney cells (HEK) and human hepatic cell line (WRL68) after $72 \mathrm{~h}$.

\begin{tabular}{lccccccc}
\hline \multicolumn{7}{c}{ IC50 values $(\boldsymbol{\mu M})$ - 72 h } \\
\hline \multicolumn{3}{c}{ HEK293 } & \multicolumn{3}{c}{ WRL68 } \\
\hline mean & & SD & mean & & SD \\
\hline oxaliplatin & 2.10 & \pm & 0.27 & 8.35 & \pm & 1.23 \\
OAc/OAc & 12.21 & \pm & 0.48 & & 33.58 & \pm & 8.39 \\
SucCa/OAc & 50.83 & \pm & 10.26 & & $>100$ & \\
SucEs/IdoCa & 77.49 & \pm & 16.10 & & $>100$ & \\
SucCa/IdoCa & 81.23 & \pm & 21.34 & & $>100$ & \\
SucEs/IdoEs & 44.16 & \pm & 8.32 & & 81.69 & \pm & 0.40 \\
SucCa/IdoEs & 33.19 & \pm & 9.03 & & 76.36 & \pm & 6.67 \\
\hline
\end{tabular}

Table S3: Cytotoxicity determined by MTT assay in human SKOV3 and VM7 cancer cells after $72 \mathrm{~h}$ incubation with and without 5 eq. $A$ A.

\begin{tabular}{lccccccc}
\hline \multicolumn{7}{c}{ SKOV3 $-\mathbf{I C}_{\mathbf{5 0}}$ values $(\boldsymbol{\mu M}) \mathbf{- 7 2} \mathbf{~ h}$} \\
\hline \multicolumn{7}{c}{-} & \multicolumn{5}{c}{$\mathbf{+ 5}$ eq. AA } \\
\hline oxaliplatin & mean & & SD & mean & SD & ratio \\
OAc/OAc & 0.76 & \pm & 0.16 & 43.35 & \pm & 4.88 & 1.05 \\
SucCa/OAc & 14.33 & \pm & 2.50 & & & & \\
SucEs/IdoCa & $>100$ & & & $>100$ & & \\
SucCa/IdoCa & $>100$ & & & $>100$ & & \\
SucEs/IdoEs & $>100$ & & & $>100$ & & \\
SucCa/IdoEs & $>100$ & & & $>100$ & & \\
\hline
\end{tabular}

\begin{tabular}{|c|c|c|c|}
\hline \multicolumn{4}{|c|}{ VM7- IC 50 values $(\mu M)-72 h$} \\
\hline & mean & & SD \\
\hline oxaliplatin & 3.94 & \pm & 0.78 \\
\hline $\mathrm{OAc} / \mathrm{OAc}$ & 43.49 & \pm & 3.33 \\
\hline SucCa/OAc & $>100$ & & \\
\hline SucEs/IdoCa & $>100$ & & \\
\hline SucCa/IdoCa & $>100$ & & \\
\hline SucEs/IdoEs & $>100$ & & \\
\hline SucCa/IdoEs & $>100$ & & \\
\hline
\end{tabular}


Table S4: Ratio of mean platinum level of tissue samples from figure 8.

\begin{tabular}{lcc}
\multicolumn{3}{c}{ Platinum ratio } \\
\hline & tumor:liver & tumor:kidney \\
\hline oxaliplatin & 0.3 & 0.3 \\
OAc/OAc & 0.4 & 0.3 \\
MalEs/IdoCa & 0.7 & 1.2 \\
MalCa/IdoCa & 0.5 & 0.5 \\
MalEs/IdoEs & 0.2 & 0.5 \\
MalCa/IdoEs & 0.6 & 0.6
\end{tabular}


Table S5: SEC-HPLC parameters for SEC-ICP-MS measurements.

\begin{tabular}{|l|l|}
\hline HPLC column: & Acquity UPLC BEH $200 \AA 1.7 \mu \mathrm{m}, 4.6 \times 150 \mathrm{~mm}$ \\
\hline Eluent: & $50 \mathrm{mM} \mathrm{CH}_{3} \mathrm{COONH}_{4}, \mathrm{pH}=6.8$ \\
\hline Flow rate: & $400 \mu \mathrm{L} / \mathrm{min}$ \\
\hline Injection volume: & $5 \mu \mathrm{L}$ \\
\hline Column temperature: & $37^{\circ} \mathrm{C}$ \\
\hline Autosampler temperature: & $37^{\circ} \mathrm{C}$ \\
\hline
\end{tabular}

Table S6: ICP-MS parameters for SEC-ICP-MS measurements.

\begin{tabular}{|l|l|}
\hline Nebulizer: & Quartz \\
\hline Spray chamber: & Scott type \\
\hline Nebulizer gas flow: & $1.08 \mathrm{~L} / \mathrm{min}$ \\
\hline Aux. gas flow: & $0.9 \mathrm{~L} / \mathrm{min}$ \\
\hline Plasma gas flow: & $15 \mathrm{~L} / \mathrm{min}$ \\
\hline Reaction gas (oxygen): & $30 \%$ \\
\hline ICP RF power: & $1550 \mathrm{~W}$ \\
\hline m/z measured: & 195,48 \\
\hline
\end{tabular}




\begin{tabular}{|c|c|c|}
\hline $\begin{array}{lrr}\text { Table } & 7: & I C P-M S \\
\text { measurement } & \text { of }\end{array}$ & & \\
\hline \multirow[t]{13}{*}{ HCT116 cells and tumor } & RF power & $1550 \mathrm{~W}$ \\
\hline & Nebulizer & MicroMist \\
\hline & Spray chamber & Scott double-pass \\
\hline & Spraying chamber temp. & $2^{\circ} \mathrm{C}$ \\
\hline & Monitored Isotopes & ${ }^{185} \mathrm{Re},{ }^{195} \mathrm{Pt},{ }^{196} \mathrm{Pt}$ \\
\hline & Measurement modes & standard mode \\
\hline & Plasma gas & $15 \mathrm{~L} \mathrm{~min}^{-1}$ \\
\hline & Nebulizer gas & $1.08 \mathrm{~L} \mathrm{~min}^{-1}$ \\
\hline & Auxiliary gas & $0.90 \mathrm{~L} \mathrm{~min}^{-1}$ \\
\hline & Cones & $\mathrm{Ni}$ \\
\hline & Cell entrance & $-60 \mathrm{~V}$ \\
\hline & Cell exit & $-110 \mathrm{~V}$ \\
\hline & Integration time & 0.1 or $0.3 \mathrm{~s}$ \\
\hline
\end{tabular}


Table S8: List of antibodies from Biolegend that were used for multi-color flow cytometry experiments.

\begin{tabular}{|c|c|c|c|c|}
\hline Fluorophore & Antigen & Reactivity & Clone & Dilution \\
\hline APC/Cyanine 7 & CD45 & Mouse & 30-F11 & $1: 200$ \\
\hline FITC & $\mathrm{CD} 3 \varepsilon$ & Mouse & $145-2 C 11$ & $1: 500$ \\
\hline BV $421^{\mathrm{TM}}$ & CD8a & Mouse & $53-6.7$ & $1: 100$ \\
\hline PE/Cyanine7 & CD4 & Mouse & GK1.5 & $1: 200$ \\
\hline $\mathrm{AF}^{\circledR} 647$ & FOXP3 & Mouse & MF-14 & $1: 50$ \\
\hline APC/Cyanine 7 & CD45 & Human & 2D1 & $1: 50$ \\
\hline FITC & CD3 & Human & UCHT1 & $1: 33$ \\
\hline PE/Cyanine 7 & CD8 & Human & SK1 & $1: 66$ \\
\hline APC & CD4 & Human & $\mathrm{A} 161 \mathrm{~A} 1$ & $1: 100$ \\
\hline $\mathrm{PE}$ & FOXP3 & Human/Mouse/Rat & $150 \mathrm{D}$ & $1: 25$ \\
\hline
\end{tabular}




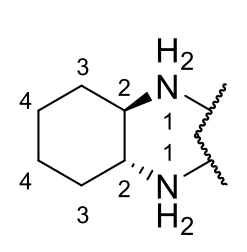

DACH-

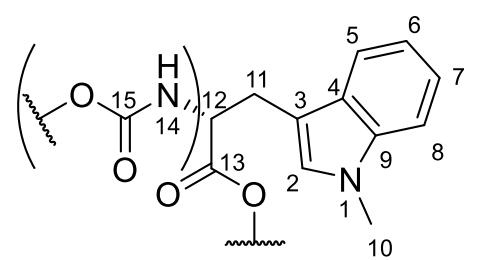

IDO-

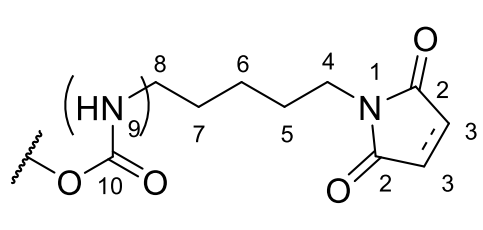

MAL-/SUC-

Scheme S1: NMR numbering scheme for the different ligand systems. 